\title{
ENSAIOS SOBRE HIATO SALARIAL E POBREZA \\ MULTIDIMENSIONAL REGIONAL
}
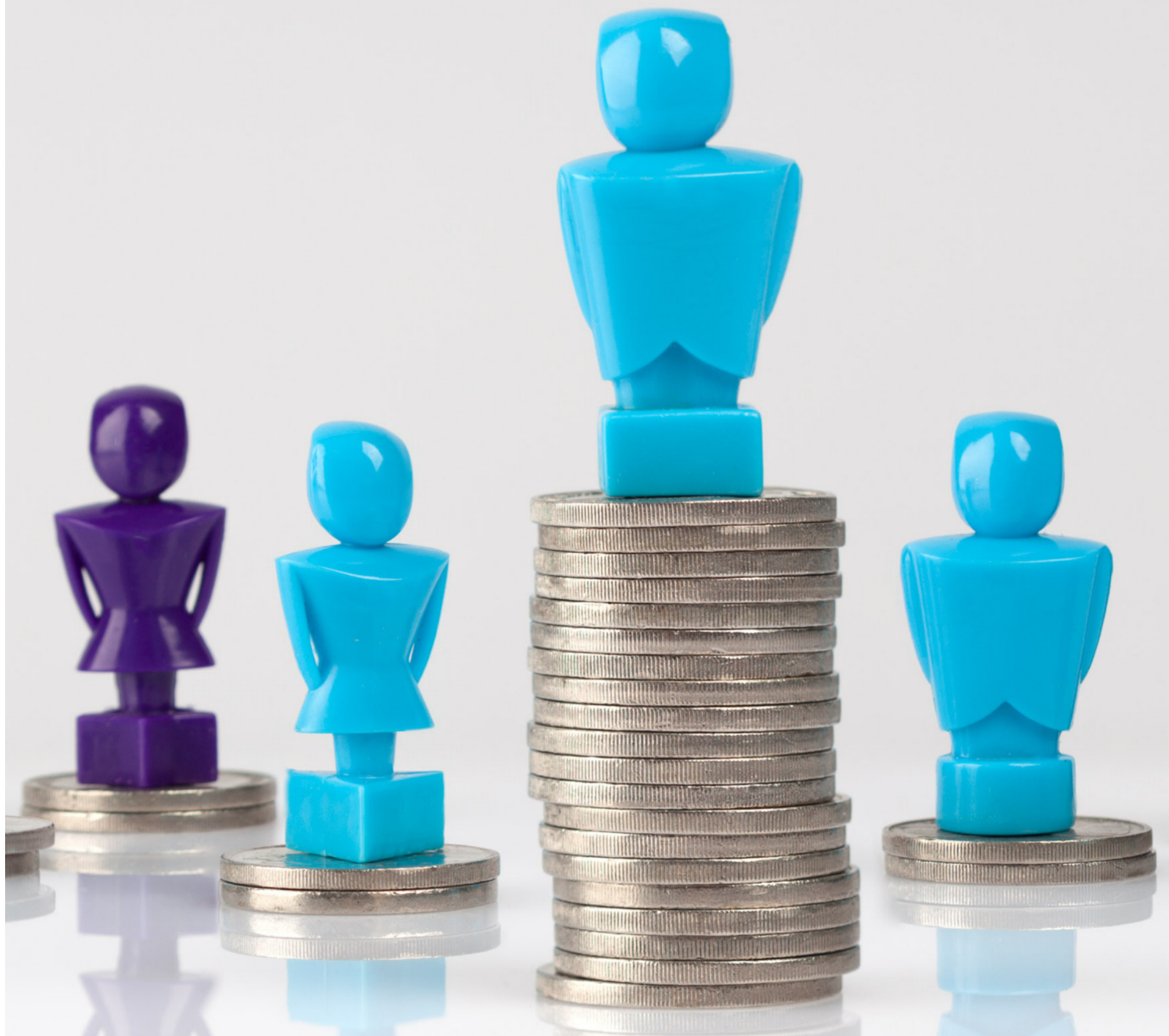

Daniel Thomaz Giacomelli Nunes Maciel Leticia Aparecida Lavoratto Esdras Warley Nunes de Jesus Fahim Elias Costa Rihbane Rodolfo de Oliveira Sarat




Daniel Thomaz Giacomelli Nunes Maciel

Leticia Aparecida Lavoratto

Esdras Warley Nunes de Jesus

Fahim Elias Costa Rihbane

Rodolfo de Oliveira Sarat

ENSAIOS SOBRE HIATO SALARIAL E POBREZA MULTIDIMENSIONAL REGIONAL

$1^{\text {a }}$ ed.

Piracanjuba-GO

Editora Conhecimento Livre

Piracanjuba-GO 
$1^{\mathrm{a}} \mathrm{ed}$

\section{Dados Internacionais de Catalogação na Publicação (CIP)}

Maciel, Daniel Thomaz Giacomelli Nunes

M164E ENSAIOS SOBRE HIATO SALARIAL E POBREZA MULTIDIMENSIONAL

REGßNifŁ Thomaz Giacomelli Nunes Maciel. Leticia Aparecida Lavoratto. Esdras Warley Nunes de

Jesus. Fahim Elias Costa Rihbane. Rodolfo de Oliveira Sarat. - Piracanjuba-GO

Editora Conhecimento Livre, 2021

79 f.: il

DOI: $10.37423 / 2021$. edcl391

ISBN: 978-65-5367-018-1

Modo de acesso: World Wide Web

Incluir Bibliografia

1. hiato-salarial 2. pobreza-multidimensional-no-meio-rural 3. economia 4. economia-regional 5. pobreza-multidimensional I. Maciel, Daniel Thomaz Giacomelli Nunes II. Lavoratto, Leticia Aparecida III. Jesus, Esdras Warley Nunes de IV. Rihbane, Fahim Elias Costa V. Sarat, Rodolfo de Oliveira VI. Título

https://doi.org/10.37423/2021.edc1391

O conteúdo dos artigos e sua correção ortográfica são de responsabilidade exclusiva dos seus respectivos autores. 


\title{
EDITORA CONHECIMENTO LIVRE
}

\section{Corpo Editorial}

\author{
Dr. João Luís Ribeiro Ulhôa \\ Dra. Eyde Cristianne Saraiva-Bonatto \\ Dr. Anderson Reis de Sousa \\ MSc. Frederico Celestino Barbosa \\ MSc. Carlos Eduardo de Oliveira Gontijo
}

$\underline{\text { MSc. Plínio Ferreira Pires }}$

Editora Conhecimento Livre

Piracanjuba-GO 
ENSAIOS SOBRE HIATO SALARIAL E POBREZA MULTIDIMENSIONAL REGIONAL

\section{dof 10.374232022 .}




Resumo: Devido a segmentação de mercado, trabalhadores com iguais atributos tendem a receber remunerações diferenciadas, com isso o trabalho utilizou decomposição de Oaxaca-Blinder para decompor o hiato salarial entre quatro grupos (trabalhadores permanentes, temporários, empregadores e os conta própria) no setor agropecuário brasileiro. Dessa forma o peso da segmentação entre trabalhadores permanentes e temporários foi de aproximadamente $66 \%$ em vantagem para os permanentes, indicando que $66 \%$ do hiato salarial para esses trabalhadores se dão em função da segmentação de mercado. A combinação que obteve a maior segmentação foi entre os trabalhadores temporários e conta própria no valor de quase $117 \%$ em vantagem para os trabalhadores em conta própria, indicando que mesmo os temporários tendo melhores atributos produtivos, ainda ganham menos por conta da segmentação.

Palavras-chave: Hiato salarial, Decomposição Oaxaca-Blinder, Segmentação de Mercado, Remuneração Agropecuária, Organização social. 


\section{Sumário}

INTRODUÇÃO

O HIATO SALARIAL NO BRASIL

A SEGMENTAÇÃO NA REMUNERAÇÃO DO SETOR AGROPECUÁRIO . .9

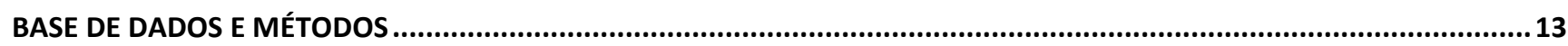

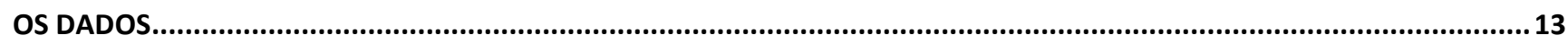

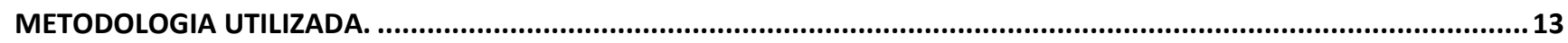

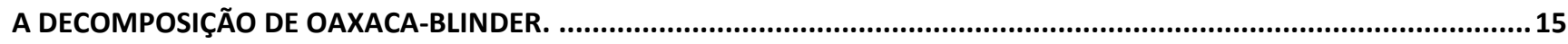



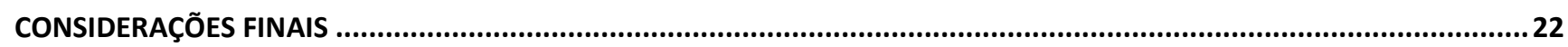

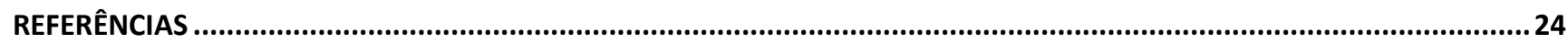

ARTIGO 2: POBREZA MULTIDIMENSIONAL DO BRASIL: CONSTRUÇÃO DE UM INDICADOR DE POBREZA UTILIZANDO A

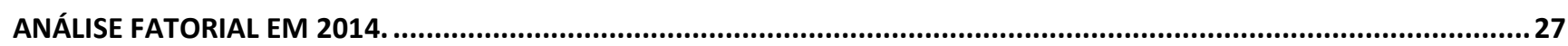

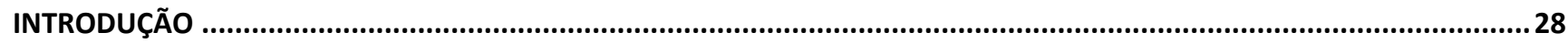

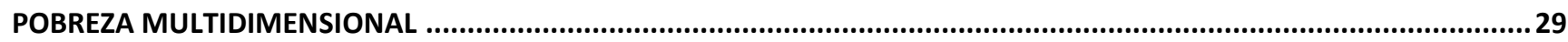

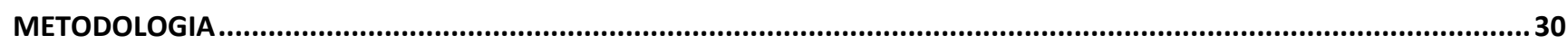

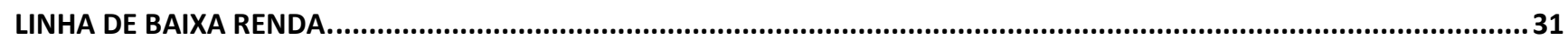

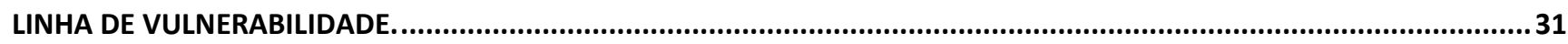

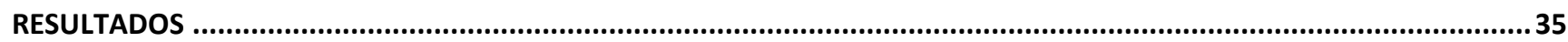

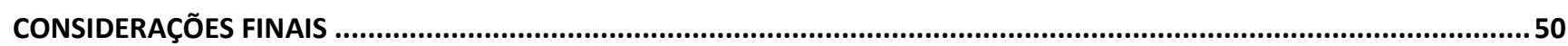

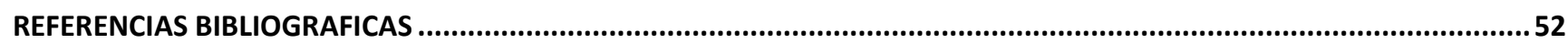

ARTIGO 3: A DISTRIBUIÇÃO DA POBREZA MULTIDIMENSIONAL NO MEIO RURAL DO ESTADO DE MATO GROSSO EM 2010

INTRODUÇÃO .54

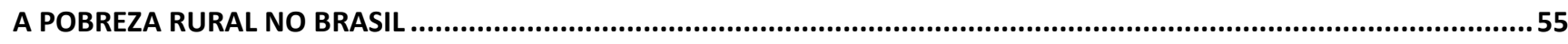

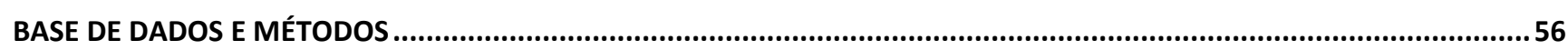

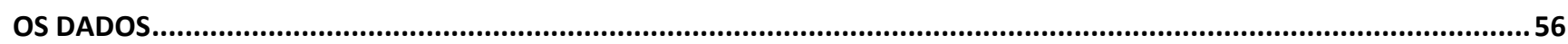

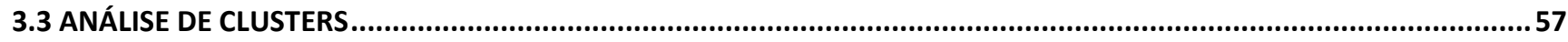


MEDIDAS DE SIMILARIDADE .57

DISTÂNCIA EUCLIDIANA. 58

MÉTODOS HIERÁRQUICOS. 59

RESULTADOS .59

5. CONSIDERAÇÕES FINAIS .64

6. REFERENCIAS 66

ANEXOS 68

APÊNDICES. 72 


\section{INTRODUÇÃO}

O Brasil apresenta um elevado grau de desigualdade de renda em comparação a outros países, dessa maneira estudos sobre as desigualdades salariais estão sendo ampliados, relacionando especialmente fatores como educação, raça, sexos, funcionários do setor público e privado, residência urbana ou rural, entre outros (Barros e Mendonça, 1995).

Em seu trabalho sobre desigualdade de renda no Brasil, Langoni (1973) estuda de que forma o mercado de trabalho gera e expõe a desigualdade de renda, concluindo que a educação é um dos principais fatores causadores de desigualdade, pois o sistema educacional brasileiro é considerado excludente fazendo com que o nível de desigualdade salarial no Brasil seja elevado (Barros e Mendonça, 1995).

De acordo com Barros e Mendonça (1995) o mercado de trabalho é imperfeito devido à existência de discriminação e segmentação, existindo assim diferenças nas remunerações de trabalhadores que possuem a mesma produtividade, segundo os autores, a discriminação se dá quando existe um tratamento desigual para com os indivíduos que possuam características iguais, gerando dessa forma diferença nas remunerações desses indivíduos. Já a segmentação de mercado ocorre quando as remunerações são diferentes para indivíduos que são igualmente produtivos, devido á atributos do setor onde estão empregados.

De acordo com Staduto (2002), o mercado de trabalho agrícola é segmentado entre os trabalhadores permanentes e os trabalhadores temporários, esses trabalhadores apresentam qualificações e oportunidades diferentes. A demanda por trabalhadores permanentes se dá pelo fato de no setor agropecuário possuir rotinas diárias de atividades, porém, o processo produtivo agropecuário apresenta picos de atividades, demandando mão-de-obra temporária, que geralmente é menos qualificada que a mão-de-obra permanente.

Dessa forma, o presente trabalho pretende ampliar o estudo sobre a determinação dos salários agrícolas e o hiato salarial, medindo empiricamente a diferença das remunerações entre os empregadores, os trabalhadores por conta própria, os trabalhadores permanentes e os temporários do setor agropecuário brasileiro no ano de 2014.

Com isso, as próximas duas secções apresentam uma breve contextualização sobre o hiato salarial no Brasil e sobre a segmentação na remuneração do setor agropecuário. Posteriormente, apresenta-se a metodologia utilizada, que será a decomposição de Oaxaca-Blinder que avaliará se há diferença nas 
remunerações e caso haja, se essa diferença se dá pelo fato da diferença nos atributos dos próprios trabalhadores ou se é devido à existência de segmentação de mercado, combinando quatro grupos analisados (empregados permanentes, temporários, empregadores e os conta própria) para com isso avaliar o peso da segregação no hiato salarial de cada uma dessas combinações.

\section{O HIATO SALARIAL NO BRASIL}

Devido à preocupação crescente com problemas relacionados a crescimento econômico e uma melhor distribuição de renda, surge em meados da década de 60 a teoria do capital humano, teoria esta que é aplicada nas decisões individuais a respeito da educação (Schultz, 1973, Becker, 1962 e 1964).

Para os neoclássicos a remuneração dos fatores de produção se dá de acordo com a produtividade marginal, enquanto que a teoria do capital humano utiliza-se da educação como uma das principais variáveis explicativa para os hiatos de rendimento, afirmando que a produtividade marginal é afetada pela educação, ou seja, a renda cresce de acordo com o crescimento educacional dos indivíduos (Barros e Mendonça, 1995).

De acordo com Pereira e Zavala (2012), é a oferta de mão-de-obra que determina a renda na teoria do capital humano, não o capital físico, pois segundo os autores possuir tecnologias, capital físico moderno e avançado de nada valeria se não houvesse pessoas capacitadas e treinadas para realizar a operação desses equipamentos. Sendo assim, para a teoria do capital humano, a experiência, a idade e o tempo de serviço do individuo são fatores determinantes da renda.

Em contraste com a teoria do capital humano e contestando o fato da educação ser considerada como variável explicativa da desigualdade social e salarial, a teoria radical baseada na teoria marxista, defende que a renda depende do acesso que o individuo tem sobre o capital, independente de atributos ou de características da oferta de mão-de-obra, afirmando ainda que a educação distorce e reproduz as desigualdades econômicas e o desenvolvimento pessoal. Para Bowles e Gintis (1975), os atributos dos trabalhadores constituídos pela teoria do capital humano não é restrito ao que diz respeito a capacidade produtiva e habilidades técnicas, mas também a raça, sexo, etnia, idade, entre outros atributos irrelevantes na teoria do capital humano (Pereira e Zavala, 2012).

Em 1970 nos Estados Unidos o elo da cadeia de raciocínio da teoria do capital humano é contestado, despertando entre os pesquisadores perguntas sobre quais os fatores influenciam a renda futura dos estudantes. Logo após surge outra teoria, cuja afirmação é a de que as escolas produzem credenciais, uma espécie de sinal e socialização para os empregadores. De acordo com a teoria credencialista serão 
contratados funcionários que possuam competência técnica e atributos culturais, ficando a cargo da educação informar sobre essas credenciais (Pereira e Zavala, 2012).

Já para a teoria da sinalização são as características pessoais como talento, inteligência e força de vontade que influenciam na renda, mas pelo fato dessas características não serem facilmente observadas, a educação formal serviria como uma forma de atestado das habilidades do trabalhador (Hinchliffe, 1987). Outra teoria apresentada é a teoria da fila, que utiliza critérios como custo de treinamento para decidir qual funcionário será contratado, fazendo com que os primeiros lugares nas filas fossem ocupados pelas pessoas que possuíssem maiores treinamentos (Thurow, 1992).

Segundo Pereira e Zavala (2012), uma atualização na teoria da sinalização é desenvolvida por Varian (1977), cuja afirmação é a de que um melhor funcionamento do mercado se dá através da sinalização, porém, a educação poderia levar a uma piora no funcionamento do mercado, tornando-se ineficiente do ponto de vista social. Sendo assim, o sinal de maior escolaridade se transformaria numa perda para a sociedade, pois os investimentos em educação não seriam mais benefícios sociais.

Também para os teóricos do modelo dual o aumento das desigualdades de renda se dá com o aumento da educação, eles argumentam que o desejo de obter maior escolaridade ao longo do tempo faz com que os investimentos do governo na educação não representam um aumento da renda desses indivíduos e que os maiores beneficiados seriam quem possuísse um maior status socioeconômico (Pereira e Zavala, 2012).

Para Barros e Mendonça $(1993,1996)$, uma desigualdade injusta é gerada quando existe diferença na remuneração de trabalhadores que possuem a mesma produtividade devido ao fato de haver segmentação e discriminação no mercado de trabalho. O mercado de trabalho é desigual quando a remuneração entre homens e mulheres, brancos e não brancos que possuem produtividade equivalente ou quando trabalhadores perfeitamente substitutos uns dos outros, mas ocupando postos de trabalhos diferentes possuam rendimentos diferentes, essa diferença se dá pelo fato de haver discriminação e segmentação no mercado de trabalho. (Pereira e Zavala, 2012).

Pereira e Zavala (2012) afirmam que a discriminação ocorre quando existe um tratamento desigual entre os indivíduos cujas características são iguais devido a sua classe, cor, ou grupos a qual pertençam. Já a segmentação do mercado de trabalho ocorre quando os trabalhadores com características pessoais semelhantes de vários segmentos de trabalho são remunerados de forma diferente, ou seja, de acordo com a qualificação desse trabalhador e não pelo segmento que este se encontra. Existem várias formas de segmentação, porém se destacam as que existem entre os setores 
formais e informais, entre empregados formais e informais ou por trabalhadores por conta própria, por regiões, por setor de atividades, por áreas rurais e urbanas, ou seja, quanto forem os agrupamentos dos postos de trabalhos, tantas formas de segmentação existirão.

\section{A SEGMENTAÇÃO NA REMUNERAÇÃO DO SETOR AGROPECUÁRIO}

O Brasil é um país em desenvolvimento e a agricultura exerce papel importante e significativo para o seu crescimento, sendo objeto de estudos de grande relevância dentro da teoria econômica. (Figueiredo et al, 2005). Estudos realizados por Moura et al. (1999), indicam que estímulos no setor agrícola faz com que haja também efeitos positivos nos demais setores, gerando efeitos benéficos para toda a economia.

A renda da população brasileira economicamente ativa do setor agropecuário é fortemente impactada pelos salários agrícolas, mesmo com a crescente participação das atividades não-agrícolas na renda das famílias que residem no meio rural. Apesar das remunerações das ocupações não-agrícolas apresentarem maiores remunerações que as atividades agrícolas, os trabalhadores agrícolas não mudam de ocupação, mesmo que haja benefícios ou que não hajam custos de deslocamento, por exemplo, pois esses trabalhadores não encontram trabalho em outras ocupações, além de não possuírem as devidas qualificações, sendo assim o trabalho nas atividades agrícolas são de suma importância para o bem-estar das famílias que possuam algum de seu membro empregado no setor agropecuário. (Staduto et al, 2002).

Foi através do modelo desenvolvido por Lewis (1969) que surgiram as primeiras polêmicas sobre o mercado de trabalho agrícola. Autores como Furtado (1972), Leibenstein (1957) e Bacha (1979) compartilhavam da mesma hipótese apresentada no trabalho de Lewis, que pressupunha que a utilidade marginal do trabalho agrícola era igual à zero ou chegava a ser negativa nos países não desenvolvidos, supondo haver desemprego disfarço no setor agropecuário.

Ao analisar os argumentos e considerar válida a hipótese apresentada por Lewis (1969), Lopez (1969) questiona o fato de trabalhadores que não contribuem para o produto marginal terem salários positivos. O modelo de Lewis (1969) responde esse questionamento afirmando que o setor agrícola que transfere mão-de-obra para as indústrias seria compostos pelos estabelecimentos familiares de subsistência.

Contrariando a pressuposição da teoria neoclássica de que os salários são determinados pela produtividade do trabalho, Leibenstein (1957) apresentou hipóteses semelhantes á apresentada por 
Lewis (1969), porém, com objetivos diferentes. O autor se preocupou em justificar as indagações a respeito da existência de salários positivos em regiões cujo produto marginal do trabalho fosse igual à zero ou negativo, argumentando que são os salários que determinam a produtividade do trabalho. Para Ele a nutrição do trabalhador está relacionada a seu salário e a diminuição desse salário acarretaria a redução da produtividade do trabalhador.

Segundo Staduto et al (2002), outro autor que apresentou posição contrária ao modelo de Lewis (1969), foi Schultz (1965), que supunha que o produto marginal do trabalho na agricultura fosse positivo, podendo até ser próximo de zero, mas nunca zero, tendo sua posição reforçada pela pesquisa realizada por Youmans e Schuh (1968), que testaram a hipótese de o produto marginal do trabalho na agricultura ser igual a zero para cinco municípios de Minas Gerais, constatando que os coeficientes de mão-de-obra nas funções de produção apresentaram resultados estatisticamente diferentes de zero para três desses municípios.

Outras discussões em relação ao mercado de trabalho agrícola foram abertas e o trabalho de Bacha (1979) se destaca. Em seu trabalho Bacha analisa o comportamento dos salários agrícolas no Brasil e o crescimento econômico, fazendo com que surgissem debates e interpretações sobre o mercado de trabalho agrícola e os seus salários na literatura nacional (Staduto et. al, 2002).

De acordo com Staduto et. al, (2002), no trabalho de Bacha (1979) foram analisados os salários urbanos e agrícolas no Estado da Guanabara e do Estado de São Paulo, constatando-se que de 1948 a 1978 mantiveram-se constantes os salários agrícolas corrigidos pelos empregadores, porém nos anos de 1963 e 1964 devido a mudança da legislação do trabalhador rural ocorreram algumas mudanças, sendo que em 1968 os salários agrícolas corrigidos pelos índices da inflação aumentaram, seguindo o aumento da relação de troca entre a agricultura e a indústria, que acarretou na redução da diferença entre os salários agrícolas e urbanos.

Para Bacha (1979), a diferença salarial agrícola e urbana se daria pelo fato da oferta de trabalho agropecuário estar acomodado nas pequenas propriedades, reagindo à relação de troca da agricultura e da indústria, pois o aumento dessa relação de troca reduz a oferta de trabalho e eleva os preços agrícolas, fazendo com que os trabalhadores intensifiquem o trabalho nas suas próprias propriedades. Além disso, os salários agrícolas e urbanos foram influenciados por fatores institucionais e conjunturais, como por exemplo, o Estatuto do Trabalhador, o salário mínimo, os ciclos econômicos, o desmonte dos sindicatos urbanos e o arrocho do salário urbano. 
Bacha (1979) utilizou algumas pressuposições do modelo de Lewis (1969), por exemplo, a de que a agricultura é formada por um setor de subsistência e a remuneração dos membros das famílias pelo produto médio, devido a estas suposições foram iniciados uma serie de debates por Gasques (1980). Segundo Gasques (1980), devido o crescimento econômico e a generalização do trabalho assalariado no setor agropecuário brasileiro, o salário agrícola na pequena propriedade deixou de ser determinado pela produtividade média de mão-de-obra, sendo determinados por fatores ligados ao mercado de trabalho e aos fatores institucionais.

Gasques (1980) afirma que os empregadores não remuneram os trabalhadores assalariados pelo produto médio do trabalho como foi defendido por Bacha (1969), pois devido ao fato dos trabalhadores assalariados não apresentaram nenhuma relação com a posse da terra, dependem significativamente do mercado de trabalho. Porém, Bacha (1980) reafirma a sua suposição sobre a remuneração do trabalho argumentando que os dados empíricos a confirmavam.

Outra contestação ao trabalho de Bacha (1979) foi realizada por Rezende (1985), que crítica à forma de obtenção do índice salário-produto. Suas críticas são fundamentadas na constatação de que os produtos cultivados pelos agricultores que trabalham por conta própria e que são ofertantes de trabalho agrícola são diferentes dos produtos cultivados pelos trabalhadores rurais, que são os demandantes de trabalho agrícola. Para Rezende (1985) seria correto obter dois índices diferentes de salário-produto para os agricultores por conta própria e os grandes produtores, e elaborar separadamente os índices de troca da agricultura e da indústria para os produtos domésticos e os destinados à exportação, o autor aplicou esses procedimentos e encontrou resultados diferentes dos de Bacha (1979), que afirmava que os fatores institucionais e as relações de troca agricultura/indústria eram os responsáveis pela elevação dos salários agrícolas (Staduto et. al, 2002).

Após 1968, Rezende formulou uma explicação alternativa para a elevação dos salários agrícolas em relação ao urbano, segundo o autor essa elevação se deu pelo ciclo de expansão do crescimento econômico, gerando um aumento das oportunidades alternativas ao trabalho assalariado agrícola. Para ele o dinamismo do mercado de trabalho agrícola explica o comportamento dos salários agrícolas (Staduto et. al, 2002).

Segundo Staduto et. al (2002), Schuh (1962) foi quem realizou um dos primeiros estudos econométricos sobre os determinantes dos salários agrícolas nos Estados Unidos de 1927 a 1957, estimando equações simultâneas de oferta e demanda de mão-de-obra. Já no Brasil foi Youmans e 
Schuh (1968) que realizaram umas das primeiras pesquisas econométricas referente ao produto marginal do trabalho e sua relação com os salários no setor agropecuário.

Nos trabalhos de Saylor (1974) e Gasques (1975), o mercado de trabalho agrícola é composto por trabalhadores homogêneos, sendo criticados por Bacha (1991) que distingue o mercado de trabalho agrícola em pelo menos dois segmentos: os trabalhadores permanentes e os temporários. Para o autor as tarefas exercidas por esses trabalhadores não são substitutas e nem complementares entre si, porém são suplementares, podendo atender as necessidades quando o outro faltar.

A relação trabalhista com os empregadores entre os trabalhadores temporários e os trabalhadores permanentes é diferente, além de que os contratos de trabalho desses dois segmentos são legalmente distintos, muitas vezes os trabalhadores permanentes ainda recebem salários indiretos, como por exemplo, moradia, água, luz, área de produção própria (Staduto et. al, 2002).

Taubman e Watcher (1986) discorrem sobre a segmentação do mercado de trabalho afirmando que com a existência de diferentes estruturas salariais dentro de um setor seriam então estabelecidas as segmentações. De acordo com Reich, Gordon e Edwards (1973), o processo de desenvolvimento do capitalismo possibilita a distinção de segmentos no mercado de trabalho agrícola.

Dessa forma considerando a segmentação de mercado agropecuário e adotando uma abordagem neoclássica, a demanda de trabalho $(D T)$ como estando em função do salário $(\mathrm{W})$, do preço do produto (Pe )e da tecnologia (Pmo), sendo referente a cada trabalhador, seja ele permanente ou temporário (Staduto et al 2002):

$$
D T^{i}=f^{i}\left(W^{i}, P e, P m o^{i}\right)
$$

Semelhante a demanda, a oferta de trabalho ( $L T$ ) estaria em função do salário $(W)$, do salário mínimo vigente ( $W M$ ) e de outras variáveis que afetaria a categoria do trabalhador:

$$
L T^{i}=g^{i}\left(W^{i}, W M, Z^{i}\right)
$$

Em equilíbrio:

$$
D T^{i}=L T^{i}
$$

Sobe essas condições, como se busca avaliar a segmentação no mercado de trabalho do setor agropecuário, é apresentado a seguir na metodologia a decomposição de Oaxaca-Blinder que será 
utilizado para mensurar o peso da segmentação de salários $W^{i}$ entre os trabalhadores permanentes e temporários, comparando também com aqueles que se declararam como conta própria e os empregadores

\section{BASE DE DADOS E MÉTODOS}

\section{OS DADOS}

Para a aplicação da pesquisa, são utilizados os dados da Pesquisa Nacional de Amostra Domiciliar PNAD do período de 2014 realizadas pelo Instituto Brasileiro de Geografia e Estatística - IBGE, e para a separação dos dados, análise dos modelos e criação das tabelas utilizou-se o programa R 3.2.1.

Ao buscar comparar a remuneração é natural notar, numa comparação entre empregados e empregadores, que deveriam ser considerados na análise proposta os benefícios, auxílios e decimo terceiro salário, que geralmente são recebidos por aqueles que possuem carteira assinada, porém como tais quesitos não são contemplados na PNAD, o estudo comparará especificamente a remuneração recebida na semana de referência.

Sobre o conjunto da pesquisa, analisou-se apenas aqueles maiores de dezoito anos, que são classificados como tendo o trabalho principal dentro do setor agropecuário, que obtiveram alguma remuneração na semana de referência da PNAD, com ou sem carteira assinada. Foram excluídos todos aqueles que não declararam qualquer uma das variáveis utilizadas que serão apresentadas no tópico a seguir.

Dessa forma a amostra utilizada foi formada por 12040 indivíduos, sendo 4324 empregos permanentes, 1533 empregos temporários, 380 empregadores, 5803 conta própria.

\section{METODOLOGIA UTILIZADA.}

Uma tabela descritiva das médias ponderadas será apresentada inicialmente, separando a amostra em quatro grupos: Empregados Temporários, Empregados Permanentes, Empregadores e Conta Própria.

Dessa maneira a média aritmética ponderada $\overline{\boldsymbol{x}}_{\boldsymbol{p}}$ seria estimada por:

$$
\bar{x}_{p}=\frac{\sum_{i=1}^{n} x_{i} p_{i}}{\sum_{i=1}^{n} p_{i}}
$$


Sendo $\boldsymbol{x}$ a variável em que se busca a média e $\boldsymbol{w}$ o peso determinado pela PNAD para o individuo $\boldsymbol{i}$. Será apresentado posteriormente a essa estatística descritiva, o modelo de regressão por Mínimos Quadrados Ponderados pelos pesos da PNAD conforme descrito por (Greene, 2003) e fundamentado no modelo de capital humano proposto por Mincer (1974) log-linearizado:

$$
W_{i}=\alpha+\sum_{j=1}^{k} \beta_{j} X_{j i}+u_{i}
$$

A seguir o quadro com a descrição das variáveis, na qual aquelas com início $d$ são identificadas como dummy:

Quadro - Descrição das variáveis

\begin{tabular}{|c|c|c|}
\hline Variáveis & Posição & Descrição \\
\hline $\ln ($ remuneração/h) & W & $\begin{array}{l}\text { Variável dependente do modelo: logaritmo neperiano da } \\
\text { remuneração no trabalho principal por hora, para os } \\
\text { trabalhadores domésticos. }\end{array}$ \\
\hline Const & $a$ & Constante do modelo \\
\hline $\ln$ (HrTrabalhadas) & $X_{01 i}$ & $\begin{array}{l}\text { Logaritmo neperiano das horas trabalhadas no trabalho } \\
\text { principal mensal }\end{array}$ \\
\hline dHomem & $X_{02 i}$ & $\begin{array}{l}\text { Dummy, assumindo valor } 1 \text { quando o indivíduo se declara } \\
\text { Homem e } 0 \text { caso contrário. }\end{array}$ \\
\hline dBranca & $X_{03 i}$ & $\begin{array}{l}\text { Dummy, assumindo valor } 1 \text { quando o indivíduo se declara } \\
\text { com cor de pele Branca e } 0 \text { caso contrário. }\end{array}$ \\
\hline dPreta & $X_{04 i}$ & $\begin{array}{l}\text { Dummy, assumindo valor } 1 \text { quando o indivíduo se declara } \\
\text { com cor de pele Preta e } 0 \text { caso contrário. }\end{array}$ \\
\hline dCentroOeste & $X_{05 i}$ & $\begin{array}{l}\text { Dummy, assumindo valor } 1 \text { quando o indivíduo reside na } \\
\text { Região Centro-Oeste do Brasil e } 0 \text { caso contrário. }\end{array}$ \\
\hline dNordeste & $X_{06 i}$ & $\begin{array}{l}\text { Dummy, assumindo valor } 1 \text { quando o indivíduo reside } \\
\text { na } \\
\text { Região Nordeste do Brasil e } 0 \text { caso contrário. }\end{array}$ \\
\hline dSudeste & $X_{07 i}$ & $\begin{array}{l}\text { Dummy, assumindo valor } 1 \text { quando o indivíduo reside } \\
\text { na } \\
\text { Região Sudeste do Brasil e } 0 \text { caso contrário. }\end{array}$ \\
\hline dSul & $X_{08 i}$ & $\begin{array}{l}\text { Dummy, assumindo valor } 1 \text { quando o indivíduo reside } \\
\text { na } \\
\text { Região Sul do Brasil e } 0 \text { caso contrário. }\end{array}$ \\
\hline dUrbanaNaoMetrop & $X_{09 i}$ & $\begin{array}{l}\text { Dummy, assumindo valor } 1 \text { quando o indivíduo } \\
\text { reside } \\
\text { numa área Urbana não metropolitana e } 0 \text { caso contrário. }\end{array}$ \\
\hline dRural & $X_{10 i}$ & $\begin{array}{l}\text { Dummy, assumindo valor } 1 \text { quando o indivíduo } \\
\text { reside } \\
\text { numa área Rural e } 0 \text { caso contrário. }\end{array}$ \\
\hline TempoNesseTrab & $X_{11 i}$ & Tempo nesse trabalho em meses \\
\hline dAnalfabeto & $X_{12 i}$ & $\begin{array}{l}\text { Dummy, assumindo valor } 1 \text { quando o indivíduo declara } \\
\text { não } \\
\text { saber ler e } 0 \text { caso contrário. }\end{array}$ \\
\hline
\end{tabular}




\begin{tabular}{|c|c|c|}
\hline EstudoAte9 & $X_{13 i}$ & $\begin{array}{l}\text { Mede os anos de estudos do indivíduo até os nove anos. } \\
\text { Recebendo valor } 9 \text { caso ele tenha escolaridade acima dos } \\
9 \text { anos ou seu próprio valor, caso tenha escolaridade } \\
\text { inferior a } \\
\text { nove anos. }\end{array}$ \\
\hline EstudoAte14 & $X_{14 i}$ & $\begin{array}{l}\text { Mede os anos de estudo superior a nove anos. } \\
\text { Assumindovalor } 1 \text { a } 5 \text { para aqueles que possuem de } 10 \\
\text { a } 14 \text { anos de } \\
\text { estudo respectivamente. }\end{array}$ \\
\hline dEstudoSuperior 15 & $X_{15 i}$ & $\begin{array}{l}\text { Dummy, assumindo valor } 1 \text { quando o indivíduo se } \\
\text { declara } \\
\text { tendo } 15 \text { ou mais anos de estudo e } 0 \text { caso contrário. }\end{array}$ \\
\hline Idade/10 & $X_{16 i}$ & Mede a idade em anos do indivíduo dividida por 10. \\
\hline$(\text { Idade } / 10)^{\wedge} 2$ & $X_{17 i}$ & $\begin{array}{l}\text { Mede a idade em anos do indivíduo dividida por } 10 \text { e } \\
\text { depois } \\
\text { elevada ao quadrado. }\end{array}$ \\
\hline ComeçTrabInf14 & $X_{18 i}$ & $\begin{array}{l}\text { Mede a diferença em anos com que começou a trabalhar } \\
\text { em } \\
\text { comparação com } 14 \text { anos. }\end{array}$ \\
\hline
\end{tabular}

Fonte: Elaborado pela pesquisa.

Separamos as variáveis educação e idade e temos que o efeito da escolaridade total seria formado por $\beta_{13} X_{13 i}+\beta_{14} X_{14 i}+\beta_{15} X_{15 i}$ e da idade por $\beta_{16} X_{16 i}+\beta_{17} X_{17 i}$, pois é esperado que essas variáveis tenham a forma de uma poligonal de vértice no ponto 9 e 15 do eixo $\mathbf{X}$ na escolaridade e no ponto 50 do eixo $\mathbf{X}$ na idade (Ney e Hoffmann, 2003; Hoffmann e NEY, 2004). Essa separação é realizada para captar o efeito da educação acima dos 9 anos e daqueles que obtêm educação igual ou superior a 15 anos, utilizando de forma análoga também para a idade.

Como há o consenso de que o trabalho precoce teria um peso desfavorável à remuneração futura, a variável $X_{18 i}$ obtém valor zero quando o indivíduo começou a trabalhar com 14 ou mais anos de idade e valor 14 - $\boldsymbol{A} \boldsymbol{g} \boldsymbol{J}_{\boldsymbol{i}}$ quando começou a trabalhar antes dos 14 anos de idade, sendo $\boldsymbol{A} \boldsymbol{g} \boldsymbol{J}_{\boldsymbol{i}}$ a idade com que começou a trabalhar.

\section{A DECOMPOSIÇÃO DE OAXACA-BLINDER.}

Devido o interesse em realizar comparações entre as remunerações dos trabalhadores permanentes, temporários, empregadores e conta própria, a pesquisa utiliza da decomposição de Oaxaca-Blinder para separar se esses grupos possuem remuneração diferenciada devido à segmentação dos tipos de trabalho e mercados inseridos ou se essa diferenciação se dá por conta das diferenças das características dos próprios trabalhadores. 
$\mathrm{Na}$ abordagem de Oaxaca-Blinder, dois grupos de análise são separados, o grupo A grupo de base e grupo B ao qual será comparado. Após separado os grupos, estima-se regressões pelo método dos mínimos quadrados a cada um dos grupos. (Vaz e Hoffmann, 2007).

$$
\begin{aligned}
& \bar{W}_{A} \\
& =\hat{\alpha}_{A}+\sum_{j=1}^{k} \hat{\beta}_{j A} \bar{X}_{j A} \text { no grupo } \mathrm{A} \\
& \qquad \bar{W}_{B}=\hat{\alpha}_{B}+ \\
& \sum_{j=1}^{k} \hat{\beta}_{j B} \bar{X}_{j B} \text { no grupo } \mathrm{B}
\end{aligned}
$$

Devido o fato do modelo de estimação dos parâmetros ser por MQP, faz-se necessário que $\overline{\boldsymbol{X}}_{\boldsymbol{j}}$ seja a média ponderada da variável $\boldsymbol{j}$ de forma análoga a demonstrada na equação 4 para encontrar $\overline{\boldsymbol{x}} \boldsymbol{p}$. Busca-se verificar uma diferença na média dos dois grupos, subtraindo uma equação na outra.

$$
\begin{aligned}
& \bar{W}_{A}-\bar{W}_{B}=\left(\hat{\alpha}_{A}-\hat{\alpha}_{B}\right)+\sum_{j=1}^{k} \hat{\beta}_{j A} \bar{X}_{j A}-\sum_{j=1}^{k} \hat{\beta}_{j B} \bar{X}_{j B} \\
& \bar{W}_{A}-\bar{W}_{B}=\left(\hat{\alpha}_{A}-\hat{\alpha}_{B}\right)+\sum_{j=1}^{k} \hat{\beta}_{j A}\left(\bar{X}_{j A}-\bar{X}_{j B}\right)-\sum_{j=1}^{k}\left(\hat{\beta}_{j A}-\hat{\beta}_{j B}\right) \bar{X}_{j B} \\
& \text { Definindo o efeito D e E: } \\
& D=\left(\hat{\alpha}_{A}-\hat{\alpha}_{B}\right)+\sum_{j=1}^{k}\left(\hat{\beta}_{j A}-\hat{\beta}_{j B}\right) \bar{X}_{j B} \\
& E=\sum_{j=1}^{k} \hat{\beta}_{j A}\left(\bar{X}_{j A}-\bar{X}_{j B}\right) \\
& \bar{W}_{A}-\bar{W}_{B}=D+E \\
& \Delta \bar{W}=D+E
\end{aligned}
$$$$
\text { Podemos escrever essa equação como sendo: }
$$

Efeito de Parâmetros - D, mensura a diferença nas remunerações devido à diferença na valoração dos atributos produtivos, sendo $\left(\widehat{\boldsymbol{\alpha}}_{\boldsymbol{A}}-\widehat{\boldsymbol{\alpha}}_{\boldsymbol{B}}\right)_{\text {a diferença de nível e }} \sum_{j=\mathbf{1}}^{\boldsymbol{k}}\left(\widehat{\boldsymbol{\beta}}_{\boldsymbol{j} \boldsymbol{A}}-\widehat{\boldsymbol{\beta}}_{\boldsymbol{j} \boldsymbol{B}}\right) \overline{\boldsymbol{X}}_{\boldsymbol{j} \boldsymbol{B}}$ a valoração diferenciada de um mesmo atributo, fixando os atributos do grupo $B$ e demonstrando se há diferença na valoração desses atributos, mensurando dessa forma a segmentação no mercado de trabalho. 0 Efeito de Médias - E, mensura quanto da diferença dos rendimentos é explicada pela diferença nas características produtivas, fixando a valoração dos atributos no grupo A. 
Finalizando, como é interessante apresentar o peso da segmentação no mercado de trabalho (efeito D), mensura-se:

$$
\text { Peso }_{D}=\frac{D}{D+E}
$$

\section{RESULTADOS}

A seguir apresentam-se as médias de cada variável utilizada, que posteriormente será utilizada em conjunto com os coeficientes encontrados nas regressões para formar a decomposição de OaxacaBlinder demonstradas na metodologia.

Tabela - Médias ponderadas das variáveis utilizadas em cada grupo de análise.

\begin{tabular}{l|r|r|r|r}
\hline \multicolumn{1}{c|}{ Variáveis } & $\begin{array}{c}\text { Empr. } \\
\text { Permanente }\end{array}$ & $\begin{array}{c}\text { Empr. } \\
\text { Temporário }\end{array}$ & $\begin{array}{c}\text { Conta } \\
\text { Própria }\end{array}$ \\
\hline $\ln ($ Rend/hr) & 3,008 & 2,649 & 4,242 & 2,826 \\
\hline Nordeste & 0,247 & 0,524 & 0,218 & 0,333 \\
\hline CentroOeste & 0,217 & 0,065 & 0,197 & 0,071 \\
\hline Sudeste & 0,260 & 0,196 & 0,292 & 0,145 \\
\hline Sul & 0,119 & 0,071 & 0,139 & 0,185 \\
\hline Homem & 0,902 & 0,879 & 0,934 & 0,878 \\
\hline Idade/10 & 3,824 & 3,772 & 5,477 & 4,787 \\
\hline (idade/10)` & 16,146 & 15,946 & 31,915 & 24,778 \\
\hline Branca & 0,318 & 0,244 & 0,611 & 0,398 \\
\hline Preta & 0,108 & 0,110 & 0,029 & 0,076 \\
\hline AAnalfabeto & 0,182 & 0,283 & 0,082 & 0,206 \\
\hline EstudoAtA9 & 4,742 & 3,863 & 6,253 & 4,203 \\
\hline EstudoAtA14 & 0,423 & 0,224 & 1,711 & 0,366 \\
\hline EstudoSuperior15 & 0,019 & 0,005 & 0,187 & 0,018 \\
\hline ln(HrTrabalhadas) & 3,780 & 3,584 & 3,687 & 3,627 \\
\hline UrbanaNaoMetrop & 0,019 & 0,013 & 0,018 & 0,014 \\
\hline Rural & 0,563 & 0,579 & 0,489 & 0,725 \\
\hline TempoNesseTrab. & 79,963 & 109,220 & 275,110 & 237,130 \\
\hline ComeAouTrabInf14 & 0,779 & 0,781 & 0,766 & 0,791 \\
\hline
\end{tabular}

Fonte: Elaborado pela pesquisa. 
A remuneração por hora trabalhada do empregador e do empregado permanente foram as maiores, apesar de não serem diretamente comparáveis é notável quem ganha mais na média. Analisando as médias das remunerações não é possível ainda dizer se essa diferença nas remunerações se dá por conta das características dos próprios trabalhadores ou por conta de uma segmentação no mercado de trabalho.

Sobre as regiões, tomou-se como base o Norte, sendo que há diferença nas distribuições de cada grupo, onde $52 \%$ da população de empregados temporários do setor agropecuário elegíveis para a pesquisa estão concentrados no Nordeste, enquanto que para os outros grupos isso não ocorre.

A maioria dos trabalhadores é predominantemente masculina, havendo em cada grupo uma média de pelo menos $87 \%$ composta por homens, com idade média próxima a 38 anos para empregados permanentes ou temporários e de próximo a 50 anos para empregadores e conta própria.

Sobre a educação formal, os quatro grupos divergem significativamente, o grupo de empregadores possuem maiores níveis de educação, já os temporários apresentam piores níveis. Sobre aqueles com educação formal igual ou superior a 15 anos, o grupo de empregadores chega a atingir $18 \%$ de sua população enquanto que os outros três grupos não chegam a $2 \%$.

Apesar de o setor agropecuário estar diretamente ligado a áreas rurais, uma parcela dos grupos analisados não está localizada em áreas rurais, sendo que o grupo com maior proporção em área rural é o grupo dos conta própria.

Era de se esperar que os trabalhadores permanentes estivessem em média maior tempo de trabalho que os temporários, porém não foi isso o observado, indicando uma rotatividade de trabalhadores nesses empregos (em média ficam aproximadamente 80 meses) maior do que os temporários. Podendo indicar que alguns empregados estejam sendo classificados como temporários, mas que deveriam estar no grupo dos permanentes.

A seguir se apresenta as regressões para as remunerações de cada grupo, sendo que o r-quadrado e outros diagnósticos das regressões se encontram no anexo: 
Ensaios Sobre Hiato Salarial E Pobreza Multidimensional Regional

Tabela - Regressão de In(W) para os Empregados Permanentes e Temporários

\begin{tabular}{|c|c|c|c|c|c|c|c|c|}
\hline \multirow{3}{*}{$\begin{array}{l}\text { Variáveis } \\
\text { st }\end{array}$} & \multicolumn{4}{|c|}{ Empr. Permanente } & \multicolumn{4}{|c|}{ Empr. Temporário } \\
\hline & coef. & $\begin{array}{l}\text { erro } \\
\text { pad. }\end{array}$ & p-val & lor & coef & $\begin{array}{l}\text { erro } \\
\text { pad. }\end{array}$ & p-va & \\
\hline & 3,611 & 0,132 & 0,000 & $* * *$ & 3,107 & 0,193 & 0,000 & $* * *$ \\
\hline $\ln$ (HrTrabalhadas) & 0,385 & 0,030 & 0,000 & $* * *$ & 0,270 & 0,039 & 0,000 & $* * *$ \\
\hline dHomem & 0,211 & 0,024 & 0,000 & $* * *$ & 0,216 & 0,038 & 0,000 & $* * *$ \\
\hline dPreta & 0,004 & 0,023 & 0,877 & & 0,018 & 0,039 & 0,643 & \\
\hline dBranca & 0,046 & 0,016 & 0,004 & $* * *$ & 0,014 & 0,029 & 0,630 & \\
\hline dCentroOeste & 0,329 & 0,023 & 0,000 & $* * *$ & 0,339 & 0,058 & 0,000 & $* * *$ \\
\hline dNordeste & $0,249^{-}$ & 0,023 & 0,000 & $* * *$ & 0,109 & 0,037 & 0,003 & $* * *$ \\
\hline dSudeste & 0,074 & 0,023 & 0,001 & $* * *$ & 0,235 & 0,043 & 0,000 & $* * *$ \\
\hline dSul & 0,119 & 0,028 & 0,000 & $* * *$ & 0,205 & 0,056 & 0,000 & $* * *$ \\
\hline dUrbanaNaoMetrop & 0,023 & 0,052 & 0,658 & & 0,087 & 0,107 & 0,420 & \\
\hline dRural & 0,070 & 0,014 & 0,000 & $* * *$ & 0,149 & 0,026 & 0,000 & $* * *$ \\
\hline TempoNesseTrab. & 0,000 & 0,000 & 0,013 & $* *$ & 0,001 & 0,000 & 0,000 & $* * *$ \\
\hline dAnalfabeto & 0,094 & 0,025 & 0,000 & $* * *$ & 0,057 & 0,037 & 0,123 & \\
\hline EstudoAte9 & 0,021 & 0,004 & 0,000 & $* * *$ & 0,013 & 0,007 & 0,044 & $* *$ \\
\hline EstudoAte14 & 0,073 & 0,011 & 0,000 & $* * *$ & 0,006 & 0,024 & 0,814 & \\
\hline dEstudoSuperior 15 & 0,143 & 0,077 & 0,063 & $*$ & 0,309 & 0,220 & 0,161 & \\
\hline Idade/10 & 0,263 & 0,033 & 0,000 & $* * *$ & 0,187 & 0,053 & 0,001 & $* * *$ \\
\hline$(\text { idade } / 10)^{\wedge} 2$ & 0,028 & 0,004 & 0,000 & $* * *$ & 0,018 & 0,006 & 0,004 & $* * *$ \\
\hline ComeçTrabInf14 & 0,012 & 0,017 & 0,483 & & 0,019 & 0,029 & 0,514 & \\
\hline
\end{tabular}

Fonte: Elaborado pela pesquisa. 
O número de horas trabalhadas foi significativo e negativo para os quatro grupos indicando que 0 aumento de horas trabalhadas reduziria sua remuneração por hora. Ser homem aumentou a remuneração também para os quatro modelos.

Para os empregados permanentes, apenas as variáveis cor da pele preta, residir em região urbana não metropolitana e possuir educação formal superior a 15 anos não foram significativas a 5\% no modelo. Enquanto que para os temporários além dessas dos empregados permanentes, as variáveis cor da pele branca, é analfabeto, anos de estudo de 9 a 14 anos e começou a trabalhar com menos de 14 anos não foram significativas.

Comparando os empregados permanentes e temporários, nota-se que os coeficientes das variáveis possuem o mesmo sentido ou são estatisticamente iguais a zero, apesar de diferentes.

Tabela - Regressão de In(W) para os Empregadores e Conta Própria.

\begin{tabular}{|c|c|c|c|c|}
\hline & \multicolumn{4}{|c|}{ Empregador } \\
\hline Variáveis & coef. & erro pad. & p-va & lor \\
\hline const & 5,707 & 0,854 & 0,000 & $* * *$ \\
\hline $\ln$ (HrTrabalhadas) & 0,621 & 0,134 & 0,000 & $* * *$ \\
\hline dHomem & 0,398 & 0,205 & 0,053 & * \\
\hline dPreta & 0,191 & 0,304 & 0,530 & \\
\hline dBranca & 0,110 & 0,111 & 0,325 & \\
\hline dCentroOeste & 0,516 & 0,178 & 0,004 & $* * *$ \\
\hline dNordeste & 0,368 & 0,173 & 0,034 & $* *$ \\
\hline dSudeste & 0,167 & 0,164 & 0,309 & \\
\hline $\mathrm{dSul}$ & 0,415 & 0,195 & 0,034 & $* *$ \\
\hline dUrbanaNaoMetrop & 0,578 & 0,365 & 0,115 & \\
\hline dRural & 0,142 & 0,111 & 0,199 & \\
\hline TempoNesseTrab. & 0,000 & 0,000 & 0,635 & \\
\hline dAnalfabeto & 0,251 & 0,226 & 0,269 & \\
\hline EstudoAte9 & 0,116 & 0,028 & 0,000 & $* * *$ \\
\hline EstudoAte14 & 0,046 & 0,063 & 0,468 & \\
\hline dEstudoSuperior 15 & 0,022 & 0,315 & 0,944 & \\
\hline Idade/10 & 0,191 & 0,243 & 0,433 & \\
\hline$(\text { idade } / 10)^{\wedge} 2$ & 0,020 & 0,022 & 0,349 & \\
\hline ComeçTrabInf14 & 0,128 & 0,117 & 0,277 & \\
\hline
\end{tabular}

\begin{tabular}{|c|c|c|c|}
\hline \multicolumn{4}{|c|}{ Conta Própria } \\
\hline coef. & erro pad. & p-va & \\
\hline 3,709 & 0,150 & 0,000 & *** \\
\hline 0,525 & 0,029 & 0,000 & $* * *$ \\
\hline 0,308 & 0,032 & 0,000 & $* * *$ \\
\hline 0,005 & 0,039 & 0,907 & \\
\hline 0,194 & 0,025 & 0,000 & $* * *$ \\
\hline 0,328 & 0,044 & 0,000 & $* * *$ \\
\hline 0,535 & 0,027 & 0,000 & $* * *$ \\
\hline 0,073 & 0,034 & 0,034 & $* *$ \\
\hline 0,218 & 0,035 & 0,000 & $* * *$ \\
\hline 0,113 & 0,089 & 0,202 & \\
\hline 0,097 & 0,023 & 0,000 & $* * *$ \\
\hline 0,000 & 0,000 & 0,211 & \\
\hline 0,124 & 0,034 & 0,000 & $* * *$ \\
\hline 0,031 & 0,005 & 0,000 & $* * *$ \\
\hline 0,071 & 0,018 & 0,000 & $* * *$ \\
\hline 0,026 & 0,118 & 0,828 & \\
\hline 0,280 & 0,045 & 0,000 & $* * *$ \\
\hline 0,026 & 0,005 & 0,000 & $* * *$ \\
\hline 0,017 & 0,025 & 0,506 & \\
\hline
\end{tabular}

Fonte: Elaborado pela pesquisa. 
Apesar de possuir bastante variáveis não significativas, a regressão para os empregadores obteve o maior r-quadrado. Comparando os quatro modelos, a maior constante foi a do empregador, o que é esperado pois é consensual que variáveis como tamanho da terra, preço e lucro dos produtos negociados sejam variáveis relevantes para a estimação e que a pesquisa não conseguiu obter.

De forma análoga a comparação entre os empregados permanentes e temporários, os empregadores e conta própria obtiveram, para os coeficientes que foram estatisticamente significativos, o mesmo sentido, apesar de magnitudes diferentes.

Tabela - Combinações da decomposição de Oaxaca-Blinder.

\begin{tabular}{l|r|r|r|r}
\hline \multicolumn{1}{c|}{ Combinações } & $\begin{array}{c}\text { D - Efeito } \\
\text { Parâmetros }\end{array}$ & $\begin{array}{c}\text { E - Efeito } \\
\text { Médias }\end{array}$ & $\begin{array}{c}\text { Variação } \\
\text { total }\end{array}$ & \multicolumn{1}{c}{$\begin{array}{c}\text { Peso da } \\
\text { Segmentação }\end{array}$} \\
\hline Permanentes - Temporários & 0,2376 & 0,1219 & 0,3595 & $66,0915 \%$ \\
\hline Permanentes - Empregador & $-1,0523$ & $-0,1817$ & $-1,2341$ & $85,2701 \%$ \\
\hline Permanentes - Conta Própria & 0,1206 & 0,0611 & 0,1817 & $66,3690 \%$ \\
\hline Temporários - Empregador & $-1,5373$ & $-0,0562$ & $-1,5936$ & $96,4701 \%$ \\
\hline Temporários - Conta Própria & $-0,2074$ & 0,0297 & $-0,1778$ & $116,6497 \%$ \\
\hline Empregador - Conta Própria & 0,8956 & 0,5202 & 1,4158 & $63,2544 \%$ \\
\hline
\end{tabular}

Fonte: Elaborado pela pesquisa.

Fazendo uma decomposição de Oaxaca-Blinder conforme o descrito na metodologia o efeito D mensura o efeito da segmentação no mercado e o efeito $\mathbf{E}$ a diferença nos atributos produtivos. Com isso para os empregados permanentes e empregados temporários, nota-se que a segmentação tem um peso de $66 \%$ no diferencial das remunerações entre esses dois grupos.

Efeitos positivos indicavam vantagem na remuneração para o grupo da esquerda, que no caso da primeira combinação representa uma vantagem para os empregados permanentes. Efeitos negativos indicam vantagem para o grupo da direita, como é o caso da segunda combinação (Permanentes Empregador) em que o efeito $\mathbf{D}$ apresenta o valor de $-1,0523$, indicando que a segmentação é favorável ao empregador em 1,0523.

O peso da segmentação atinge valores superiores a $100 \%$ quando há diferença nos sinais entre os efeitos, isso ocorreu entre os trabalhadores temporários e os conta própria, em que a segmentação favorece os conta própria e os atributos produtivos favorecem os temporários. Esse foi também a combinação com maior diferença no peso da segmentação, indicando que os atributos produtivos dos temporários superam os conta própria, mas que os conta própria em média são melhores remunerados dado a segmentação no mercado de trabalho. 
Tabela - Diagnósticos das regressões.

\begin{tabular}{|c|c|c|c|c|}
\hline Estatísticas & $\begin{array}{c}\text { Empr. } \\
\text { Permanente }\end{array}$ & $\begin{array}{c}\text { Empr. } \\
\text { Temporário }\end{array}$ & Empregador & $\begin{array}{c}\text { Conta } \\
\text { Própria }\end{array}$ \\
\hline Média var. dependente & 3,008 & 2,649 & 4,242 & 2,826 \\
\hline Soma resíd. quadrados & 882,155 & 334,117 & 319,671 & $3.409,786$ \\
\hline R-quadrado & 0,286 & 0,192 & 0,382 & 0,259 \\
\hline R-quadrado ajustado & 0,283 & 0,183 & 0,351 & 0,256 \\
\hline $\mathrm{F}(18, \mathrm{n})$ & 96,019 & 20,032 & 12,412 & 112,028 \\
\hline P-valor(F) & 0,000 & 0,000 & 0,000 & 0,000 \\
\hline D.P. var. dependente & 0,535 & 0,520 & 1,169 & 0,890 \\
\hline E.P. da regressão & 0,453 & 0,470 & 0,941 & 0,768 \\
\hline $\begin{array}{l}\text { Log da } \\
\text { verossimilhança }\end{array}$ & $-2.698,843$ & $-1.007,478$ & $-506,350$ & $-6.691,299$ \\
\hline Critério de Schwarz & $5.556,752$ & $2.154,320$ & $1.125,563$ & $13.547,250$ \\
\hline Critério de Akaike & $5.435,685$ & $2.052,955$ & $1.050,699$ & $13.420,600$ \\
\hline $\begin{array}{l}\text { Critério Hannan- } \\
\text { Quinn }\end{array}$ & $5.478,431$ & $2.090,676$ & $1.080,405$ & $13.464,660$ \\
\hline
\end{tabular}

Fonte: Elaborado pela pesquisa.

O setor agropecuário possui rotinas diárias necessitando de trabalhadores permanentes para exercer essas funções, porém em períodos como o plantio e a safra o setor apresenta picos de atividades, demandando mão-de-obra temporária que geralmente é menos qualificada que a mão-de-obra permanente. Dessa forma é consensual a presença de trabalhadores temporários que ganham menos.

Finalizando, apesar de a segmentação estar associado a injustiça quando se compara diferenças nas remunerações entre homens e mulheres ou entre raças, é necessário ressalvar que esse não é o caso, pois por exemplo, no caso da remuneração entre trabalhadores e empregadores é consensual que além do poder de mercado, os empregadores possuem recursos produtivos adicionais como terras e capital que estarão incluídos dentro da segmentação. Agora para a comparação entre os trabalhadores permanentes e temporários, a segmentação favorável aos permanentes indica que é desejável a transposição dos temporários em permanentes ou que essa segmentação seja reduzida através de políticas públicas.

\section{CONSIDERAÇÕES FINAIS}

Apesar da crescente participação das atividades não agrícolas na renda das famílias no meio rural, os salários agrícolas geram fortes impactos na renda da população economicamente ativa do setor agropecuário, dessa forma, o bem-estar das famílias que tenham algum membro trabalhando no setor agropecuário está diretamente relacionado com trabalho nas atividades agrícolas. 
Por haver segmentação, o mercado de trabalho gera desigualdades de renda quando remunera de forma diferenciada os trabalhadores com a mesma produtividade, dessa maneira o trabalho buscou identificar o hiato salarial entre quatro grupos do setor agropecuário brasileiro, os empregadores, os trabalhadores por conta própria, os trabalhadores permanentes e os temporários, analisando se essa diferença existe por causa da segmentação ou se é causada pela diferença nos atributos produtivos.

Com isso o trabalho utilizou a decomposição de Oaxaca-Blinder para decompor esse hiato salarial entre efeito D (segmentação) e efeito $\mathbf{E}$ (atributos produtivos). Dessa forma, foi possível medir também o peso da segmentação e qual seria a diferença nas remunerações caso ela não existisse.

O peso da segmentação entre trabalhadores permanentes e temporários foi de aproximadamente $66 \%$ em vantagem para os permanentes, enquanto que a combinação que obteve a maior segmentação foi entre os trabalhadores temporários e conta própria no valor de quase $117 \%$ em vantagem para os trabalhadores em conta própria, indicando que mesmo os temporários tendo melhores atributos produtivos, ainda ganham menos por conta da segmentação. Conforme o discutido essa segmentação pode estar associada não apenas ao poder de mercado, mas a posses como terras e capital. 


\section{REFERÊNCIAS}

Programa R: http://www.r-project.org/

BACHA, C. J. C. Determinação dos salários na agricultura. Revista Brasileira de Economia, v. 45, n. 3, p. 441-471, 1991.

BACHA, E. Crescimento econômico, salários urbanos e rurais: o caso do Brasil. Pesquisa e Planejamento Econômico, Rio de Janeiro, v. 9, n. 3, p. 585-628, 1979.

- - - C Crescimento econômico, salários urbanos e rurais: o caso do Brasil - réplica. Pesquisa e Planejamento Econômico, Rio de Janeiro, v. 10, n. 2, p. 645-646, ago. 1980.

BALSADI, Otavio Valentim; SILVA, Alan Ricardo da. Emprego permanente e temporário na agricultura paulista no período 2004-07. 2009.

BARROS, Ricardo Paes de; MENDONÇA, Rosane. Geração e reprodução da desigualdade de renda no Brasil. Perspectivas da economia brasileira 1994, Rio de Janeiro: IPEA, p. 471-490, 1993.

.1995. Os determinantes da desigualdade no Brasil. 1995.

.1996. Os determinantes da desigualdade no Brasil. Perspectivas da economia brasileira, Rio de Janeiro: IPEA, p. 421-474, 1996.

BARROS, Ricardo Paes de; FRANCO, Samuel; MENDONÇA, Rosane. Discriminação e segmentação no mercado de trabalho e desigualdade de renda no Brasil. Texto para Discussão ${ }^{\circ}{ }^{1288}$. Rio de Janeiro: IPEA, 2007.

BLINDER, Alan S. Wage discrimination: reduced form and structural estimates. Journal of Human resources, p. 436-455, 1973.

BRAGA, Breno; FIRPO, Sergio; GONZAGA, Gustavo. Escolaridade e o Diferencial de Rendimentos entre o Setor Privado e o Setor Público no Brasil. Pesquisa e Planejamento Econômico, v. 39, n. 3, p. 431464, 2009.

BECKER, Gary. Investment in Human Capital: A Theoretical Analysis. J. Polit. Econ., Oct 1962, 7 (5), pt. 2, p. 9-49.

. Human capital. New York: National Bureau of Economic Research, 1964.

BOWLES, S.; GINTIS, H. The problem with human capital theory: a marxian critique. American Economic Review, v. 65, n. 2, p. 74-82, maio /1975.

FIGUEIREDO, Margarida Garcia de; BARROS, Alexandre Lahós Mendonça de; GUILHOTO, Joaquim José Martins. Relação econômica dos setores agrícolas do Estado do Mato Grosso com os demais setores pertencentes tanto ao Estado quanto ao restante do Brasil. Revista de Economia e Sociologia Rural, v. 43, n. 3, p. 557-575, 2005.

FURTADO, C. Análise do modelo brasileiro. Rio de Janeiro: Civilização Brasileira, 1972. 
GASQUES, J. G. Oferta e demanda de mão-de-obra volante no estado de São Paulo. Piracicaba: Escola Superior de Agricultura “Luiz de Queiroz", Universidade de São Paulo, 1975 (Dissertação de Mestrado).

- - - Crescimento econômico, salários urbanos e rurais: o caso do Brasil - comentário. Pesquisa e Planejamento Econômico, Rio de Janeiro, v. 10, n. 2, p. 637-664, 1980.

- - - - Uma análise dos fatores que afetam os salários na agricultura. São Paulo: Instituto de Pesquisa Econômica, Universidade de São Paulo, 1981 (Tese de Doutorado).

GASQUES, J. G., CONCEIÇÃO, J. C. P. R. Transformações estruturais da agricultura e produtividade total dos fatores. Brasília: IPEA, 2000 (Texto para Discussão, 768).

HINCHLIFFE, K. Education and the labour market. In: Psacharopoulos, G (ed.). Economics on education research and studies. Washington, D.C.: World Bank/ Pergamon Press, p.141-146, 1987.

HOFFMANN, Rodolfo; NEY, Marlon Gomes. Desigualdade, escolaridade e rendimentos na agricultura, indústria e serviços, de 1992 a 2002. Economia e Sociedade, v. 13, n. 2, p. 23, 2004.

LANGONI, Carlos Geraldo. Distribuição da renda e desenvolvimento econômico do Brasil. Rio de Janeiro: Expressão e Cultura, 1973.

LEIBENSTEIN, H. The theory of underemployment in backward economies. The Journal of Political Economy, n. 2, p. 91-103, Apr. 1957.

LEWIS, A. O desenvolvimento econômico com oferta ilimitada de mão-de-obra. In: AGARWALA, N. A., SINGH, S. P. (coords.). A economia do desenvolvimento. São Paulo: Companhia e Editora Forense, 1969.

LOPEZ, M. R. O desemprego disfarçado na agricultura. Revista Brasileira de Economia, v. 23, n. 4, p. 23-44, 1969.

MACHADO, Ana Flávia; OLIVEIRA, Ana Maria Hermeto Camilo de; ANTIGO, Mariângela. Evolução do diferencial de rendimentos entre setor formal e informal no Brasil: o papel das características não observadas. Revista de Economia Contemporânea, v. 12, n. 2, p. 355-388, 2008.

MATOS, Raquel Silvério; MACHADO, Ana Flávia. Diferencial de rendimento por cor e sexo no Brasil (1987-2001). Revista Econômica, v. 8, n. 1, 2006.

MINCER, Jacob. Schooling, Experience, and Earnings. Human Behavior \& Social Institutions, No. 2. 1974.

MORAES, Márcia Azanha Ferraz Dias de. O mercado de trabalho da agroindústria canavieira: desafios e oportunidades. Economia Aplicada, v. 11, n. 4, p. 605-619, 2007.

MOURA, J. G.; CÂMARA, S.F.; LIMA, R.C. Eficiência alocativa e crescimento econômico: o papel do setor agrícola. Congresso Brasileiro de Economia e Sociologia Rural, 41, Foz do Iguaçu, 1999. Anais. Brasília: SOBER, 1999.

NEY, Marlon Gomes; HOFFMANN, R. Desigualdade de renda na agricultura: o efeito da posse da terra. Economia, v. 4, n. 1, p. 113-152, 2003. 
OAXACA, R. 1973. Male-female wage differential in urban labor markets. International Economic Review, vol. 14, 1973, p. 693-709.

PEREIRA, Rosângela Saldanha; ZAVALA, Arturo Zavala. Educação e rendimentos do trabalho no Brasil: desafios de um cenário de transformações. Si Somos Americanos, Revista de Estudios Transfronterizos, v. 12, n. 2, p. 203-227, 2012.

REICH, M., GORDON, D. M., EDWARDS, R. C. A theory of labor market segmentation. American Economic Review, v. 63, n. 2, p. 359-365, 1973.

SAYLOR, R. G. Procura e oferta de mão-de-obra agrícola no Estado de São Paulo. Agricultura em São Paulo, v. 21, n. 3, p. 129-146, 1974.

SCHUH, G. E. An econometric investigation of the market of hired labor in agriculture. Journal Farm Economic, v. 44, n. 2, p. 307-321, May 1962.

SCHULTZ, T. W. A transformação da agricultura tradicional. São Paulo: Zahar, 1965.

SCHULTZ, Theodore W. O Capital Humano - Investimentos em Educação e Pesquisa. Rio de Janeiro: Zahar Editores. 1973.

SOARES, Sergei Suarez Dillon. Distribuição de renda no Brasil de 1976 a 2004 com ênfase no período entre 2001 e 2004. Texto para Discussão n 1166. IPEA 2006.

STADUTO, Jefferson Andronio Ramundo; BACHA, Carlos José Caetano; BACCHI, Mirian Rumenos Piedade. Determinação dos salários na agropecuária brasileira. 2002.

STADUTO, Jefferson Andronio Ramundo. Determinação dos salários na agropecuária brasileiraperíodo de 1971 a 1996. 2002. Tese de Doutorado. Universidade de São Paulo.

TAUBMAN, P., WACHTER, M. L. Segmented labor markets. In: ASHENFELTER, O. C., LAYARD, R. Handbook of labor Economic. Amsterdã: North-Holland, 1986.

THUROW, Lester C. Education and Economic Inequality. Public Interest, Summer 1972, (28), pp.66-81.

VARIAN, Hal R. Microeconomia: princípios básicos. 2 ed. Rio de Janeiro: campuys, 1997.

VAZ, Daniela Verzola; HOFFMANN, Rodolfo. Remuneração nos serviços no Brasil: o contraste entre funcionários públicos e privados. Economia e Sociedade, v. 16, n. 2, p. 199-232, 2007.

VILELA, Thaís et al. Análise do diferencial de renda do trabalho em 2008 entre diferentes gerações de trabalhadores no Brasil. Revista Economia, 2012.

YOUMANS, R., SCHUH, G. E. An empirical study of the agricultural labor market in a developing country, Brazil. American Journal of Agricultural Economics, v. 50, n. 4, p. 943-961, Nov. 1968.

ZUCCHI, Juliana Domingues; HOFFMAN, Rodolfo. Diferenças de renda associadas à cor: Brasil, 2001. Pesquisa \& Debate, v. 15, n. 1 (25), 2004. 


\section{ARTIGO 2: POBREZA MULTIDIMENSIONAL DO BRASIL: CONSTRUÇÃO DE UM INDICADOR DE} POBREZA UTILIZANDO A ANÁLISE FATORIAL EM 2014.

Resumo: A pobreza é um fenômeno complexo e de múltiplas dimensões, não se restringindo apenas à insuficiência de consumo, mas pelas privações aos quais os indivíduos estão expostos. O objetivo deste artigo foi o de identificar como a pobreza multidimensional é distribuída, através da criação de indicadores de baixa renda, vulnerabilidades e de pobreza, tendo como base os dados da Pnad de 2014, após a criação desses indicadores foi realizada uma análise fatorial exploratória, que identificará cinco níveis de privações em que uma família possa estar. Os resultados mostram que não há diferença significativa entre homens e mulheres na pobreza familiar, além disso, as pessoas que não são de cor branca foram as que apresentaram os maiores índices de pobreza multidimensional, já para a área de residência, os indicadores das pessoas que residem nas áreas rurais apresentaram resultados acima da média nacional, evidenciando a fragilidade do meio rural. Os Estados que apresentaram os maiores índices foi o Maranhão, Pernambuco e Alagoas e os de menores índices foram Mato Grosso, Mato Grosso do Sul, Goiás, Distrito Federal, Paraná, Santa Catarina e o Rio Grande do Sul.

Palavras-chave: Pobreza Multidimensional, Vulnerabilidades, Análise Fatorial. 


\section{INTRODUÇÃO}

No Brasil, a pobreza atinge milhões de brasileiros e apesar de não ser considerado um fenômeno baseado exclusivamente na renda, a concentração de renda é um fator de peso (Moreira, 2011). Até o ano de 2013 o Brasil vinha obtendo resultados expressivos em relação ao PIB comparando com outras economias, porém a pobreza sempre foi um problema que esteve presente, atingindo milhões de brasileiros.

Sen (1999) afirma que países com alto PIB per capita podem ter baixa qualidade de vida, com grande massa populacional submetida, por exemplo, à mortalidade prematura. Caso semelhante a isso podem ser observado no Brasil e China, pois possuem baixo índice de desenvolvimento social, porém com PIBs elevado.

A pobreza é reconhecida como um fenômeno complexo e de múltiplas dimensões, não se restringindo apenas à insuficiência de consumo, mas pelas privações aos quais os indivíduos estão expostos, sendo relacionada não apenas com a renda e o mercado de trabalho, mas também com políticas e relações sociais.

O presente artigo pretende analisar e identificar como se dá a distribuição da pobreza multidimensional para as famílias utilizando dos dados da Pesquisa Nacional por Amostra de Domicílios (PNAD) do ano de 2014, através de indicadores de baixa renda, vulnerabilidades e de pobreza, criando índices para os homens e mulheres, pessoas de cor brancas e não brancas e para as pessoas que residem na área urbana e na área rural, e também os índices de pobreza multidimensional para cada Unidade de Federação.

O trabalho esta organizado em 6 seções além dessa introdução, logo após será realizada a conceituação da pobreza multidimensional, apresentando diferentes perspectivas encontradas por autores para identificá-la. Na segunda seção será apresentada a metodologia adotada pelo trabalho, a criação de um Índice de Pobreza Multidimensional que classificará as famílias como tendo ou não pobreza multidimensional. Este índice será formado por duas linhas (de baixa renda e de vulnerabilidade), semelhantes a proposta feito pelo Conselho Nacional de Avaliação de Políticas de Desenvolvimento Social - CONEVAL (2009). Após a criação desses indicadores será realizada uma análise fatorial exploratória, a qual identificará cinco níveis em que uma família possa estar.

A análise fatorial é uma técnica de análise multivariada que identifica um número relativamente pequeno de fatores que podem ser usados para representar relações entre muitas variáveis que estão 
inter-relacionadas. A redução a um número menor de variáveis, também chamados muitas vezes de "fatores", "dimensões" ou "componentes", maximiza o poder de explicação do conjunto de todas as variáveis e possibilitam identificar subgrupos de questões que avaliam uma mesma habilidade ou capacidade cognitiva. (Pasquali, 2009; Primi, 2003, 2006).

Em seguida serão apresentados os resultados encontrados que foram gerados por meio dos indicadores de Baixa Renda, Vulnerabilidades e de Pobreza formando o índice de pobreza multidimensional para todas as Unidades da Federação. Por fim serão realizadas as considerações finais e as referencias bibliográficas.

\section{POBREZA MULTIDIMENSIONAL}

Há um consenso cada vez mais amplo sobre a natureza multidimensional da pobreza, sendo associadas às condições de vida que vulneram a dignidade das pessoas, limitam seus direitos, restringem suas liberdades fundamentais, impedem a satisfação de suas necessidades básicas e impossibilitam sua plena integração social em que tais elementos não podem ser reduzidos a uma única característica ou dimensão. (CONEVAL, 2009).

Amartya Sen (2000), após a análise da ausência de capacidade em alguns indivíduos, caracteriza a pobreza como sendo a negação de oportunidades básicas para o desenvolvimento dos indivíduos como cidadãos, ou seja, significa que o cidadão é privado de ter uma boa saúde, educação, ter um padrão de vida descente, ter dignidade e amor próprio, poder desfrutar de sua vida e ter liberdade, entre muitas outras privações, dessa forma, a pessoa que possuísse alto grau de privação seria considerada pobre.

As privações que uma família possui está relacionada a pobreza de forma que tais privações restringem a liberdade dessa família. Essa privação pode ser mensurada tanto de forma relativa, ou seja, comparando-se famílias ou de forma absoluta, que delimita uma linha de análise. (Sen ,2000).

Existem diversas formas de se mensurar essas privações, visto que a pobreza pode ser classificada por alguns como falta de renda e por outros é analisada como sendo um

fenômeno multidimensional, sendo medida por vários subitens que o pesquisar considera importantes para uma família, sendo assim, a falta desses subitens seriam prejudiciais a essas famílias, essa falta mediria a pobreza de uma família. (Sen, 1999). 
Outras definições também são bastante empregadas nas literaturas sobre o assunto, como a de Narayan:

\begin{abstract}
"Pobreza é fome, é falta de abrigo. Pobreza é estar doente e não poder ir ao médico. Pobreza é não poder ir à escola e não saber ler. Pobreza é não ter emprego, é temer o futuro, é viver um dia de cada vez. Pobreza é perder o seu filho para uma doença trazida pela água não tratada. Pobreza é falta de poder, falta de representação e liberdade". (Narayan, 2000).
\end{abstract}

Para Barros e Franco (2006), não existe um padrão exato que defina a pobreza, porém há o reconhecimento de que a pobreza é um fenômeno de caráter multidimensional, segundo eles, os índices de pobreza unidimensional são ineficientes porque considera que todos os indivíduos utilizam a renda de forma semelhante, o que pode não ocorrer, sendo assim definem a pobreza como um fenômeno de caráter multidimensional.

Mestrum (2002 apud Lima 2005), afirma que a multidimensionalidade da pobreza tem como potencial situar os pobres e os nãos pobres dentro de uma sociedade, dividindo-os por um ponto de vista que não considere apenas a renda como causadora dessa pobreza, mas a diversos elementos importantes, possibilitando dessa forma a verificação de grupos onde os elementos que são relacionados com a renda são satisfatórios, enquanto que os outros elementos que não estão relacionados à renda estão sendo insatisfatórios para esses indivíduos. Dessa forma, as análises de pobreza que consideram exclusivamente a renda e as análises feitas pelo pensamento utilitarista não poderiam avaliar a pobreza pela ótica multidimensional.

A pobreza necessita que seja construído um indicador que corresponda a abordagem multidimensional, conforme Salama \& Destremau (1999) a construção de itens para a pobreza é cheia de avaliações subjetivas que influenciam no resultado final da análise, dessa forma, deve-se considerar vários aspectos da pobreza para proporcionar um melhor entendimento do seu problema.

\title{
METODOLOGIA
}

O presente trabalho utiliza os microdados da Pesquisa Nacional por Amostra de Domicílio - PNAD 2014 divulgadas pelo Instituto Brasileiro de Geografia e Estatística - IBGE, para criar um Índice de Pobreza Multidimensional que classificará as famílias como tendo ou não pobreza multidimensional. A criação das tabelas, mapas e análise fatorial foram realizadas através do programa R-3.2.3 for Windows.

Esse índice será formado por duas linhas semelhante à proposta feita pelo CONEVAL (2009) para criação de um indicador de pobreza multidimensional comparável Inter regionalmente. A primeira, 
linha de baixa renda, identifica as famílias com renda abaixo de 140 reais per capita como tendo insuficiência de renda. A segunda, linha de vulnerabilidade, identificará em cinco níveis as privações de uma família. Dessa forma, as famílias com pobreza multidimensional serão aquelas com insuficiência de renda e vulnerabilidade média ou pior.

\section{LINHA DE BAIXA RENDA.}

Essa linha segregará as famílias que não possuem ao menos 140 reais per capita como tendo baixa renda:

$$
B R= \begin{cases}1 & \text { Se Renda per capita }<R \$ 140 \text { per capita } \\ 0 & \text { Se Renda per capita } \geq R \$ 140 \text { per capita }\end{cases}
$$

\section{É possível também criar uma linha extrema baixa renda:}

$$
B R E= \begin{cases}1 & \text { Se Renda per capita }<R \$ 70 \text { per capita } \\ 0 & \text { Se Renda per capita } \geq R \$ 70 \text { per capita }\end{cases}
$$

\section{LINHA DE VULNERABILIDADE.}

Utilizando-se dos indicadores de vulnerabilidade e pobreza de Barros et al (2006) demonstradas em anexo e da análise fatorial exploratória, identifica-se cinco níveis em que uma família pode estar.

Segundo Lattin, Carroll e Green (2011), a análise fatorial é um método estatístico que supõem que as variâncias dos dados multivariados observados na amostra

podem ser explicadas por um numero menor de fatores específicos, na qual o estudo examina o interrelacionamento entre os dados para encontrar um conjunto menor de fatores que revele o que as variáveis coletadas da amostra partilham em comum, através do método de rotação Varimax, que de acordo com os autores trata-se de um método de rotação ortogonal cuja pretensão é de que existam alguns pesos significativos para cada componente principal e que todos os outros pesos sejam próximos de zero, ou seja, tem como objetivo a maximização de variação entre os pesos de cada componente. Dessa forma o trabalho busca a tendência da amostra e consequentemente também a 
tendência da população brasileira em 2014. Os testes da análise fatorial estão nos apêndices desse artigo.

Para a criação da Linha de vulnerabilidade utiliza-se dos indicadores coletados anteriormente (C, D, H, T e V) e com base no modelo geral de Lattin, Carroll e Green (2011) para análise fatorial exploratória demonstra em seu modelo geral que:

$$
\left\{\begin{array}{l}
I_{1}=\lambda_{11} \varepsilon_{1}+\lambda_{12} \varepsilon_{2}+\ldots+\lambda_{1 c} \varepsilon_{c}+\delta_{1} \\
I_{2}=\lambda_{21} \varepsilon_{1}+\lambda_{22} \varepsilon_{2}+\ldots+\lambda_{2 c} \varepsilon_{c}+\delta_{2} \\
I_{3}=\lambda_{31} \varepsilon_{1}+\lambda_{32} \varepsilon_{2}+\ldots+\lambda_{3 c} \varepsilon_{c}+\delta_{3} \\
\vdots \\
I_{p}=\lambda_{p 1} \varepsilon_{1}+\lambda_{p 2} \varepsilon_{2}+\ldots+\lambda_{p c} \varepsilon_{c}+\delta_{p}
\end{array}\right\}
$$

Em notação matricial torna-se:

$$
I=\lambda \varepsilon_{c}^{\prime}+\delta
$$

Respeitando a igualdade:

$$
\operatorname{var}\left(I_{i}\right)=\operatorname{var}\left(\lambda \varepsilon_{c}^{\prime}+\delta_{i}\right)=\lambda^{2}{ }_{i}+\operatorname{var}\left(\delta_{i}\right)=1
$$

Sendo que $I$ representa os dados da amostra, os coeficientes $\lambda$ representam o grau que cada medita I reflete sobre os fatores $\mathcal{E}$, como a relação de I não é perfeitamente explicada pela interação de $\lambda$ com os fatores $\varepsilon$ adiciona-se o termo $\delta$ que explica a variância remanescente de $\boldsymbol{I}$.

A criação da Linha de vulnerabilidade tem como base o modelo matricial de dois fatores da seguinte forma: 


$$
I_{k}=\lambda_{k 1} X_{1}+\lambda_{k 2} X_{2}+\delta_{k}
$$

Sendo que $I_{k}$ representa os dados da amostra, os coeficientes $\lambda_{k 1}$ e $\lambda_{k 2}$ representam o grau que cada medita $I_{k}$ reflete sobre os fatores $X_{1} \mathrm{e} X_{2, \text { como a relação de }} I_{k}$ não é perfeitamente explicada pela interação de $\lambda_{k 1} \mathrm{e} \lambda_{k 2}$ com os fatores $X_{1} \mathrm{e} X_{2}$, adiciona-se o termo $\delta_{k}$ que explica a variância remanescente de $I_{k}$.Com base nos indicadores de vulnerabilidade das famílias de Barros et al (2006) e com o modelo acima se encontra os seguintes fatores $X_{1} \mathrm{e} X_{2}$ representando cada dimensão da vulnerabilidade:

$$
X_{1}=\left[\begin{array}{c}
X_{1 C} \\
X_{1 D} \\
X_{1 H} \\
X_{1 R} \\
X_{1 T} \\
X_{1 V}
\end{array}\right] \quad X_{2}=\left[\begin{array}{c}
X_{2 C} \\
X_{2 D} \\
X_{2 H} \\
X_{2 R} \\
X_{2 T} \\
X_{2 V}
\end{array}\right]
$$

Recombinam-se os indicadores $I_{k}$ em $\alpha_{k}$ :

$$
\alpha_{k i}=\frac{\left(I_{k i}-\frac{1}{n} \sum_{i=1}^{n} I_{k i}\right)}{\sqrt{\frac{1}{n-1} \sum_{i=1}^{n}\left(I_{k i}-\frac{1}{n} \sum_{i=1}^{n} I_{k i}\right)^{2}}}
$$

Sendo a matriz de $\alpha_{k}$ para cada dimensão representada por $\gamma_{i \text { : }}$ 


$$
\gamma_{i}=\left[\begin{array}{l}
\alpha_{C i} \\
\alpha_{D i} \\
\alpha_{H i} \\
\alpha_{R i} \\
\alpha_{T i} \\
\alpha_{V i}
\end{array}\right]
$$

A interação de ${ }^{\gamma_{i}}$ será feita pela multiplicação de sua matriz transposta com as matrizes dos fatores $X_{1}$ e $X_{2}$ formando $W_{1}$ e $W_{2}$ :

$$
\begin{aligned}
W_{1 i} & =\gamma_{i}{ }^{T} X_{1} \\
W_{2 i} & =\gamma_{i}{ }^{T} X_{2}
\end{aligned}
$$

A Vulnerabilidade Familiar - VF é construída pela interação $W_{1}$ e $W_{2}$ com $W_{\beta}$ da seguinte forma:

$$
V F_{i}=\sqrt{\left(W_{1 i}-W_{\beta}\right)^{2}+\left(W_{2 i}-W_{\beta}\right)^{2}}
$$

Sendo que $W_{\beta}$ é formando pela máxima vulnerabilidade da matriz $\gamma_{i}$ (e consequentemente formando pela máxima vulnerabilidade de cada indicador de pobreza multidimensional) a Vulnerabilidade Familiar é formando pela comparação fatorial dos indicadores que representam as dimensões de que cada família está exposta.

Dessa forma, se constrói cinco intervalos de classes para delimitar os níveis de vulnerabilidade de cada família: 
Tabela 1 - Siglas e Legendas das próximas tabelas.

\begin{tabular}{|l|l|l|}
\hline Sigla & Nível de Vulnerabilidade & Intervalo \\
\hline VMB & Vulnerabilidade muito baixa & $02,68-10,28$ \\
\hline VB & Vulnerabilidade baixa & $10,28-17,88$ \\
\hline VM & Vulnerabilidade média & $17,88-25,48$ \\
\hline VA & Vulnerabilidade alta & $25,48-33,08$ \\
\hline VMA & Vulnerabilidade muito alta & $33,08-40,67$ \\
\hline
\end{tabular}

Fonte: Pesquisa.

Índice de pobreza multidimensional

$$
I P M= \begin{cases}1 & \text { Se } B R=1 \text { e VF }>17,88 \\ 0 & \text { caso contrário }\end{cases}
$$

O Índice de pobreza multidimensional - IPM classifica as famílias com presença de pobreza multidimensional como aquelas com baixa renda e vulnerabilidade média ou pior. O índice assumirá valor 1 se a família é classificada com pobreza.

\section{RESULTADOS}

Serão apresentados a seguir, os resultados encontrados com base nos dados da Pesquisa Nacional por Amostra de Domicílio - PNAD de 2014, através dos índices de pobreza multidimensional, gerados por meio dos indicadores de Baixa Renda, Vulnerabilidades e de Pobreza.

Os índices de pobreza multidimensional serão calculados e estão expostos nas tabelas abaixo, que contêm os índices para os homens, mulheres, pessoas de cor branca e não brancas e para as pessoas que residem tanto nas áreas urbanas quanto nas áreas rurais, comparando os resultados com as médias nacionais. Após cada tabela temos as figuras, que contém os mapas das Unidades de Federação onde são demonstrados quais os Estados que apresentaram os maiores e os menores índices de pobreza multidimensional.

A seguir, temos uma tabela contento as siglas e legendas que serão utilizadas nas próximas tabelas. 
Tabela 2 - Siglas e Legendas das próximas tabelas.

\begin{tabular}{|l|l|}
\hline SIGLA & LEGENDA \\
\hline UF & Unidade de Federação \\
\hline BRE & Baixa Renda Extrema (70,00 Reais Per Capita) \\
\hline BR & Baixa Renda (140,00 Reais Per Capita) \\
\hline VMB & Vulnerabilidade Muito Baixa \\
\hline VB & Vulnerabilidade Baixa \\
\hline VM & Vulnerabilidade Média \\
\hline VA & Vulnerabilidade Alta \\
\hline VMA & Vulnerabilidade Muito Alta \\
\hline IPM & Índice de Pobreza Multidimensional \\
\hline
\end{tabular}

Fonte: Pesquisa.

Foi classificado com pobreza multidimensional as famílias que obtiveram vulnerabilidade média ou superior e baixa renda, com isso é possível verificar as localidades com maior porcentagem de vulneráveis.

A seguir apresenta-se a tabela com o índice de pobreza multidimensional e os indicadores (Baixa Renda, Vulnerabilidades e Pobreza) para o Brasil em 2014.

Tabela 3 - Renda, vulnerabilidade e pobreza multidimensional do Brasil em 2014.

\begin{tabular}{|l|l|l|l|l|l|l|l|l|}
\hline UF & BRE & BR & VMB & VB & VM & VA & VMA & IPM \\
\hline Acre & 0,06 & 0,10 & 0,12 & 0,01 & 0,03 & 0,27 & 0,69 & 0,10 \\
\hline Alagoas & 0,08 & 0,14 & 0,09 & 0,01 & 0,12 & 0,62 & 0,26 & 0,14 \\
\hline Amapá & 0,04 & 0,06 & 0,11 & 0,00 & 0,02 & 0,63 & 0,35 & 0,06 \\
\hline Amazonas & 0,07 & 0,12 & 0,11 & 0,01 & 0,04 & 0,59 & 0,36 & 0,11 \\
\hline Bahia & 0,06 & 0,10 & 0,06 & 0,01 & 0,35 & 0,59 & 0,05 & 0,10 \\
\hline Ceará & 0,06 & 0,12 & 0,07 & 0,01 & 0,33 & 0,60 & 0,06 & 0,12 \\
\hline Distrito Federal & 0,04 & 0,05 & 0,03 & 0,19 & 0,02 & 0,55 & 0,18 & 0,05 \\
\hline Espírito Santo & 0,05 & 0,07 & 0,05 & 0,00 & 0,23 & 0,56 & 0,21 & 0,07 \\
\hline Goiás & 0,04 & 0,05 & 0,05 & 0,14 & 0,21 & 0,55 & 0,10 & 0,05 \\
\hline Maranhão & 0,09 & 0,16 & 0,13 & 0,01 & 0,09 & 0,79 & 0,11 & 0,16 \\
\hline Mato Grosso & 0,05 & 0,05 & 0,05 & 0,01 & 0,23 & 0,58 & 0,18 & 0,05 \\
\hline Mato Grosso do Sul & 0,02 & 0,03 & 0,07 & 0,03 & 0,17 & 0,57 & 0,23 & 0,03 \\
\hline
\end{tabular}




\begin{tabular}{|l|l|l|l|l|l|l|l|l|}
\hline Minas Gerais & 0,04 & 0,06 & 0,04 & 0,01 & 0,40 & 0,54 & 0,05 & 0,05 \\
\hline Pará & 0,09 & 0,13 & 0,10 & 0,01 & 0,04 & 0,69 & 0,26 & 0,13 \\
\hline Paraíba & 0,08 & 0,13 & 0,09 & 0,01 & 0,17 & 0,58 & 0,24 & 0,12 \\
\hline Paraná & 0,03 & 0,04 & 0,04 & 0,01 & 0,36 & 0,55 & 0,09 & 0,04 \\
\hline Pernambuco & 0,11 & 0,14 & 0,06 & 0,01 & 0,31 & 0,62 & 0,06 & 0,14 \\
\hline Piauí & 0,05 & 0,12 & 0,09 & 0,01 & 0,13 & 0,66 & 0,20 & 0,12 \\
\hline Rio de Janeiro & 0,06 & 0,06 & 0,03 & 0,00 & 0,39 & 0,55 & 0,06 & 0,06 \\
\hline Rio Grande do Norte & 0,06 & 0,11 & 0,07 & 0,00 & 0,12 & 0,63 & 0,25 & 0,11 \\
\hline Rio Grande do Sul & 0,05 & 0,05 & 0,05 & 0,02 & 0,38 & 0,55 & 0,05 & 0,05 \\
\hline Rondônia & 0,06 & 0,09 & 0,08 & 0,00 & 0,02 & 0,40 & 0,58 & 0,09 \\
\hline Roraima & 0,07 & 0,09 & 0,06 & 0,00 & 0,01 & 0,40 & 0,58 & 0,09 \\
\hline Santa Catarina & 0,04 & 0,05 & 0,03 & 0,01 & 0,28 & 0,55 & 0,16 & 0,05 \\
\hline São Paulo & 0,09 & 0,09 & 0,02 & 0,00 & 0,42 & 0,53 & 0,04 & 0,09 \\
\hline Sergipe & 0,07 & 0,12 & 0,09 & 0,01 & 0,19 & 0,60 & 0,20 & 0,12 \\
\hline Tocantins & 0,08 & 0,13 & 0,10 & 0,00 & 0,04 & 0,75 & 0,20 & 0,13 \\
\hline BRASIL & 0,06 & 0,09 & 0,06 & 0,02 & 0,27 & 0,57 & 0,14 & 0,09 \\
\hline
\end{tabular}

Fonte: Pesquisa.

Na tabela 3 é apresentada a pobreza multidimensional do Brasil para o ano de 2014. De acordo com os valores obtidos, o Estado do Pernambuco foi o que apresentou o maior índice de Baixa Renda Extrema, já o Estado do Maranhão apresentou os maiores índices de pobreza de acordo com os indicadores de Baixa Renda, Vulnerabilidade Muito Baixa e Vulnerabilidade Baixa. O Distrito Federal apresentou o maior indicador de Vulnerabilidade Baixa, São Paulo teve o maior indicador de Vulnerabilidade Média e o Acre foi quem obteve o maior indicador Vulnerabilidade Muito Alta.

Será representado a seguir na Figura 1 o mapa da pobreza multidimensional do Brasil em 2014. 
Figura 1 - Mapa da pobreza multidimensional do Brasil em 2014

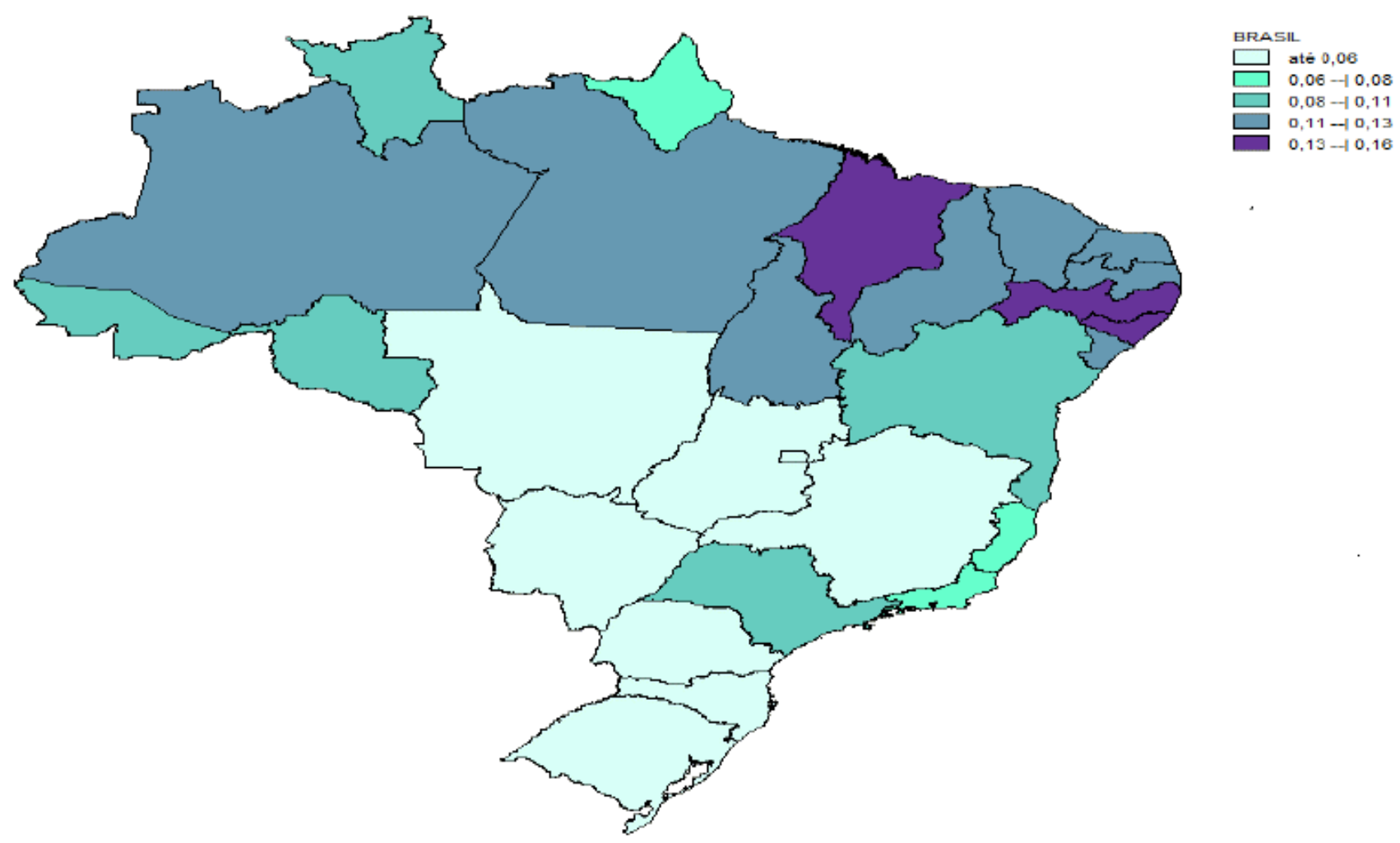

Fonte: Pesquisa.

De acordo com o mapa, as Unidades de Federação que obtiveram os maiores índices de pobreza multidimensional para o Brasil no ano de 2014 foram o Maranhão, Pernambuco e Alagoas, enquanto que Mato Grosso, Mato Grosso do Sul, Goiás, Distrito Federal, Minas Gerais, Paraná, Santa Catarina e o Rio Grande do Sul foram os que obtiveram os menores índices de pobreza multidimensional no Brasil em 2014.

Tabela 4 - Renda, vulnerabilidade e pobreza multidimensional dos homens.

\begin{tabular}{|l|l|l|l|l|l|l|l|l|}
\hline UF & BRE & BR & VMB & VB & VM & VA & VMA & IPM \\
\hline Brasil - Homem & 0,06 & 0,09 & 0,06 & 0,02 & 0,27 & 0,57 & 0,14 & 0,09 \\
\hline Acre & 0,07 & 0,10 & 0,12 & 0,01 & 0,03 & 0,27 & 0,69 & 0,10 \\
\hline Alagoas & 0,08 & 0,14 & 0,09 & 0,01 & 0,12 & 0,62 & 0,25 & 0,14 \\
\hline Amapá & 0,04 & 0,06 & 0,11 & 0,00 & 0,02 & 0,62 & 0,36 & 0,06 \\
\hline Amazonas & 0,08 & 0,12 & 0,11 & 0,01 & 0,04 & 0,59 & 0,36 & 0,12 \\
\hline Bahia & 0,06 & 0,10 & 0,07 & 0,01 & 0,35 & 0,59 & 0,05 & 0,10 \\
\hline Ceará & 0,06 & 0,12 & 0,07 & 0,01 & 0,32 & 0,60 & 0,07 & 0,12 \\
\hline Distrito Federal & 0,04 & 0,05 & 0,03 & 0,20 & 0,02 & 0,55 & 0,18 & 0,05 \\
\hline
\end{tabular}




\begin{tabular}{|l|l|l|l|l|l|l|l|l|}
\hline Espírito Santo & 0,05 & 0,06 & 0,04 & 0,00 & 0,22 & 0,56 & 0,22 & 0,06 \\
\hline Goiás & 0,04 & 0,05 & 0,05 & 0,14 & 0,21 & 0,55 & 0,10 & 0,05 \\
\hline Maranhão & 0,10 & 0,17 & 0,13 & 0,01 & 0,09 & 0,79 & 0,11 & 0,16 \\
\hline Mato Grosso & 0,05 & 0,05 & 0,06 & 0,01 & 0,23 & 0,58 & 0,18 & 0,05 \\
\hline Mato Grosso do Sul & 0,03 & 0,03 & 0,07 & 0,03 & 0,17 & 0,56 & 0,23 & 0,03 \\
\hline Minas Gerais & 0,04 & 0,05 & 0,04 & 0,01 & 0,40 & 0,54 & 0,05 & 0,05 \\
\hline Pará & 0,09 & 0,14 & 0,10 & 0,01 & 0,04 & 0,69 & 0,26 & 0,13 \\
\hline Paraíba & 0,07 & 0,12 & 0,08 & 0,01 & 0,16 & 0,59 & 0,25 & 0,12 \\
\hline Paraná & 0,04 & 0,04 & 0,04 & 0,01 & 0,36 & 0,55 & 0,09 & 0,04 \\
\hline Pernambuco & 0,11 & 0,14 & 0,06 & 0,01 & 0,31 & 0,62 & 0,06 & 0,14 \\
\hline Piauí & 0,05 & 0,12 & 0,09 & 0,01 & 0,13 & 0,66 & 0,21 & 0,12 \\
\hline Rio de Janeiro & 0,06 & 0,06 & 0,03 & 0,00 & 0,38 & 0,55 & 0,06 & 0,06 \\
\hline Rio Grande do Norte & 0,06 & 0,11 & 0,08 & 0,00 & 0,12 & 0,62 & 0,25 & 0,11 \\
\hline Rio Grande do Sul & 0,04 & 0,05 & 0,05 & 0,02 & 0,38 & 0,54 & 0,06 & 0,05 \\
\hline Rondônia & 0,06 & 0,09 & 0,08 & 0,00 & 0,02 & 0,40 & 0,58 & 0,09 \\
\hline Roraima & 0,07 & 0,09 & 0,06 & 0,00 & 0,01 & 0,40 & 0,59 & 0,09 \\
\hline Santa Catarina & 0,05 & 0,05 & 0,03 & 0,01 & 0,28 & 0,55 & 0,16 & 0,05 \\
\hline São Paulo & 0,09 & 0,09 & 0,02 & 0,00 & 0,42 & 0,52 & 0,04 & 0,09 \\
\hline Sergipe & 0,07 & 0,12 & 0,09 & 0,01 & 0,18 & 0,61 & 0,20 & 0,12 \\
\hline Tocantins & 0,08 & 0,13 & 0,10 & 0,00 & 0,04 & 0,75 & 0,20 & 0,13 \\
\hline Total Brasil & 0,06 & 0,09 & 0,06 & 0,02 & 0,27 & 0,57 & 0,14 & 0,09 \\
\hline
\end{tabular}

Fonte: Pesquisa.

Na tabela 4 é apresentada a pobreza multidimensional dos homens no Brasil para o ano de 2014. Todos os indicadores (Baixa Renda, Vulnerabilidades e Pobreza) dos homens foram compatíveis com a média nacional, indicando que para a pobreza familiar, homens e mulheres não obtiveram diferenças significativas para o índice de pobreza proposto.

A seguir na Figura 2 apresenta-se o mapa que evidencia as Unidades da Federação e os índices de pobreza multidimensional para os homens. 
Figura 2 - Mapa da pobreza multidimensional dos homens.

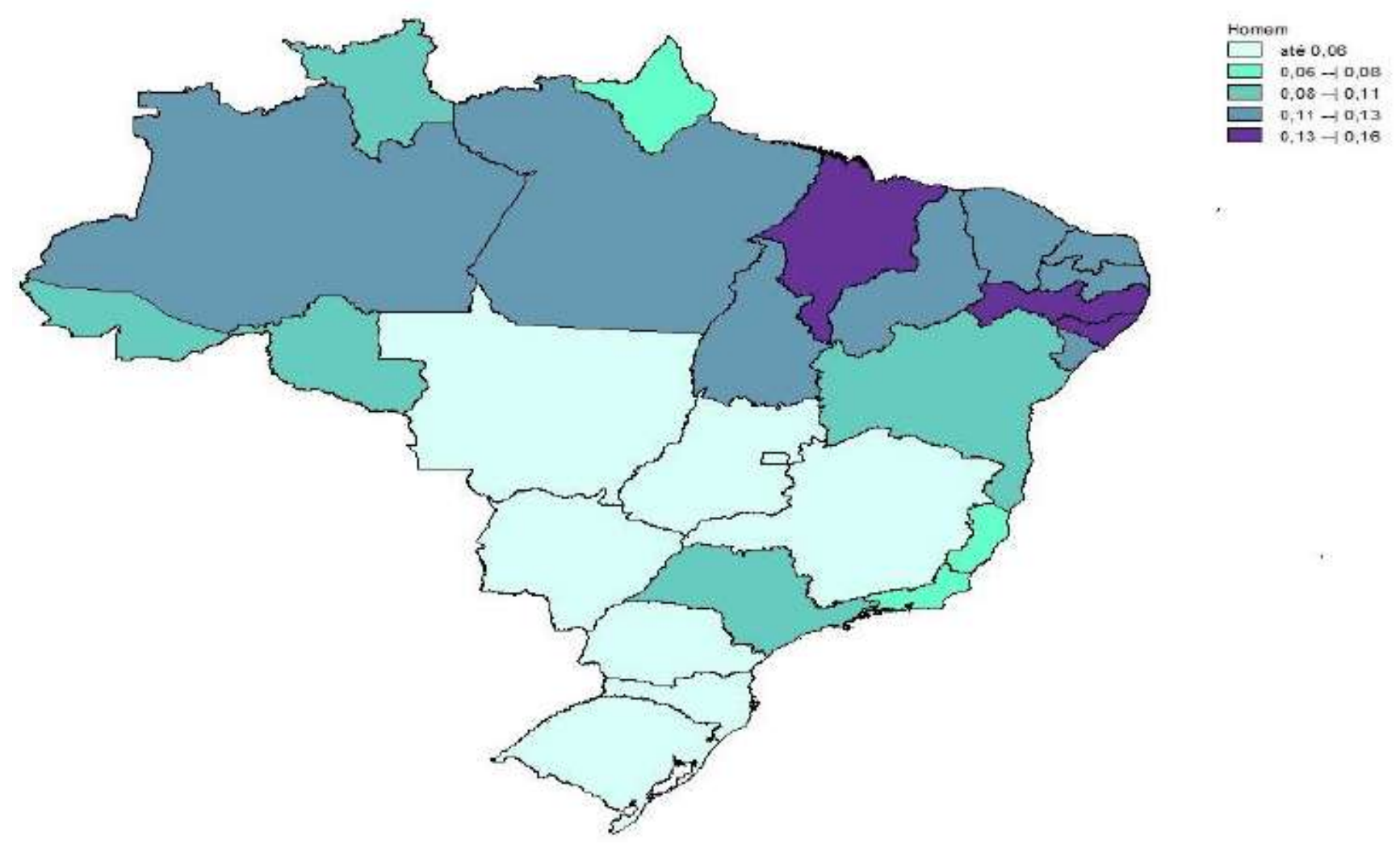

Fonte: Pesquisa.

As Unidades de Federação que apresentaram os maiores índices de pobreza multidimensional para os homens estão destacados no mapa acima com a cor roxa, foram elas: Maranhão, Pernambuco e Alagoas. Já as regiões mais claras do mapa são referentes às Unidades da Federação que apresentaram os menores índices de pobreza para os homens, são elas: Mato Grosso, Mato Grosso do Sul, Goiás, Distrito Federal, Minas Gerais, Paraná, Santa Catarina e o Rio Grande do Sul.

Tabela 5 - Renda, vulnerabilidade e pobreza multidimensional das mulheres.

\begin{tabular}{|l|l|l|l|l|l|l|l|l|}
\hline UF & BRE & BR & VMB & VB & VM & VA & VMA & IPM \\
\hline Brasil - Mulher & 0,06 & 0,09 & 0,06 & 0,02 & 0,27 & 0,58 & 0,13 & 0,09 \\
\hline Acre & 0,06 & 0,10 & 0,12 & 0,01 & 0,03 & 0,26 & 0,70 & 0,09 \\
\hline Alagoas & 0,08 & 0,15 & 0,09 & 0,01 & 0,11 & 0,62 & 0,26 & 0,14 \\
\hline Amapá & 0,04 & 0,06 & 0,11 & 0,00 & 0,02 & 0,63 & 0,34 & 0,06 \\
\hline Amazonas & 0,07 & 0,11 & 0,11 & 0,01 & 0,04 & 0,59 & 0,37 & 0,11 \\
\hline Bahia & 0,06 & 0,10 & 0,06 & 0,01 & 0,35 & 0,59 & 0,04 & 0,10 \\
\hline Ceará & 0,06 & 0,12 & 0,07 & 0,01 & 0,33 & 0,60 & 0,06 & 0,12 \\
\hline
\end{tabular}




\begin{tabular}{|l|l|l|l|l|l|l|l|l|} 
Distrito Federal & 0,04 & 0,05 & 0,03 & 0,19 & 0,02 & 0,56 & 0,18 & 0,05 \\
\hline Espírito Santo & 0,05 & 0,07 & 0,05 & 0,00 & 0,23 & 0,56 & 0,21 & 0,07 \\
\hline Goiás & 0,04 & 0,05 & 0,05 & 0,14 & 0,21 & 0,55 & 0,09 & 0,05 \\
\hline Maranhão & 0,09 & 0,16 & 0,13 & 0,01 & 0,08 & 0,80 & 0,11 & 0,16 \\
\hline Mato Grosso & 0,04 & 0,05 & 0,05 & 0,01 & 0,22 & 0,58 & 0,18 & 0,05 \\
\hline Mato Grosso do Sul & 0,02 & 0,03 & 0,07 & 0,03 & 0,16 & 0,57 & 0,23 & 0,03 \\
\hline Minas Gerais & 0,04 & 0,06 & 0,04 & 0,01 & 0,40 & 0,55 & 0,05 & 0,05 \\
\hline Pará & 0,09 & 0,13 & 0,10 & 0,01 & 0,04 & 0,68 & 0,26 & 0,13 \\
\hline Paraíba & 0,09 & 0,13 & 0,09 & 0,01 & 0,17 & 0,58 & 0,24 & 0,13 \\
\hline Paraná & 0,03 & 0,04 & 0,04 & 0,01 & 0,37 & 0,55 & 0,08 & 0,04 \\
\hline Pernambuco & 0,11 & 0,15 & 0,06 & 0,01 & 0,31 & 0,62 & 0,06 & 0,14 \\
\hline Piaú́ & 0,05 & 0,12 & 0,09 & 0,01 & 0,14 & 0,66 & 0,19 & 0,12 \\
\hline Rio de Janeiro & 0,06 & 0,06 & 0,03 & 0,00 & 0,39 & 0,55 & 0,06 & 0,06 \\
\hline Rio Grande do Norte & 0,06 & 0,11 & 0,07 & 0,00 & 0,11 & 0,63 & 0,25 & 0,11 \\
\hline Rio Grande do Sul & 0,05 & 0,06 & 0,05 & 0,02 & 0,38 & 0,55 & 0,05 & 0,05 \\
\hline Rondônia & 0,06 & 0,08 & 0,08 & 0,00 & 0,02 & 0,40 & 0,58 & 0,08 \\
\hline Roraima & 0,07 & 0,09 & 0,07 & 0,00 & 0,01 & 0,41 & 0,58 & 0,09 \\
\hline Santa Catarina & 0,04 & 0,05 & 0,03 & 0,01 & 0,28 & 0,55 & 0,16 & 0,05 \\
\hline São Paulo & 0,09 & 0,10 & 0,02 & 0,00 & 0,42 & 0,53 & 0,04 & 0,09 \\
\hline Sergipe & 0,06 & 0,12 & 0,09 & 0,01 & 0,19 & 0,59 & 0,20 & 0,12 \\
\hline Tocantins & 0,08 & 0,13 & 0,10 & 0,00 & 0,04 & 0,75 & 0,20 & 0,12 \\
\hline Total Brasil & 0,06 & 0,09 & 0,06 & 0,02 & 0,27 & 0,57 & 0,14 & 0,09 \\
\hline & & Fonte: & \\
\hline
\end{tabular}

Fonte: Pesquisa.

Na tabela 5 temos a pobreza multidimensional do Brasil para as mulheres. Da mesma forma que os homens, as mulheres também apresentaram todos os indicadores (Baixa Renda, Vulnerabilidades e Pobreza) compatíveis com a média nacional, reforçando a ideia de que não há diferenças significativas entre os sexos para a pobreza familiar.

Na Figura 3 são apresentados no mapa os índices de pobreza multidimensional para as mulheres em todas as Unidades da Federação. 
Figura 3 - Mapa da pobreza multidimensional das mulheres.

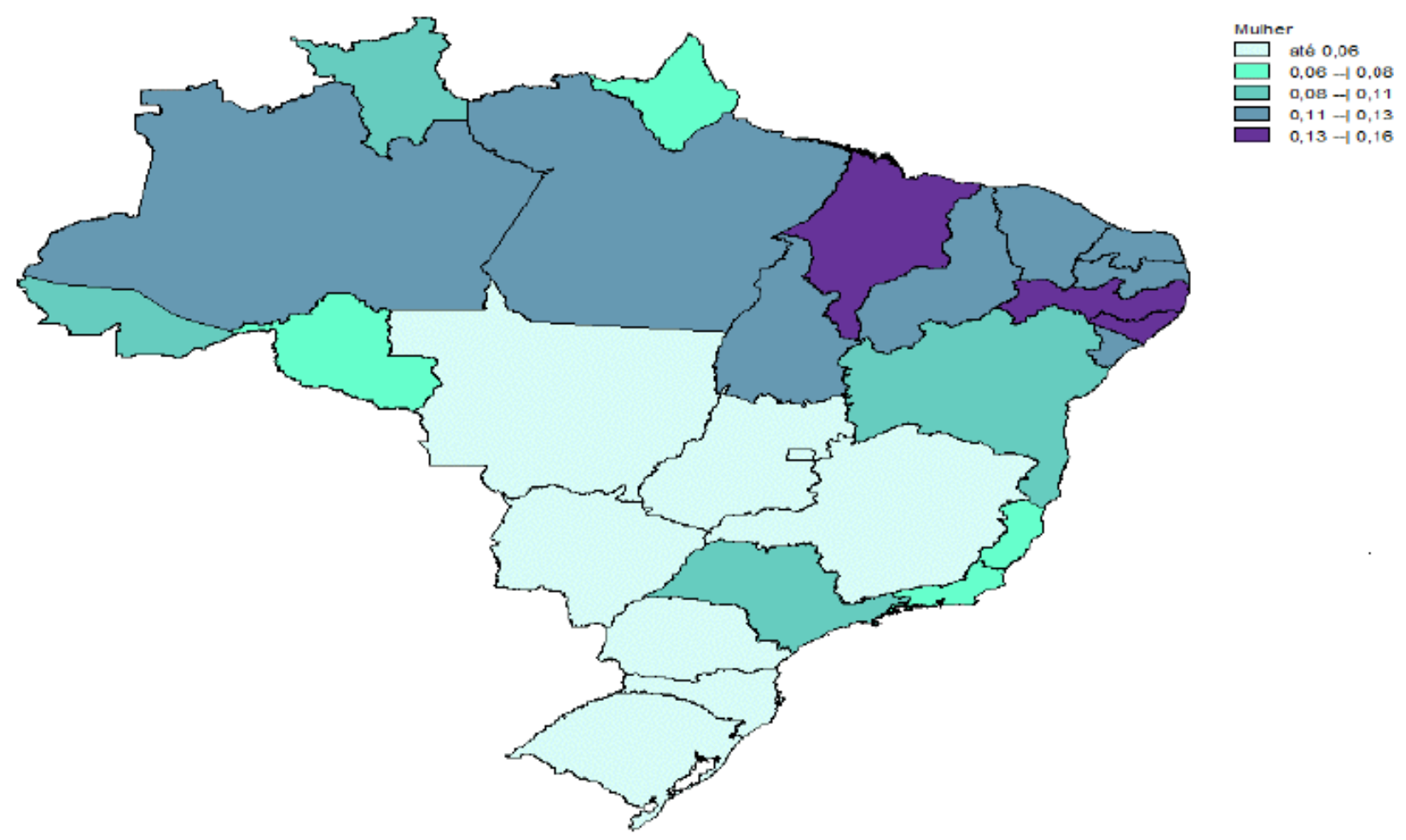

Fonte: Pesquisa.

Os resultados encontrados mostram que tanto os maiores índices de pobreza multidimensional quanto os menores índices são iguais aos encontrados para os homens. Outra característica considerada para o índice de pobreza multidimensional das Unidades de federação foi com relação à cor. Na tabela 6 temos os índices de pobreza para as pessoas de cor branca. Os Indicadores de Baixa Renda e de Vulnerabilidade Baixa foram compatíveis com a média nacional. Já o indicador de Vulnerabilidade Média apresentou valores maiores que a média nacional, enquanto que os indicadores de Baixa Renda, Vulnerabilidade Muito Baixa, Vulnerabilidade Alta e Vulnerabilidade Muito Alta apresentaram valores abaixo da média nacional. Estão representados na figura 4 os índices de pobreza multidimensional para as pessoas de cor branca em todas as Unidades da Federação.

Tabela 6 - Renda, vulnerabilidade e pobreza multidimensional dos brancos.

\begin{tabular}{|l|l|l|l|l|l|l|l|l|}
\hline UF & BRE & BR & VMB & VB & VM & VA & VMA & IPM \\
\hline Brasil - Branco & 0,06 & 0,08 & 0,05 & 0,02 & 0,30 & 0,56 & 0,11 & 0,08 \\
\hline Acre & 0,07 & 0,10 & 0,12 & 0,01 & 0,03 & 0,27 & 0,70 & 0,10 \\
\hline Alagoas & 0,09 & 0,14 & 0,10 & 0,00 & 0,10 & 0,63 & 0,26 & 0,14 \\
\hline Amapá & 0,05 & 0,08 & 0,13 & 0,00 & 0,05 & 0,60 & 0,35 & 0,08 \\
\hline
\end{tabular}




\begin{tabular}{|l|l|l|l|l|l|l|l|l|}
\hline Amazonas & 0,06 & 0,10 & 0,10 & 0,00 & 0,03 & 0,61 & 0,35 & 0,10 \\
\hline Bahia & 0,05 & 0,10 & 0,07 & 0,01 & 0,34 & 0,59 & 0,06 & 0,10 \\
\hline Ceará & 0,06 & 0,11 & 0,07 & 0,01 & 0,33 & 0,61 & 0,06 & 0,11 \\
\hline Distrito Federal & 0,04 & 0,04 & 0,04 & 0,16 & 0,01 & 0,55 & 0,20 & 0,04 \\
\hline Espírito Santo & 0,06 & 0,07 & 0,05 & 0,00 & 0,24 & 0,56 & 0,19 & 0,07 \\
\hline Goiás & 0,04 & 0,05 & 0,05 & 0,14 & 0,23 & 0,55 & 0,08 & 0,05 \\
\hline Maranhão & 0,10 & 0,17 & 0,13 & 0,01 & 0,07 & 0,83 & 0,09 & 0,17 \\
\hline Mato Grosso & 0,04 & 0,04 & 0,06 & 0,01 & 0,20 & 0,59 & 0,20 & 0,04 \\
\hline Mato Grosso do Sul & 0,02 & 0,03 & 0,06 & 0,02 & 0,16 & 0,56 & 0,25 & 0,03 \\
\hline Minas Gerais & 0,04 & 0,05 & 0,04 & 0,01 & 0,39 & 0,55 & 0,06 & 0,05 \\
\hline Pará & 0,09 & 0,14 & 0,09 & 0,01 & 0,04 & 0,66 & 0,29 & 0,14 \\
\hline Paraíba & 0,08 & 0,13 & 0,10 & 0,01 & 0,16 & 0,58 & 0,25 & 0,13 \\
\hline Paraná & 0,03 & 0,04 & 0,04 & 0,01 & 0,36 & 0,55 & 0,09 & 0,04 \\
\hline Pernambuco & 0,11 & 0,14 & 0,06 & 0,01 & 0,32 & 0,61 & 0,06 & 0,14 \\
\hline Piauí & 0,05 & 0,13 & 0,11 & 0,01 & 0,13 & 0,67 & 0,19 & 0,13 \\
\hline Rio de Janeiro & 0,05 & 0,06 & 0,03 & 0,00 & 0,39 & 0,55 & 0,05 & 0,06 \\
\hline Rio Grande do Norte & 0,07 & 0,12 & 0,08 & 0,01 & 0,12 & 0,61 & 0,26 & 0,12 \\
\hline Rio Grande do Sul & 0,05 & 0,06 & 0,05 & 0,02 & 0,37 & 0,55 & 0,05 & 0,06 \\
\hline Rondônia & 0,06 & 0,08 & 0,07 & 0,00 & 0,01 & 0,40 & 0,59 & 0,08 \\
\hline Roraima & 0,08 & 0,09 & 0,07 & 0,00 & 0,01 & 0,39 & 0,59 & 0,09 \\
\hline Santa Catarina & 0,05 & 0,05 & 0,03 & 0,01 & 0,28 & 0,56 & 0,15 & 0,05 \\
\hline São Paulo & 0,09 & 0,09 & 0,03 & 0,00 & 0,41 & 0,53 & 0,04 & 0,09 \\
\hline Sergipe & 0,06 & 0,11 & 0,10 & 0,01 & 0,19 & 0,59 & 0,20 & 0,11 \\
\hline Tocantins & 0,13 & 0,11 & 0,01 & 0,04 & 0,76 & 0,19 & 0,13 \\
\hline Total Brasil & 0,06 & 0,02 & 0,27 & 0,57 & 0,14 & 0,09 \\
\hline
\end{tabular}

Fonte: Pesquisa. 
Figura 4 - Mapa da pobreza multidimensional dos brancos.
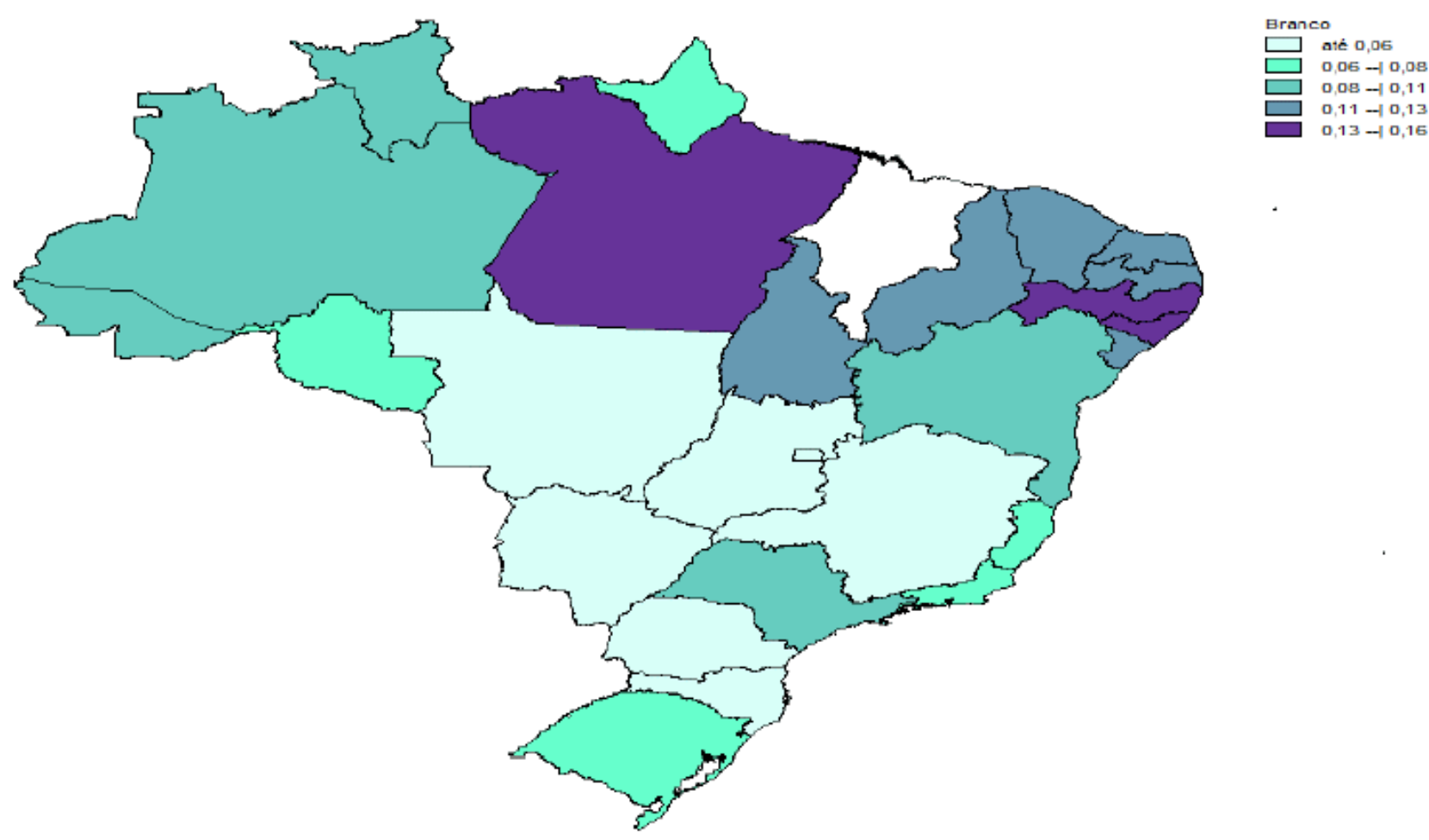

Fonte: Pesquisa.

Nota-se que as Unidades de Federação que apresentaram os maiores índices de pobreza multidimensional para as pessoas de cor branca foram o Maranhão, Pará, Pernambuco e Alagoas. Em contrapartida as Unidades de Federação que obtiveram os menores índices de pobreza multidimensional para as pessoas de cor branca foram: Mato Grosso, Mato Grosso do Sul, Goiás, Distrito Federal, Minas Gerais, Paraná e Santa Catarina.

Tabela 7 - Renda, vulnerabilidade e pobreza multidimensional dos não brancos.

\begin{tabular}{|l|l|l|l|l|l|l|l|l|}
\hline UF & BRE & BR & VMB & VB & VM & VA & VMA & IPM \\
\hline Brasil - NãoBranco & 0,07 & 0,10 & 0,07 & 0,02 & 0,24 & 0,58 & 0,15 & 0,10 \\
\hline Acre & 0,06 & 0,10 & 0,12 & 0,01 & 0,03 & 0,27 & 0,69 & 0,10 \\
\hline Alagoas & 0,08 & 0,14 & 0,09 & 0,01 & 0,12 & 0,61 & 0,26 & 0,14 \\
\hline Amapá & 0,03 & 0,05 & 0,10 & 0,00 & 0,01 & 0,63 & 0,35 & 0,05 \\
\hline Amazonas & 0,07 & 0,12 & 0,11 & 0,01 & 0,04 & 0,59 & 0,37 & 0,12 \\
\hline Bahia & 0,06 & 0,10 & 0,06 & 0,01 & 0,36 & 0,59 & 0,04 & 0,10 \\
\hline Ceará & 0,06 & 0,12 & 0,07 & 0,01 & 0,33 & 0,60 & 0,07 & 0,12 \\
\hline Distrito Federal & 0,04 & 0,05 & 0,03 & 0,21 & 0,02 & 0,56 & 0,17 & 0,05 \\
\hline Espírito Santo & 0,05 & 0,06 & 0,04 & 0,00 & 0,22 & 0,56 & 0,22 & 0,06 \\
\hline
\end{tabular}




\begin{tabular}{|c|c|c|c|c|c|c|c|c|}
\hline Goiás & 0,04 & 0,05 & 0,05 & 0,14 & 0,20 & 0,55 & 0,11 & 0,05 \\
\hline Maranhão & 0,09 & 0,16 & 0,13 & 0,01 & 0,09 & 0,78 & 0,11 & 0,16 \\
\hline Mato Grosso & 0,05 & 0,06 & 0,05 & 0,01 & 0,24 & 0,57 & 0,17 & 0,06 \\
\hline Mato Grosso do Sul & 0,02 & 0,03 & 0,07 & 0,03 & 0,17 & 0,57 & 0,22 & 0,03 \\
\hline Minas Gerais & 0,04 & 0,06 & 0,05 & 0,01 & 0,41 & 0,54 & 0,04 & 0,06 \\
\hline Pará & 0,09 & 0,13 & 0,10 & 0,01 & 0,04 & 0,69 & 0,25 & 0,13 \\
\hline Paraíba & 0,08 & 0,12 & 0,08 & 0,01 & 0,17 & 0,58 & 0,24 & 0,12 \\
\hline Paraná & 0,03 & 0,04 & 0,04 & 0,00 & 0,37 & 0,54 & 0,08 & 0,04 \\
\hline Pernambuco & 0,11 & 0,15 & 0,06 & 0,01 & 0,31 & 0,62 & 0,06 & 0,14 \\
\hline Piauí & 0,05 & 0,12 & 0,08 & 0,01 & 0,13 & 0,66 & 0,20 & 0,12 \\
\hline Rio de Janeiro & 0,06 & 0,07 & 0,03 & 0,00 & 0,38 & 0,55 & 0,07 & 0,07 \\
\hline Rio Grande do Norte & 0,06 & 0,11 & 0,07 & 0,00 & 0,11 & 0,63 & 0,25 & 0,11 \\
\hline Rio Grande do Sul & 0,04 & 0,05 & 0,05 & 0,02 & 0,40 & 0,52 & 0,06 & 0,05 \\
\hline Rondônia & 0,06 & 0,09 & 0,08 & 0,00 & 0,02 & 0,40 & 0,58 & 0,09 \\
\hline Roraima & 0,07 & 0,09 & 0,06 & 0,00 & 0,01 & 0,40 & 0,58 & 0,09 \\
\hline Santa Catarina & 0,04 & 0,04 & 0,03 & 0,01 & 0,27 & 0,54 & 0,18 & 0,04 \\
\hline São Paulo & 0,09 & 0,10 & 0,02 & 0,00 & 0,43 & 0,52 & 0,04 & 0,10 \\
\hline Sergipe & 0,07 & 0,12 & 0,09 & 0,01 & 0,19 & 0,60 & 0,20 & 0,12 \\
\hline Tocantins & 0,08 & 0,13 & 0,10 & 0,00 & 0,04 & 0,75 & 0,20 & 0,13 \\
\hline Total Brasil & 0,06 & 0,09 & 0,06 & 0,02 & 0,27 & 0,57 & 0,14 & 0,09 \\
\hline
\end{tabular}

Fonte: Pesquisa.

Na tabela 7 é apresentada a pobreza multidimensional para as pessoas de cor não branca no Brasil. 0 indicador de Vulnerabilidade Baixa apresentou valor compatível com a média nacional. Os indicadores de Baixa Renda, Baixa Renda Extrema, Vulnerabilidade Muito Baixa, Vulnerabilidade Alta e Vulnerabilidade Muito Alta obtiveram valores maiores que os da média nacional, enquanto que o índice de Vulnerabilidade Média obteve valor menor que o apresentado na média nacional.

Dessa maneira, de acordo com os resultados encontrados nos índices, temos que a pobreza multidimensional é maior para aquelas pessoas que não são de cor branca.

Abaixo temos na figura 5 a concentração da pobreza multidimensional para as pessoas não brancas em cada Unidade de Federação. 
Figura 5 - Mapa da pobreza multidimensional dos não brancos.

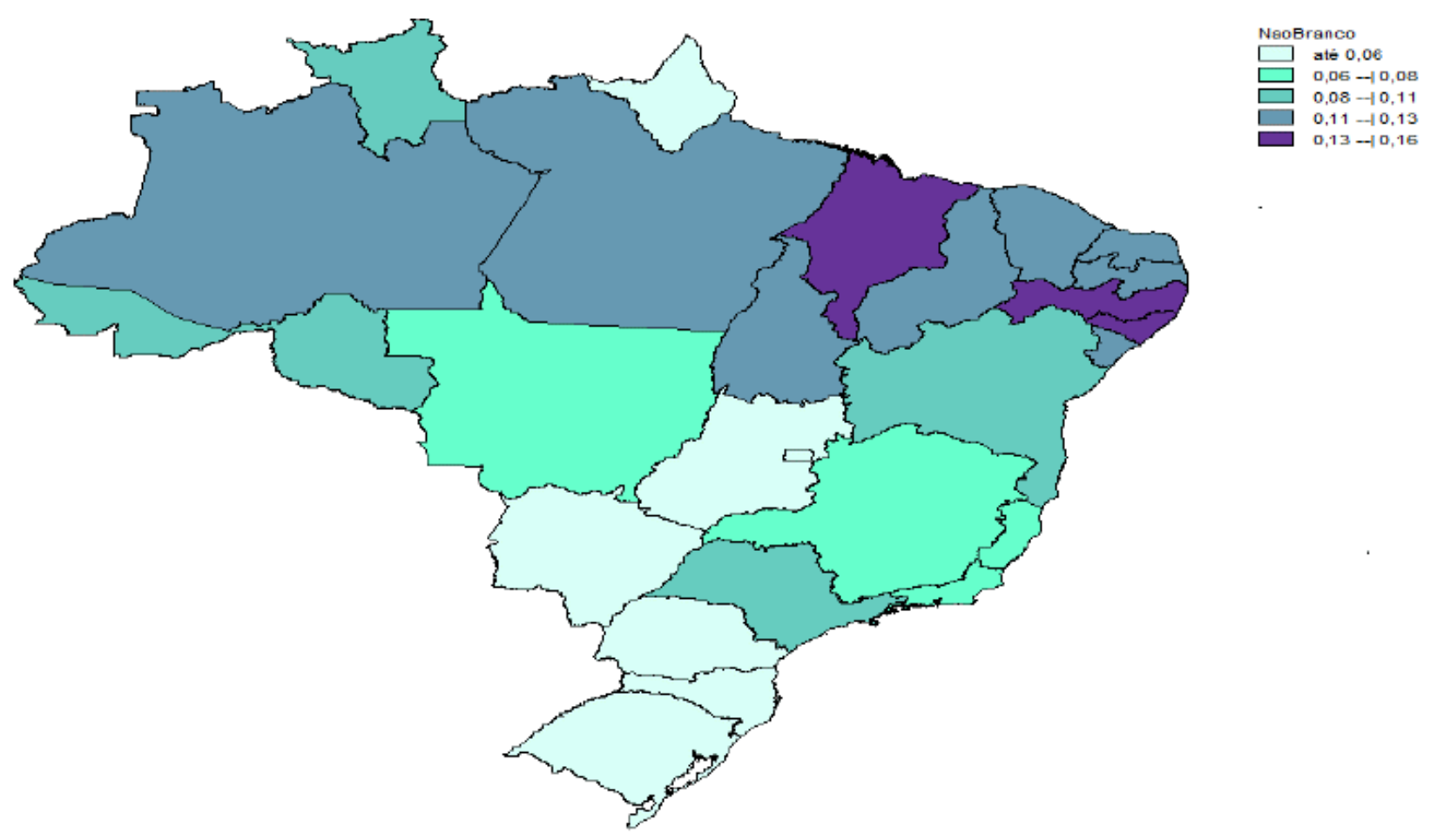

Fonte: Pesquisa.

De acordo com os indicadores, as Unidades de Federação que apresentaram os maiores índices de pobreza para as pessoas de cor não branca foram o Maranhão, Pernambuco e Alagoas, já as de menores índices foram Mato Grosso do Sul, Goiás, Distrito Federal, Paraná, Santa Catarina e Rio Grande do Sul.

Consideramos também neste trabalho o local de residência das pessoas, calculando os índices de pobreza multidimensional para os que residem na área urbana e para os que estão nas áreas rurais.

Tabela 8 - Renda, vulnerabilidade e pobreza multidimensional área urbana.

\begin{tabular}{|l|l|l|l|l|l|l|l|l|}
\hline UF & BRE & BR & VMB & VB & VM & VA & VMA & IPM \\
\hline Brasil - Urbano & 0,06 & 0,09 & 0,06 & 0,02 & 0,28 & 0,57 & 0,13 & 0,08 \\
\hline Acre & 0,07 & 0,10 & 0,12 & 0,01 & 0,03 & 0,27 & 0,69 & 0,10 \\
\hline Alagoas & 0,07 & 0,14 & 0,10 & 0,00 & 0,11 & 0,64 & 0,24 & 0,14 \\
\hline Amapá & 0,04 & 0,05 & 0,11 & 0,00 & 0,02 & 0,63 & 0,35 & 0,05 \\
\hline Amazonas & 0,07 & 0,11 & 0,11 & 0,01 & 0,03 & 0,59 & 0,37 & 0,10 \\
\hline Bahia & 0,05 & 0,10 & 0,06 & 0,01 & 0,37 & 0,59 & 0,04 & 0,09 \\
\hline Ceará & 0,06 & 0,11 & 0,07 & 0,01 & 0,35 & 0,59 & 0,05 & 0,11 \\
\hline
\end{tabular}




\begin{tabular}{|l|l|l|l|l|l|l|l|l|} 
Distrito Federal & 0,04 & 0,05 & 0,03 & 0,19 & 0,02 & 0,55 & 0,18 & 0,05 \\
\hline Espírito Santo & 0,06 & 0,07 & 0,04 & 0,00 & 0,24 & 0,56 & 0,20 & 0,07 \\
\hline Goiás & 0,04 & 0,05 & 0,05 & 0,14 & 0,21 & 0,55 & 0,10 & 0,05 \\
\hline Maranhão & 0,10 & 0,16 & 0,12 & 0,01 & 0,09 & 0,80 & 0,10 & 0,16 \\
\hline Mato Grosso & 0,04 & 0,05 & 0,06 & 0,01 & 0,23 & 0,58 & 0,18 & 0,05 \\
\hline Mato Grosso do Sul & 0,02 & 0,03 & 0,06 & 0,02 & 0,15 & 0,59 & 0,24 & 0,03 \\
\hline Minas Gerais & 0,04 & 0,05 & 0,04 & 0,01 & 0,40 & 0,54 & 0,05 & 0,05 \\
\hline Pará & 0,09 & 0,13 & 0,09 & 0,01 & 0,04 & 0,68 & 0,28 & 0,13 \\
\hline Paraíba & 0,08 & 0,13 & 0,09 & 0,01 & 0,14 & 0,59 & 0,25 & 0,13 \\
\hline Paraná & 0,03 & 0,04 & 0,04 & 0,01 & 0,37 & 0,54 & 0,08 & 0,04 \\
\hline Pernambuco & 0,10 & 0,14 & 0,06 & 0,01 & 0,32 & 0,61 & 0,06 & 0,14 \\
\hline Piauí & 0,05 & 0,13 & 0,08 & 0,01 & 0,18 & 0,64 & 0,17 & 0,13 \\
\hline Rio de Janeiro & 0,06 & 0,06 & 0,03 & 0,00 & 0,39 & 0,55 & 0,06 & 0,06 \\
\hline Rio Grande do Norte & 0,07 & 0,11 & 0,08 & 0,00 & 0,11 & 0,63 & 0,26 & 0,11 \\
\hline Rio Grande do Sul & 0,05 & 0,06 & 0,05 & 0,02 & 0,38 & 0,54 & 0,06 & 0,06 \\
\hline Rondônia & 0,07 & 0,09 & 0,08 & 0,00 & 0,02 & 0,37 & 0,61 & 0,09 \\
\hline Roraima & 0,08 & 0,10 & 0,07 & 0,00 & 0,01 & 0,40 & 0,59 & 0,10 \\
\hline Santa Catarina & 0,04 & 0,05 & 0,03 & 0,01 & 0,28 & 0,55 & 0,16 & 0,05 \\
\hline São Paulo & 0,09 & 0,10 & 0,02 & 0,00 & 0,42 & 0,53 & 0,04 & 0,10 \\
\hline Sergipe & 0,06 & 0,12 & 0,09 & 0,01 & 0,17 & 0,60 & 0,22 & 0,12 \\
\hline Tocantins & 0,08 & 0,13 & 0,10 & 0,00 & 0,04 & 0,76 & 0,20 & 0,13 \\
\hline Total Brasil & 0,06 & 0,09 & 0,06 & 0,02 & 0,27 & 0,57 & 0,14 & 0,09 \\
\hline
\end{tabular}

Fonte: Pesquisa.

Na tabela 8 temos os índices de pobreza multidimensional no Brasil para as pessoas que residem nas áreas urbanas. Os indicadores apresentaram valores semelhantes aos da média nacional, exceto o índice de Vulnerabilidade Muito Alta que está abaixo da média nacional e o de Vulnerabilidade Média que apresentou valores acima da média nacional.

No mapa abaixo representado na figura 6 contém o índice de pobreza multidimensional de cada Unidade de Federação. 
Figura 6 - Mapa da pobreza multidimensional da área urbana.

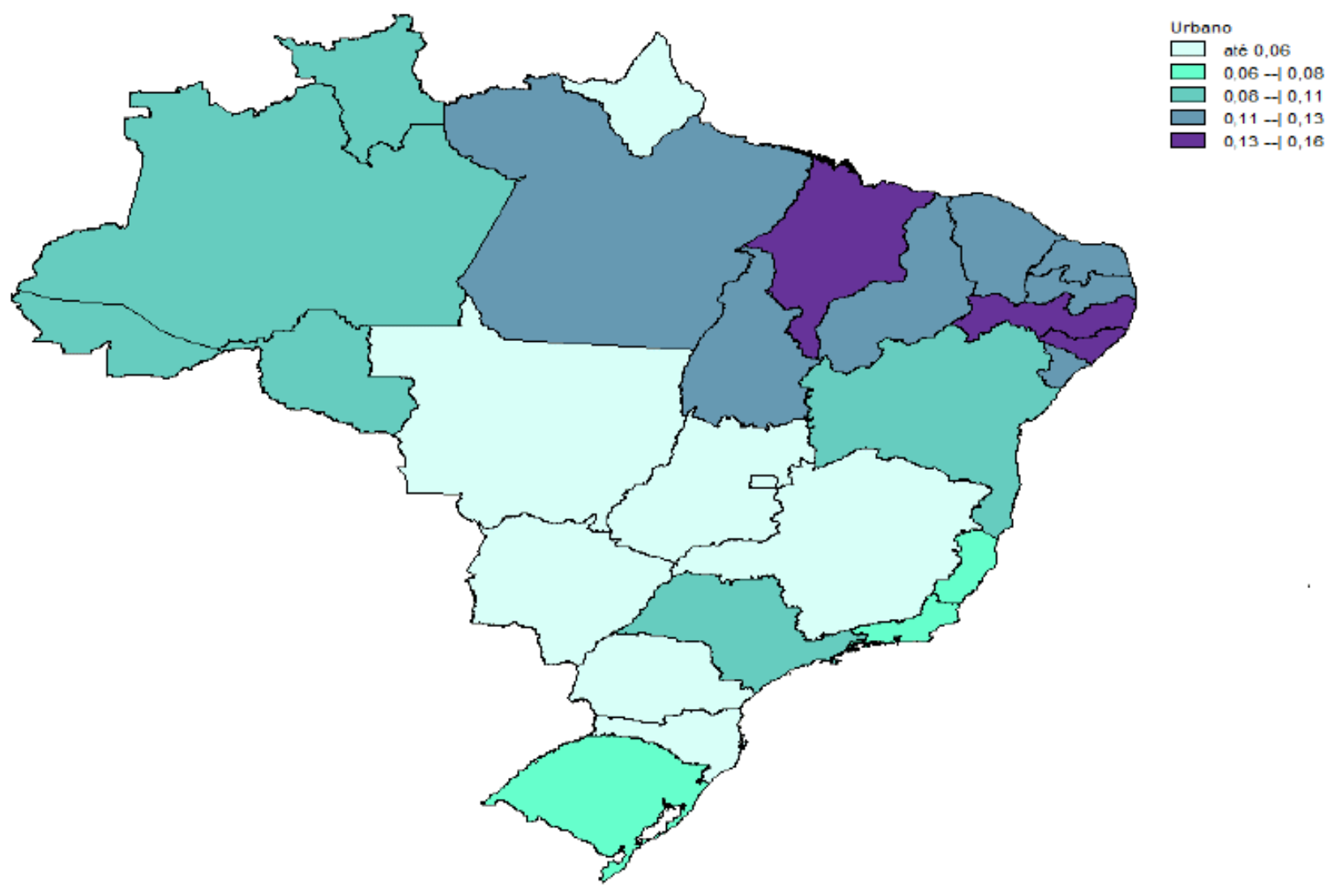

Fonte: Pesquisa.

Estão representados no mapa com as cores mais escuras os Estados do Maranhão, Pernambuco e de Alagoas, foram eles que obtiveram os maiores índices de pobreza multidimensional para as pessoas que residem nas áreas urbanas. Enquanto isso, Mato Grosso, Mato Grosso do Sul, Goiás, Distrito Federal, Minas Gerais, Paraná, Santa Catarina e o Amapá foram as Unidades de Federação que apresentaram os menores índices de pobreza multidimensional.

Tabela 9 - Renda, vulnerabilidade e pobreza multidimensional da área rural.

\begin{tabular}{|l|l|l|l|l|l|l|l|l|}
\hline UF & BRE & BR & VMB & VB & VM & VA & VMA & IPM \\
\hline Brasil - Rural & 0,07 & 0,11 & 0,08 & 0,02 & 0,20 & 0,61 & 0,17 & 0,10 \\
\hline Acre & 0,06 & 0,10 & 0,12 & 0,00 & 0,03 & 0,26 & 0,71 & 0,09 \\
\hline Alagoas & 0,11 & 0,15 & 0,07 & 0,01 & 0,13 & 0,56 & 0,30 & 0,15 \\
\hline Amapá & 0,04 & 0,08 & 0,10 & 0,00 & 0,00 & 0,59 & 0,41 & 0,08 \\
\hline Amazonas & 0,10 & 0,15 & 0,11 & 0,00 & 0,05 & 0,59 & 0,36 & 0,15 \\
\hline Bahia & 0,07 & 0,12 & 0,08 & 0,01 & 0,29 & 0,62 & 0,08 & 0,12 \\
\hline Ceará & 0,06 & 0,14 & 0,08 & 0,01 & 0,25 & 0,63 & 0,11 & 0,13 \\
\hline
\end{tabular}




\begin{tabular}{|l|l|l|l|l|l|l|l|l|}
\hline Distrito Federal & 0,04 & 0,04 & 0,03 & 0,14 & 0,02 & 0,65 & 0,19 & 0,04 \\
\hline Espírito Santo & 0,04 & 0,06 & 0,05 & 0,00 & 0,16 & 0,53 & 0,30 & 0,06 \\
\hline Goiás & 0,01 & 0,03 & 0,05 & 0,17 & 0,21 & 0,58 & 0,04 & 0,02 \\
\hline Maranhão & 0,09 & 0,17 & 0,14 & 0,01 & 0,08 & 0,78 & 0,13 & 0,16 \\
\hline Mato Grosso & 0,05 & 0,06 & 0,05 & 0,01 & 0,23 & 0,56 & 0,19 & 0,06 \\
\hline Mato Grosso do Sul & 0,04 & 0,06 & 0,10 & 0,06 & 0,32 & 0,39 & 0,14 & 0,06 \\
\hline Minas Gerais & 0,05 & 0,06 & 0,05 & 0,01 & 0,42 & 0,54 & 0,03 & 0,06 \\
\hline Pará & 0,09 & 0,14 & 0,13 & 0,02 & 0,05 & 0,71 & 0,21 & 0,14 \\
\hline Paraíba & 0,06 & 0,10 & 0,08 & 0,00 & 0,27 & 0,53 & 0,21 & 0,10 \\
\hline Paraná & 0,04 & 0,04 & 0,04 & 0,01 & 0,29 & 0,61 & 0,09 & 0,04 \\
\hline Pernambuco & 0,15 & 0,18 & 0,08 & 0,01 & 0,23 & 0,68 & 0,08 & 0,18 \\
\hline Piauí & 0,05 & 0,11 & 0,10 & 0,01 & 0,04 & 0,70 & 0,25 & 0,11 \\
\hline Rio de Janeiro & 0,07 & 0,07 & 0,03 & 0,00 & 0,29 & 0,57 & 0,14 & 0,07 \\
\hline Rio Grande do Norte & 0,05 & 0,10 & 0,07 & 0,01 & 0,15 & 0,60 & 0,25 & 0,10 \\
\hline Rio Grande do Sul & 0,03 & 0,04 & 0,05 & 0,02 & 0,37 & 0,58 & 0,03 & 0,04 \\
\hline Rondônia & 0,05 & 0,08 & 0,07 & 0,00 & 0,01 & 0,50 & 0,49 & 0,08 \\
\hline Roraima & 0,04 & 0,05 & 0,03 & 0,00 & 0,01 & 0,41 & 0,57 & 0,05 \\
\hline Santa Catarina & 0,06 & 0,06 & 0,04 & 0,01 & 0,27 & 0,57 & 0,16 & 0,06 \\
\hline São Paulo & 0,07 & 0,07 & 0,03 & 0,00 & 0,41 & 0,49 & 0,06 & 0,07 \\
\hline Sergipe & 0,07 & 0,11 & 0,08 & 0,02 & 0,23 & 0,61 & 0,14 & 0,11 \\
\hline Tocantins & 0,07 & 0,12 & 0,13 & 0,01 & 0,06 & 0,74 & 0,19 & 0,12 \\
\hline Total Brasil & 0,06 & 0,09 & 0,06 & 0,02 & 0,27 & 0,57 & 0,14 & 0,09 \\
\hline
\end{tabular}

Fonte: Pesquisa.

Estão representados acima na tabela 9 os índices de pobreza multidimensional no Brasil para as pessoas que residem na área rural. Os indicadores que apresentaram valores acima da média nacional foram os de Baixa Renda, Baixa Renda Extrema, Vulnerabilidade Muito Baixa, Vulnerabilidade Alta, Vulnerabilidade Muito Alta. O indicador de Vulnerabilidade Média apresentou valores abaixo da média nacional

Na figura 7 estão representados os índices de pobreza multidimensional de todas as Unidades de Federação. 
Figura 7 - Mapa da pobreza multidimensional da área rural.



Fonte: Pesquisa.

Os Estados do Amazonas, Pará, Maranhão, Pernambuco e Alagoas foram os que apresentaram os maiores índices de pobreza multidimensional para a área rural. Os menores índices pertencem as seguintes Unidades de Federação: Goiás, Distrito Federal, Paraná, Rio Grande do Sul e Roraima.

É possível verificar que os índices de pobreza multidimensional para as áreas rurais estão presentes em muito mais Unidades de Federação do que comparada com as outras características que foram analisadas, concluindo que de fato o meio rural é mais fragilizado do que o meio urbano.

\section{CONSIDERAÇÕES FINAIS}

Apesar do Brasil não ser considerado como sendo um país pobre, possuí muitas pessoas que são consideradas pobres, possuindo um desafio histórico de romper com as desigualdades sociais, visto que muito pobres ficam vulneráveis e afastados da sociedade moderna, muito além de possuírem condições mínimas de desenvolvimento humano.

A pobreza é reconhecida como um fenômeno complexo e de múltiplas dimensões, relacionada não apenas ao mercado de trabalho e a renda, mas também com políticas e as relações sociais. Dessa 
forma, há um consenso cada vez mais amplo da multidimensionalidade da pobreza, associada com as privações ao qual os indivíduos estão expostos.

O objetivo deste trabalho foi o de classificar as famílias com pobreza multidimensional através de indicadores de baixa renda, vulnerabilidades e de pobreza, criando índices para os homens e mulheres, pessoas de cor brancas e não brancas e para as pessoas que residem na área urbana e na área rural. Foram apresentados também os mapas contento a pobreza multidimensional para cada Unidade de Federação. Após a criação desses indicadores será realizada uma análise fatorial exploratória, a qual identificará cinco níveis em que uma família possa estar.

Os resultados encontrados indicam que tanto para os homens quanto para as mulheres os indicadores encontrados de baixa renda, vulnerabilidade e de pobreza foram compatíveis com a média nacional. Com isso, é possível verificar que para a pobreza familiar a diferença entre ser homem ou mulher não é significativa.

Numa comparação entre as pessoas de cor branca com pessoas não brancas, o trabalho apresentou que as pessoas que não são de cor branca possuem os maiores índices de pobreza multidimensional. Já para os residentes nas áreas urbanas ou nas áreas rurais, o trabalho apresentou resultados que evidenciam o quanto o meio rural é mais fragilizado do que as áreas urbanas, pois os indicadores de baixa renda, vulnerabilidade e pobreza para as pessoas que residem nas áreas rurais apresentaram resultados acima da média nacional.

Um fato importante observado nos resultados foi o de que os Estados do Maranhão, Pernambuco e de Alagoas foram os que sempre apresentaram os maiores índices de pobreza multidimensional, enquanto que Mato Grosso, Mato Grosso do Sul, Goiás, Distrito Federal, Paraná, Santa Catarina e o Rio Grande do Sul estão entre as Unidades de federação que apresentaram os menores índices de pobreza multidimensional no Brasil no ano de 2014. 


\section{REFERENCIAS BIBLIOGRAFICAS}

Programa R: http://www.r-project.org/

BARROS, Ricardo Paes de; CARVALHO, Mirela de; FRANCO, Samuel. Pobreza multidimensional no Brasil. 2006.

CONEVAL, Consejo Nacional de Evaluación de la Política de Desarrollo Social. Metodología para la medición multidimensional de la pobreza en México, México DF. CONEVAL, 2009.

LATTIN, James; CARROLL, J. Douglas; GREEN, Paul E. Análise de Dados Multivariados. São Paulo: Cengage Learning, 2011. $455 \mathrm{p}$.

LIMA, Ana Luiza Machado de Codes. Modelagem de Equações Estruturais: uma Contribuição Metodológica para o Estudo da Pobreza. Tese de doutorado. Universidade Federal da Bahia. Maio de 2005.

MAXWELL, S. The meaning and measurement of poverty. ODI Poverty Briefing, n. 3, fev. 1999.

MESTRUM, F. Mondialisation et Pauvreté: De I'Utilité de la Pauvreté Dans le Nouvel Ordre Mondial. Paris: L'Harmattan, 2002.

MOREIRA, Juliana Duffles Donato. Estratégias de redução da pobreza e das desigualdades no Brasil. Dissertação (Mestrado). Universidade Federal do Rio de Janeiro. Rio de Janeiro. Agosto de 2011.

NARAYAN, D. Voices of the poor - Can anyone hear us? Washington, D.C.: The World Bank, Oxford University Press, 2000.

PASQUALI, L. (2009). Inteligência: um conceito equívoco. Em: R. Primi. (Org.), Temas em avaliação psicológica. (pp. 56-60). Campinas, SP: IBAP.

PRIMI, R. Inteligência: avanços nos modelos teóricos e nos instrumentos de medida. Avaliação Psicológica, 2 (1), 67-77 (2003). . Validade de construto de um instrumento informatizado de avaliação dinâmica da inteligência fluida. Psico (PUCRS), 37, 109-122. (2006). SALAMA, Pierre; DESTREMAU, Blandine. O tamanho da pobreza. Editora Garamond, 1999.

SEN, Amartya. Developmentas Freedom: Winner of the nobel prize for economics. First published. New York: Oxford University Press, 1999.

SEN, Amartya Kumar; MENDES, Ricardo Doninelli. Desenvolvimento como liberdade. São Paulo: Companhia das Letras, 2000.

SEN, Amartya. El desarrollo como libertad. Gaceta Ecológica, n. 55, p. 14-20, 2000. 


\section{ARTIGO 3: A DISTRIBUIÇÃO DA POBREZA MULTIDIMENSIONAL NO MEIO RURAL DO ESTADO DE} MATO GROSSO EM 2010.

Resumo: Este trabalho analisou como a pobreza no meio rural do Estado de Mato Grosso em 2010 esta distribuída. A pesquisa utilizou os dados do Censo Demográfico de 2010 do IBGE, referente aos 141 municípios do Estado, verificando os índices de pobreza na média e no desvio padrão e aplicou a metodologia da análise de Cluster, que consiste no agrupamento de objetos em grupos cada vez maiores segundo o aumento da distancia entre eles. Os principais resultados constatou que os municípios mais pobres apresentaram índices de pobreza de $39 \%$. Com a renda o resultado foi o esperado, apesar da pobreza multidimensional não considerar a renda como fator principal na determinação da pobreza, os municípios que apresentaram os maiores índices de pobreza obtiveram as menores rendas. Nos municípios mais pobres há maior participação dos homens como chefes de família, além de possuírem maior faixa etária. Os municípios mais pobres apresentaram os menores índices de educação formal, sugerindo que haja uma intervenção no meio rural no desenvolvimento educacional, como forma de combater o crescimento dos índices de pobreza nas áreas rurais do Estado de Mato Grosso.

Palavras-chave: Pobreza Multidimensional, Pobreza Rural, Análise de Cluster. 


\section{INTRODUÇÃO}

A pobreza é reconhecida como um fenômeno complexo e de múltiplas dimensões, não se restringindo apenas à insuficiência de consumo, mas pelas privações aos quais os indivíduos estão expostos, sendo relacionada não apenas com a renda e o mercado de trabalho, mas também com políticas e relações sociais.

No Brasil, a pobreza atinge milhões de brasileiros e apesar de não ser considerado um fenômeno baseado exclusivamente na renda, a concentração de renda é um fator de peso, pois segundo o Banco Mundial em 2010, o Brasil atingiu a 155 posição dentre os 169 países analisados com respeito ao índice de GINI, comparando com a sua colocação no rank dos maiores PIB o Brasil é 6o. (World Bank, 2010; Moreira, 2011).

Autores como Byerlee et al (2005) constataram que países com maiores crescimento agrícolas por trabalhador tenderiam a maiores velocidades de redução da pobreza rural de acordo com uma análise pautada na renda, porém para esse estudo o Brasil foi um caso fora do comum, em que por mais que haja um bom crescimento agrícola em comparação com outros países, sua redução da pobreza rural foi abaixo do esperado, isso aconteceu devido ao fato de que o crescimento agrícola estava concentrado em lavouras de exportação, como é o caso do estado de Mato Grosso, ao invés de estar em estados do Nordeste, onde se encontra um grande número de pobres.

O presente artigo pretende analisar e identificar como se dá a distribuição da pobreza no meio rural do Estado de Mato Grosso. O trabalho esta organizado em 4 seções além dessa introdução, logo após será realizada a conceituação da pobreza apresentando diferentes perspectivas encontradas por autores para identificá-la. Na segunda seção será apresentada a metodologia adotada pelo trabalho, formando um índice de pobreza e finalizando com uma análise de Cluster.

Na análise de cluster ocorre à separação de uma população heterogênea, transformando-a em vários subgrupos mais homogêneos. O agrupamento é diferente da classificação, pois as classes não são prédefinidas e a semelhança entre os elementos é que determinam como estes serão agrupados. (Doni, 2004). Com isso, pretende-se aplicar essa análise nos indicadores de pobreza que serão apresentados para agrupar os municípios de Mato Grosso e dessa forma contribuir para a identificação das diferenças na pobreza rural. 
Na terceira seção, serão apresentados os resultados, onde espera-se ser possível a identificação da distribuição da pobreza no meio rural do Estado de Mato Grosso no ano de 2010. Já na ultima seção serão abordadas as considerações finais, sintetizando os principais resultados encontrados.

\section{A POBREZA RURAL NO BRASIL}

Amartya Sen (2000), após a análise da ausência de capacidade em alguns indivíduos, caracteriza a pobreza como sendo a privação dessas capacidades. Segundo o autor, tais capacidades seriam o determinante da liberdade desses indivíduos, dessa maneira a pessoa que possuísse alto grau de privação seria considerada pobre, pelo fato de possuir pouca liberdade para viver a vida que valoriza. Sen rejeita a determinação da quantidade de recursos na medida de bem-estar, para ele o bem-estar está relacionado ao fato de estar bem, afirmando ainda que o padrão de vida não deve ser relacionado à quantidade de recursos de uma pessoa, mas em sua qualidade de vida e consequentemente em sua liberdade.

Barros, Silva e Franco (2006), definem a pobreza como sendo um fenômeno de caráter multidimensional, pois segundo os autores os índices de pobreza unidimensional seriam ineficientes, visto que estes consideraram que todos os indivíduos usam a renda de forma semelhante, o que de fato pode não ocorrer.

Mestrum (2002 apud Lima 2005), afirma que a multidimensionalidade da pobreza tem como potencial situar os pobres e os nãos pobres dentro de uma sociedade, dividindo-os por um ponto de vista que não considere apenas a renda como causadora dessa pobreza, mas a diversos elementos importantes, possibilitando dessa forma a verificação de grupos onde os elementos que são relacionados com a renda são satisfatórios, enquanto que os outros elementos que não estão relacionados à renda estão sendo insatisfatórios para esses indivíduos.

A modernização da agricultura no Brasil colocou o país como um dos maiores produtores e exportadores agrícolas, ocupando confortáveis colocações no que tange aos índices de produtividade e eficiência econômica no mercado mundial. Embora o modelo de desenvolvimento adotado tenha alcançado números significativos para a economia Brasileira, o destaque negativo para o alcance desse status foi à reafirmação do modelo concentrador, da intensificação da desigualdade no meio rural, do êxodo rural, da redução das oportunidades de trabalho e da geração de processos sustentáveis, visto que esse modelo não se preocupou com a sustentabilidade ambiental e com a igualdade social. (MACHADO et al., 2008). 
Conforme Maciel et al (2014), constatou-se que a pobreza na área rural de Mato Grosso tem caráter multidimensional em que a renda por pessoa não é capaz de explicar diretamente a pobreza multidimensional a que as famílias estão expostas, apesar do potencial agropecuário, a área rural não se distingue do consenso com relação à pobreza.

Há ainda o reconhecimento por Wanderley (2000) e Mocelin (2010), de que o meio rural é mais fragilizado do que o meio urbano, devido ao fato das ações de combate a pobreza serem empregadas mais facilmente nas áreas urbanas, devido à concentração das pessoas, sendo assim, a área rural possui maiores dificuldades no acesso a serviços essenciais básicos.

\section{BASE DE DADOS E MÉTODOS}

\section{OS DADOS}

Para a aplicação da pesquisa, utiliza-se da base de dados do Censo Demográfico do período de 2010 realizado pelo Instituto Brasileiro de Geografia e Estatística - IBGE, que apresentou os dados referentes aos 141 municípios de Mato Grosso. Para a análise dos resultados foram considerados os 10 municípios que apresentaram os maiores e os 10 municípios com os menores índices de pobreza na média e no desvio padrão, além da análise de Cluster gerada através software SPSS 20 for Windows. Índice de pobreza e variáveis selecionadas

Adotou-se o índice sintético (S) de pobreza multidimensional de Barros, Silva e Franco (2006), em que será aplicado para os residentes das áreas rurais do estado de Mato Grosso. Sendo esse índice formado por seis dimensões:

Quadro 1 - Dimensões de pobreza multidimensional.

\begin{tabular}{|l|}
\hline Dimensão VF: Representa a vulnerabilidade familiar. \\
Dimensão AC: Representa o acesso ao conhecimento. \\
Dimensão AT: Representa o acesso ao trabalho. \\
Dimensão DR: Representa a disponibilidade de recursos. \\
Dimensão DI: Representa o desenvolvimento infantil. \\
Dimensão CH: Representa as condições habitacionais.
\end{tabular}

Fonte: Pesquisa com base em Barros, Silva e Franco (2006).

Esse índice final S é formado pela média aritmética simples de cada Dimensão $\left({ }^{D_{j}}\right)$ da pobreza: 


$$
S=\frac{\sum_{j=1}^{6} D_{j}}{6}
$$

Sendo que cada Dimensão é formada pela média aritmética de cada item (li):

$$
D_{j}=\frac{\sum_{i=1}^{k} I_{i}}{k}
$$

Como o objetivo do trabalho está em analisar a pobreza de cada município. Encontra-se a média de pobreza rural de cada município ponderada pelos pesos de cada família no Censo Demográfico 2010:

$$
\overline{M_{\imath}}=\frac{\sum_{i=1}^{n} S_{i} W_{i}}{\sum_{i=1}^{n} W_{i}}
$$

Com isso cada município deve variar de 0 a 1, sendo os mais pobres com o indicador mais próximo de 1. Os subitens detalhados e a pobreza média de cada município serão apresentados no anexo.

\subsection{ANÁLISE DE CLUSTERS}

A análise de cluster é um procedimento de estatística multivariada que busca realizar o agrupamento de um conjunto de dados em subgrupos homogêneos chamados de clusters, através de medidas e relações de proximidade ou similaridade, além de separar esses grupos segundos suas distâncias ou dissimilaridades. (CÂMARA, 2009).

Conforme Xavier (2012), a análise de cluster consiste em agrupar um conjunto de observações de modo que as observações que pertençam a um mesmo grupo sejam parecidas entre si e diferentes das dos demais grupos.

\section{MEDIDAS DE SIMILARIDADE}

Os métodos de análise de cluster demandam de uma medida de similaridade entre os elementos a serem agrupados, geralmente é expressa como uma função distância ou métrica. Seja $M$ um conjunto, uma métrica em $M$ é uma função $d: M x M \rightarrow R$, tal que para quaisquer $x, y, z$ I $M$, tenhamos: 


\section{1. $d_{x y}>0$ - para todo $\mathrm{x} \neq \mathrm{y}$}

2. $d_{x y}=0 \Leftrightarrow$ para todo $\mathrm{x}=y$

3. $d_{x y}=d_{y x}$

4. $d_{x y} \leq d_{x z}+d_{z y}$

\section{DISTÂNCIA EUCLIDIANA}

A distância euclidiana não é afetada por adição, mas por mudanças de escala. Sejam dois elementos $X$ $=[X 1, X 2, \ldots, X p]$ e $Y=[Y 1, Y 2, \ldots, Y p]$, é definida por:

$$
d_{x y}=\sqrt{(X 1-Y 1)^{2}+(X 2-Y 2)^{2}+\cdots+(X p-Y p)^{2}}=\sqrt{\sum_{i=1}^{p}(X i-Y i)^{2}}
$$

A distância euclidiana entre dois elementos é dada matricialmente por:

$$
\begin{gathered}
d_{a b}=\left[\left(X_{a}-X_{b}\right)^{\prime} \cdot\left(X_{a}-X_{b}\right)\right]^{1 / 2} \\
X_{a}=\left[\begin{array}{llll}
X_{a 1} & X_{a 2} & \cdots & X_{a p}
\end{array}\right]^{\prime} \\
X_{b}=\left[\begin{array}{llll}
X_{b 1} & X_{b 2} & \cdots & X_{b p}
\end{array}\right]^{\prime}
\end{gathered}
$$

Sendo $X_{a}$ e $X_{b}$ o vetor de característica.

Pelo fato dos dados não estarem no mesmo padrão de medidas, as variáveis serão padronizadas:

$$
Z_{i j}=\frac{X_{i j-} \bar{X}_{j}}{S_{j}}, \quad Z_{i j} \sim\left(0,1_{j}\right)
$$

Como a pesquisa utilizará a Distância Euclidiana Quadrática em que se coloca maior peso nos objetos que estão mais separados, a seguinte expressão a define: 


$$
d_{x y}=|X 1-Y 1|+|X 2-Y 2|+\ldots+|X p-Y p|=\sum_{i=1}^{p}|X i-Y i|
$$

\section{MÉTODOS HIERÁRQUICOS}

O método hierárquico de cluster consiste em uma série de sucessivos agrupamentos ou sucessivas divisões de elementos, onde os elementos são classificados em métodos aglomerativos (bottom-up) e métodos de divisão ou divisivos (top-down).

Como não se pretende escolher uma medida hierárquica arbitraria, preferiu-se utilizar o método de Ward para definir a distâncias entre grupos. Nesse método, a função distância é dada por:

$$
d_{(U V) w}=\frac{\left(\left(N_{w}+N_{U}\right) d_{U W}+\left(N_{W}+N_{V}\right) d_{V W}-N_{w} \cdot d_{U V}\right)}{N_{w}+N_{U}+N_{V}}
$$

Onde: $N U$ e $N W$ são os números de elementos no grupo $U$ e $V$, respectivamente; $d U W$ e $d V W$ são as distâncias entre os elementos UW e VW.

\section{RESULTADOS}

Com base na metodologia classificou-se a pobreza rural de cada município de acordo com a média ponderada da classificação de cada família com relação à pobreza rural. A seguir apresenta-se o mapa do estado de Mato Grosso, em que delimitou-se 5 intervalos de classes com respeito ao município mais pobre (Campinápolis) e menos pobre (Tapurah):

Figura 1 - Distribuição da pobreza rural em Mato Grosso no ano de 2010.



Fonte: Pesquisa. 
Os 10 municípios de Mato Grosso que apresentaram os maiores índices de pobreza na média e no desvio padrão foram: Campinápolis, Colniza, Jangada, Acorizal, Porto Estrela, Alto Boa Vista, Cotriguaçu, Comodoro, Rosário Oeste e Peixoto de Azevedo. Já os municípios que apresentaram os menores índices de pobreza na média e no desvio padrão foram: Juscimeira, Nova Mutum, Ribeirãozinho, Primavera do Leste, Ipiranga do Norte, Campos de Júlio, Lucas do Rio Verde, Alto Taquari, Campo Novo do Parecis e Tapurah. Será apresentada a seguir, uma caracterização da amostra:

Tabela 1 - Distribuição das características dos mais e menos pobres.

\begin{tabular}{|c|c|c|c|}
\hline \multicolumn{2}{|l|}{ Variáveis } & \multicolumn{2}{|l|}{2010} \\
\hline & & Média & Desvio Padrão \\
\hline \multicolumn{4}{|l|}{ Pobreza } \\
\hline & Os 10 municípios mais pobres & 0,392 & 0,123 \\
\hline & Os 10 municípios menos pobres & 0,281 & 0,096 \\
\hline \multicolumn{4}{|c|}{ Quantidade de Moradores por dormitório } \\
\hline & Os 10 municípios mais pobres & 2,050 & 1,279 \\
\hline & Os 10 municípios menos pobres & 1,573 & 0,719 \\
\hline \multicolumn{4}{|c|}{ Renda Per Capita } \\
\hline & Os 10 municípios mais pobres & 185,475 & 260,279 \\
\hline & Os 10 municípios menos pobres & 495,309 & 793,594 \\
\hline \multicolumn{4}{|c|}{ Chefe Homem } \\
\hline & Os 10 municípios mais pobres & 0,812 & 0,378 \\
\hline & Os 10 municípios menos pobres & 0,769 & 0,398 \\
\hline \multicolumn{4}{|c|}{ Idade do Chefe } \\
\hline & Os 10 municípios mais pobres & 46,794 & 16,098 \\
\hline & Os 10 municípios menos pobres & 41,753 & 13,334 \\
\hline \multicolumn{4}{|c|}{ Cor do Chefe Branca } \\
\hline & Os 10 municípios mais pobres & 0,244 & 0,414 \\
\hline & Os 10 municípios menos pobres & 0,532 & 0,488 \\
\hline \multicolumn{4}{|c|}{ Cor do Chefe Preta } \\
\hline & Os 10 municípios mais pobres & 0,089 & 0,273 \\
\hline & Os 10 municípios menos pobres & 0,046 & 0,207 \\
\hline Cor do Ch & efe amarelo & & \\
\hline
\end{tabular}




\begin{tabular}{|c|c|c|c|}
\hline & Os 10 municípios mais pobres & 0,008 & 0,070 \\
\hline & Os 10 municípios menos pobres & 0,011 & 0,051 \\
\hline \multicolumn{4}{|c|}{ Cor do Chefe Pardo } \\
\hline & Os 10 municípios mais pobres & 0,575 & 0,466 \\
\hline & Os 10 municípios menos pobres & 0,404 & 0,483 \\
\hline \multicolumn{4}{|c|}{ Chefe Analfabeto } \\
\hline & Os 10 municípios mais pobres & 0,244 & 0,430 \\
\hline & Os 10 municípios menos pobres & 0,130 & 0,335 \\
\hline \multicolumn{4}{|c|}{ Chefe Ensino Fundamental } \\
\hline & Os 10 municípios mais pobres & 0,825 & 0,379 \\
\hline & Os 10 municípios menos pobres & 0,908 & 0,285 \\
\hline \multicolumn{4}{|c|}{ Chefe Ensino Médio } \\
\hline & Os 10 municípios mais pobres & 0,087 & 0,280 \\
\hline & Os 10 municípios menos pobres & 0,153 & 0,359 \\
\hline \multicolumn{4}{|c|}{ Chefe Ensino Superior } \\
\hline & Os 10 municípios mais pobres & 0,003 & 0,040 \\
\hline & Os 10 municípios menos pobres & 0,005 & 0,044 \\
\hline \multicolumn{4}{|c|}{ Chefe Casado } \\
\hline & Os 10 municípios mais pobres & 0,473 & 0,497 \\
\hline & Os 10 municípios menos pobres & 0,567 & 0,496 \\
\hline \multicolumn{4}{|c|}{ Horas Trabalhadas pelo Chefe } \\
\hline & Os 10 municípios mais pobres & 35,200 & 21,345 \\
\hline & Os 10 municípios menos pobres & 30,650 & 23,067 \\
\hline \multicolumn{4}{|c|}{ Chefe Aposentado } \\
\hline & Os 10 municípios mais pobres & 0,113 & 0,313 \\
\hline & Os 10 municípios menos pobres & 0,337 & 0,467 \\
\hline \multicolumn{4}{|c|}{ Tem Subsistência } \\
\hline & Os 10 municípios mais pobres & 0,100 & 0,297 \\
\hline & Os 10 municípios menos pobres & 0,128 & 0,328 \\
\hline
\end{tabular}

Fonte: Pesquisa.

Na tabela 1 são apresentadas as variáveis utilizadas para a caracterização das famílias no meio rural que estão localizadas nos 10 municípios mais pobres e nos 10 municípios menos pobres do estado de Mato Grosso, através das médias e do desvios padrão das variáveis. 
Os resultados encontrados apresentaram que os 10 municípios mais pobres possuem em média um indicador de pobreza de 39\%, enquanto que para os 10 municípios considerados menos pobres, a média desse índice foi de $28 \%$. Dessa forma, a diferença na média entre os municípios mais e menos pobres é de $11 \%$ com relação ao indicador de pobreza. Além do fato de os municípios mais pobres apresentarem maiores desvios com relação às médias, o que de fato é esperado.

Com relação à quantidade de moradores por dormitório, os maiores índices foram encontrados para os municípios mais pobres, indicando que quanto mais pessoas dividindo o mesmo dormitório são maiores os índices de pobreza para aquela família.

Como já era esperado, a variável renda é em média menor para os municípios mais pobres, porém onde há menores índices de pobreza na média, há maior variabilidade na distribuição de renda. Outro resultado encontrado foi o de que nos municípios mais pobres, $81 \%$ das famílias possui como chefe o homem, indicando que as famílias que são chefiadas por mulheres estão nos municípios menos pobres, onde há maior variação. Para os municípios mais pobres, a média da idade dos chefes de família apresentou o maior índice, indicando que as famílias mais pobres possuem os chefes mais velhos.

Os municípios mais pobres em média, são compostos por chefes de família de cor parda, enquanto que nos municípios que apresentaram em média menores índices de pobreza, os chefes de família são de cor branca. Com relação à escolaridade do chefe de família, os municípios mais pobres são os que possuem menor educação formal. Os chefes de famílias nos municípios mais pobres são em média $47 \%$ casados, e trabalham em média mais horas semanais que os que estão nos municípios menos pobres.

Os municípios onde há menores índices de pobreza em média são os que apresentam mais chefes de família em média que são aposentados e também apresentam maiores índices para subsistência.

Dessa se apresenta a seguir a análise de Cluster, que agrupa objetos em grupos cada vez maiores segundo o aumento da dissimilaridade (distância) entre eles: 
Figura 2- Mapa dos clusters de pobreza rural em Mato Grosso no ano de 2010.

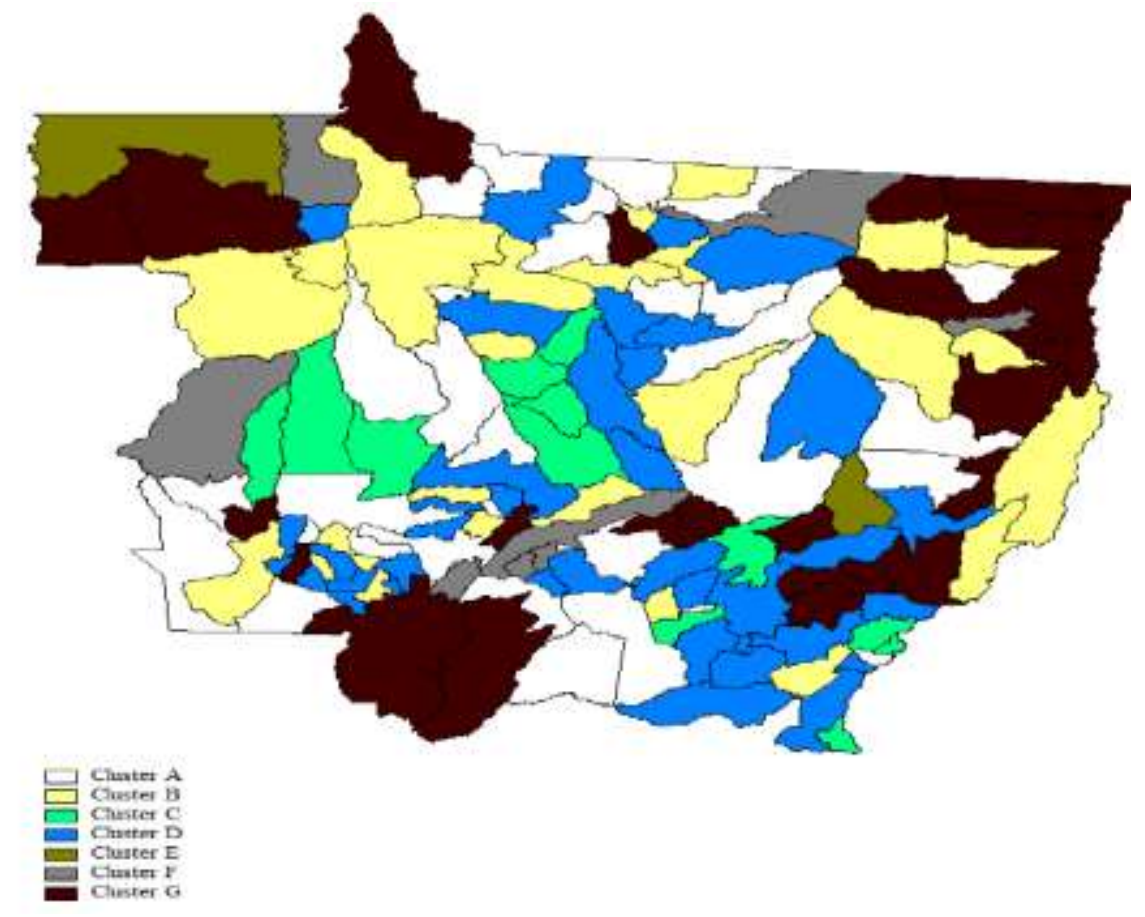

Fonte: Pesquisa.

Figura 3 - Novos Clusters de pobreza rural em Mato Grosso no ano de 2010.

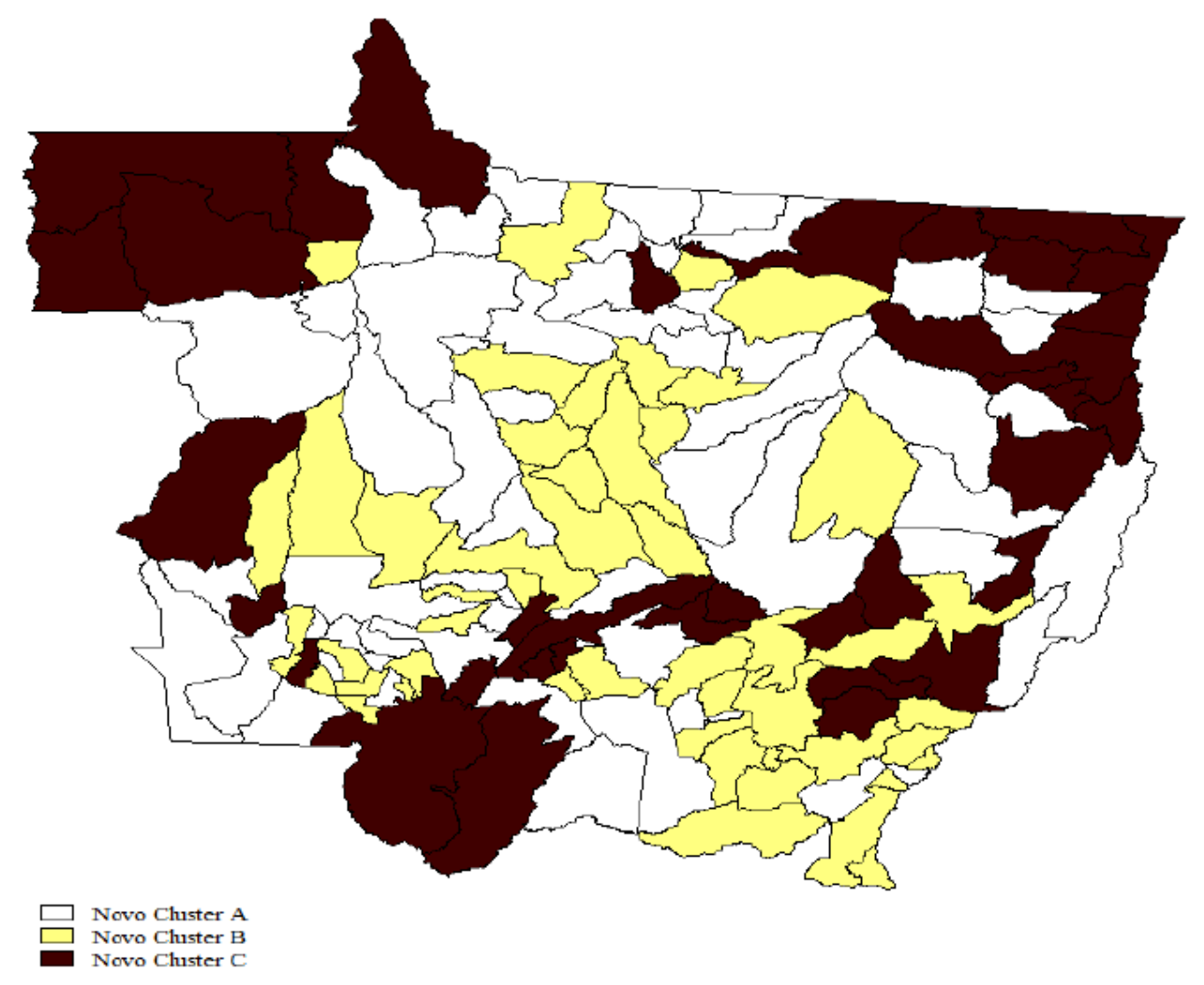

Fonte: Pesquisa. 
Os clusters foram delimitados dos mais próximos aos menos próximos, no 1ํ. cluster está inserido o estado de Mato Grosso, inserido apenas para que a análise fosse feita. Os clusters vão se agrupando conforme a distancia reescalada pelo Ward linkage, conforme demostrado no dendograma, dessa forma, com relação à pobreza os clusters mais baixos possuem uma disparidade maior com relação a Mato Grosso como um todo.

Os clusters foram hierarquizados, ou seja, organizados e com base nessa hierarquização o grupo de municípios que estão mais distantes, ou seja, no ultimo cluster são: Colíder, General Carneiro, Jauru, Novo Santo Antônio, Conquista D’Oeste, Alto Paraguai, Planalto da Serra, Serra Nova Dourada, Tesouro, Aripuanã, Rondolândia, Apiacás, Nova Nazaré, Barra do Garças, Santa Terezinha, Confresa, Nova Brasilândia, Vila Rica, Poconé, Santa Cruz do Xingu, Luciara, Cáceres, Ribeirão Cascalheira, Santo Antônio do Leste e São Félix do Araguaia. Porém, o fato do cluster estar mais distante não significa necessariamente que não são os mais próximos ou os mais pobres do Estado, o cluster é mais distante com relação à metodologia de Ward e essa distancia é definida pela distancia euclidiana ao quadrado.

\section{CONSIDERAÇÕES FINAIS}

A pobreza é um fenômeno de caráter multidimensional, o que também ficou constatado para a área rural do Estado de Mato Grosso, em que a renda por pessoa não é capaz de explicar diretamente a pobreza multidimensionais a que as famílias estão expostas. Dessa forma, não se pode afirmar que a pessoa é pobre somente pelo fato de não possuir renda. Apesar de o Estado ser mundialmente reconhecido pelo potencial no setor agropecuário, se constatou que há fragilidade no meio rural em relação a pobreza se comparado ao meio urbano, não se distinguindo do consenso que diz respeito a pobreza.

O trabalho teve como objetivo identificar como a pobreza no meio rural do Estado de Mato Grosso esta distribuída no ano de 2010, utilizando dados do Censo Demográfico de 2010, analisando os índices de pobreza na média e no desvio padrão e também a metodologia de análise de Cluster, a qual busca agrupar elementos de dados baseando-se na similaridade entre eles. Os grupos são determinados de forma a obter-se homogeneidade dentro dos grupos e heterogeneidade entre eles.

Como principais resultados foram obtidos através da análise dos 10 municípios que obtiveram os maiores e os menores índices de pobreza no meio rural do Estado. Os municípios mais pobres apresentaram um índice de pobreza de 39\%, e o trabalho identificou que a quanto maior for o número de pessoas por dormitórios, maior será o índice de pobreza. Com relação à renda o resultado foi o 
esperado, apesar de que a pobreza multidimensional não considera a renda como fator principal na determinação da pobreza, mas de toda forma os municípios que apresentaram os maiores índices de pobreza foram os que obtiveram as menores rendas.

Nos municípios que apresentaram os maiores índices de pobreza, tem o homem representando o chefe de família, cerca de $81 \%$, e esses chefes de família são de faixa etária mais elevada, de cor parda, além de apresentarem menores índices no que se refere a educação formal, sendo necessário que haja uma intervenção nessa região no que diz respeito ao desenvolvimento educacional, como forma de combater o crescimento dos índices de pobreza nas áreas rurais do Estado de Mato Grosso. 


\section{REFERENCIAS}

Dados: <http://www.ibge.gov.br> SPSS:

<http://www-01.ibm.com/software/analytics/spss/downloads.html>

ANDERBERG, Michael R. Cluster analysis for applications. New York: Academic Press, 1973.

BARROS, Ricardo Paes de; SILVA, Mirela de Carvalho Pereira da ; FRANCO, Samuel. Pobreza Multidimensional no Brasil. Rio de Janeiro, outubro de 2006. (Texto para discussão №1227).

BYERLEE, D.; Diao, X.; JACKSON, C. Agriculture, Rural development, and pro-poor growth: country experiences in the post-reform era. Agriculture and Rural Development Discussion Paper, 21. Washington, D.C.: World Bank. 72p. 2005.

CÂMARA, Fernando Portela. Psiquiatria e estatística. Parte II: Fundamentos da análise de clusters (classificação numérica). The international Journal of Psychiatry, v. 14, n. 1, 2009.

DONI, Marcelo Viana. Análise de cluster: métodos hierárquicos e de particionamento. São Paulo: Universidade Presbiteriana Mackenzie, São Paulo, 2004.

JAIN, A. K.; MURTY, M. N.; FLYNN, P. J. Data clustering: a review. ACM Computing Surveys, New York, v. 31, n. 3, p. 265-323, Sept., 1999.

LIMA, Ana Luiza Machado de Codes. Modelagem de Equações Estruturais: uma Contribuição Metodológica para o Estudo da Pobreza. Tese de doutorado. Universidade Federal da Bahia. Maio de 2005.

MACHADO, A. G.; CAUME, D. J.; FIGUEIREDO, R. S.; OLIVEIRA NETO, O. J.

Multifuncionalidade e pluriatividade como alternativas de desenvolvimento da agricultura familiar no Brasil. Desafio, v. 9, n. 17, p. 19-30, 2008.

MACIEL, D. T. G. N. ; LAVORATTO, L. A. ; MARCHIORO, L. W. ; LOPES, A pobreza multidimensional no meio rural de Mato Grosso: um estudo sobre as características dos chefes de família em 2010. In: 52은 Congresso da SOBER 2014, 2014, Goiânia. 52으 Congresso da SOBER 2014, 2014.

MACIEL, D. T. G. N. ; ZALAVA, A. A. Z. ; LAVORATTO, L. A. . Diferencial nas remunerações entre homens e mulheres: uma análise para Mato Grosso entre 2006 e 2013 para o setor formal agropecuário 2014.

MARIJA J. NORUŠIS; SPSS INC. SPSS professional statistics 6.1. Prentice Hall, 1994.

MESTRUM, F. Mondialisation et Pauvreté: De I'Utilité de la Pauvreté Dans le Nouvel Ordre Mondial. Paris: L'Harmattan, 2002.

MOCELIN, Cassia Engres. O Programa Bolsa Família enquanto principal estratégia de enfrentamento à pobreza rural no contexto brasileiro atual. Seminário Interinstitucional de ensino, pesquisa e extensão, v. $15,2010$. 
MOREIRA, Juliana Duffls Donato. Estratégias de redução da pobreza e das desigualdades no Brasil. Dissertação (Mestrado). Universidade Federal do Rio de Janeiro. Rio de Janeiro. Agosto de 2011.

NARAYAN, D. Voices of the poor - Can anyone hear us? Washington, D.C.: The World Bank, Oxford University Press, 2000 SEN, Amartya Kumar; MENDES, Ricardo Doninelli. Desenvolvimento como liberdade. São Paulo: Companhia das Letras, 2000.

SILVA, Ana Márcia Rodrigues da; LACEREDA, Fernanda Calasans C.; NEDER, Henrique Dantas. A evolução do estudo da pobreza: da abordagem monetária à privação de capacitações. In: Bahia Análise \& Dados.Pobreza, desigualdade e ciclos econômicos. Salvador: SEI, v. 21, n. 3, p.509-527, jul-set/2011.

XAVIER, Vinicius Layter. Resolução do Problema de Agrupamento segundo o Critério de Minimização da Soma de Distâncias. 2012. Tese de Doutorado. Universidade Federal do Rio de Janeiro.

WANDERLEY, Nazareth. A emergência de uma Nova Ruralidade nas Sociedades Modernas Avançadas - O 'Rural' como Espaço Singular e Ator Coletivo. Estudos Sociedade Agricultura, n.15:87-145. 2000.

World Bank GINI index. Disponível em: http://data.worldbank.org/indicator/SI.POV. GINI/ acessado em 07/11/2015. 
Quadro 2: Indicador de presença de vulnerabilidade das famílias.

\begin{tabular}{l} 
Fecundidade: \\
V1. Alguma mulher teve filho nascido vivo no último ano. \\
V2. Alguma mulher teve filho nascido vivo nos últimos dois anos. \\
\hline Atenção e cuidados especiais com crianças, adolescentes e jovens: \\
V3. Presença de criança. \\
V4. Presença de criança ou adolescente. \\
V5. Presença de criança, adolescente ou jovem. \\
$\qquad \underline{\text { Atenção e cuidados especiais com idosos: }}$ \\
V6. Presença de idoso. \\
\hline V7. Ausência de cônjuge. \\
V8. Menos da metade dos membros encontram-se em idade ativa. \\
\hline Presença da mãe: \\
V9. Existe criança no domicílio cuja mãe já tenha morrido. \\
V10. Existe criança no domicílio que não viva com a mãe.
\end{tabular}

Fonte: Barros, Silva e Franco (2006).

Quadro 3: Indicador de acesso ao conhecimento.

\begin{tabular}{|c|}
\hline $\begin{array}{l}\text { C1. Presença de adulto analfabeto. } \\
\text { C2. Presença de adulto analfabeto funcional. }\end{array}$ \\
\hline $\begin{array}{l}\text { Escolaridade: } \\
\text { C3. Ausência de adulto com fundamental completo. } \\
\text { C4. Ausência de adulto com secundário completo. } \\
\text { C5. Ausência de adulto com alguma educação superior. }\end{array}$ \\
\hline $\begin{array}{l}\text { Qualificação profissional: } \\
\text { C6. Ausência de trabalhador com qualificação média ou alta. }\end{array}$ \\
\hline
\end{tabular}

Fonte: Barros, Silva e Franco (2006). 
Quadro 4: Indicador de acesso ao trabalho

Disponibilidade de trabalho:

T1. Menos da metade dos membros em idade ativa encontram-se ocupados.

T2. Ausência de trabalhador que esteja a mais de seis meses no trabalho atual.

\section{Qualidade do posto de trabalho:}

T3. Ausência de ocupado no setor formal.

T4. Ausência de ocupado em atividade não-agrícola.

\section{Remuneração:}

T5. Ausência de ocupado com rendimento superior a 1 salário mínimo.

T6. Ausência de ocupado com rendimento superior a 2 salários mínimos.

Fonte: Barros, Silva e Franco (2006).

Quadro 5: Indicador de disponibilidade

\section{Extrema pobreza:}

R1. Renda familiar per capita inferior à linha de extrema pobreza.

\section{Pobreza:}

R2. Renda familiar per capita inferior à linha de pobreza.

Capacidade de geração de renda:

R3. Maior parte da renda familiar advém de transferências.

Fonte: Barros, Silva e Franco (2006).

Quadro 6: Indicador de desenvolvimento 


\section{Trabalho precoce:}

D1. Presença de ao menos uma criança com menos de 14 anos trabalhando.

D2. Presença de ao menos uma criança com menos de 16 anos trabalhando.

\section{Acesso à escola:}

D3. Presença de ao menos uma criança de 0-6 anos fora da escola.

D4. Presença de ao menos uma criança de 7-14 anos fora da escola.

D5. Presença de ao menos uma criança de 7-17 anos fora da escola.

\section{Progresso escolar:}

D6. Presença de ao menos uma criança de até 14 anos com mais de 2 anos de atraso.

D7. Presença de ao menos um adolescente de 10 a 14 anos analfabeto.

D8. Presença de ao menos um jovem de 15 a 17 anos analfabeto.

D9. Presença de ao menos uma mãe que tenha algum filho que já tenha morrido.

D10. Presença de mais de uma mãe que tenha algum filho que já tenha morrido.

D11. Presença de mãe que já teve algum filho nascido morto.

Fonte: Barros, Silva e Franco (2006). 
Quadro 7: Indicador de condições habitacionais

\section{Propriedade:}

H1. Domicílio não é próprio.

H2. Domicílio não é nem próprio nem cedido.

Déficit habitacional:

H3. Densidade de 2 ou mais moradores por dormitório.

Abrigabilidade:

H4. Material de construção não é permanente.

Acesso a abastecimento de água:

H5. Acesso inadequado à água.

Acesso a saneamento:

H6. Esgotamento sanitário inadequado.

Acesso à coleta de lixo:

H7. Lixo não é coletado.

Acesso à energia elétrica:

H8. Sem acesso à eletricidade.

H9. Não tem ao menos a um dos itens: fogão ou geladeira.

H10. Não tem ao menos a um dos itens: fogão, geladeira, televisão ou rádio.

H11. Não tem ao menos a um dos itens: fogão, geladeira, televisão, rádio ou telefone.

H12. Não tem ao menos a um dos itens: fogão, geladeira, televisão, rádio, telefone ou computador.

Fonte: Barros, Silva e Franco (2006). 
Tabela 2 - Classificação dos municípios com relação à pobreza e os clusters.

\begin{tabular}{|c|c|c|c|}
\hline Municípios & Pobreza & Lista Clusters & Lista Novo Clusters \\
\hline Paranaíta & 0,3331 & Cluster A & Novo Cluster A \\
\hline Novo Mundo & 0,3328 & Cluster A & Novo Cluster A \\
\hline Salto do Céu & 0,3328 & Cluster A & Novo Cluster A \\
\hline Tangará da Serra & 0,3326 & Cluster A & Novo Cluster A \\
\hline Santo Antônio do Leverger & 0,3339 & Cluster A & Novo Cluster A \\
\hline Ponte Branca & 0,3316 & Cluster A & Novo Cluster A \\
\hline União do Sul & 0,3317 & Cluster A & Novo Cluster A \\
\hline Arenápolis & 0,3349 & Cluster A & Novo Cluster A \\
\hline Nova Monte Verde & 0,3349 & Cluster A & Novo Cluster A \\
\hline Porto Esperidião & 0,3357 & Cluster A & Novo Cluster A \\
\hline Nova Lacerda & 0,3451 & Cluster A & Novo Cluster A \\
\hline Novo Horizonte do Norte & 0,3453 & Cluster A & Novo Cluster A \\
\hline Cláudia & 0,3457 & Cluster A & Novo Cluster A \\
\hline Barão de Melgaço & 0,3418 & Cluster A & Novo Cluster A \\
\hline Vila Bela da Santíssima Trindade & 0,3423 & Cluster A & Novo Cluster A \\
\hline Brasnorte & 0,3441 & Cluster A & Novo Cluster A \\
\hline Nossa Senhora do Livramento & 0,3433 & Cluster A & Novo Cluster A \\
\hline Nova Canaã do Norte & 0,3383 & Cluster A & Novo Cluster A \\
\hline São José do Rio Claro & 0,3383 & Cluster A & Novo Cluster A \\
\hline Matupá & 0,3381 & Cluster A & Novo Cluster A \\
\hline Chapada dos Guimarães & 0,3375 & Cluster A & Novo Cluster A \\
\hline Paranatinga & 0,3374 & Cluster A & Novo Cluster A \\
\hline Carlinda & 0,3369 & Cluster A & Novo Cluster A \\
\hline Água Boa & 0,3397 & Cluster A & Novo Cluster A \\
\hline Feliz Natal & 0,3392 & Cluster A & Novo Cluster A \\
\hline
\end{tabular}




\begin{tabular}{|c|c|c|c|}
\hline Nova Maringá & 0,3411 & Cluster A & Novo Cluster A \\
\hline São Pedro da Cipa & 0,3409 & Cluster A & Novo Cluster A \\
\hline Barra do Bugres & 0,3405 & Cluster A & Novo Cluster A \\
\hline Canabrava do Norte & 0,3404 & Cluster A & Novo Cluster A \\
\hline Canarana & 0,3402 & Cluster A & Novo Cluster A \\
\hline Nova Marilândia & 0,3223 & Cluster B & Novo Cluster A \\
\hline Querência & 0,3225 & Cluster B & Novo Cluster A \\
\hline Araguaiana & 0,3228 & Cluster B & Novo Cluster A \\
\hline Reserva do Cabaçal & 0,3226 & Cluster B & Novo Cluster A \\
\hline Denise & 0,3214 & Cluster B & Novo Cluster A \\
\hline Mirassol d'Oeste & 0,3213 & Cluster B & Novo Cluster A \\
\hline Itaúba & 0,3210 & Cluster B & Novo Cluster A \\
\hline Juína & 0,3212 & Cluster B & Novo Cluster A \\
\hline Nova Bandeirantes & 0,3218 & Cluster B & Novo Cluster A \\
\hline Juara & 0,3297 & Cluster B & Novo Cluster A \\
\hline Nova Ubiratã & 0,3296 & Cluster B & Novo Cluster A \\
\hline Indiavaí & 0,3290 & Cluster B & Novo Cluster A \\
\hline Porto Alegre do Norte & 0,3290 & Cluster B & Novo Cluster A \\
\hline Itanhangá & 0,3288 & Cluster B & Novo Cluster A \\
\hline São José do Xingu & 0,3289 & Cluster B & Novo Cluster A \\
\hline Alto Garças & 0,3286 & Cluster B & Novo Cluster A \\
\hline Nova Guarita & 0,3284 & Cluster B & Novo Cluster A \\
\hline Pontes e Lacerda & 0,3281 & Cluster B & Novo Cluster A \\
\hline Guarantã do Norte & 0,3267 & Cluster B & Novo Cluster A \\
\hline Nova Santa Helena & 0,3267 & Cluster B & Novo Cluster A \\
\hline Cocalinho & 0,3267 & Cluster B & Novo Cluster A \\
\hline Jaciara & 0,3260 & Cluster B & Novo Cluster A \\
\hline Nobres & 0,3264 & Cluster B & Novo Cluster A \\
\hline Castanheira & 0,3238 & Cluster B & Novo Cluster A \\
\hline Tabaporã & 0,3237 & Cluster B & Novo Cluster A \\
\hline Bom Jesus do Araguaia & 0,3246 & Cluster B & Novo Cluster A \\
\hline Rio Branco & 0,3251 & Cluster B & Novo Cluster A \\
\hline Campo Novo do Parecis & 0,2719 & Cluster C & Novo Cluster B \\
\hline
\end{tabular}




\begin{tabular}{l|c|l|l} 
Tapurah & 0,2630 & Cluster C & Novo Cluster B \\
\hline Campos de Júlio & 0,2826 & Cluster C & Novo Cluster B \\
\hline Lucas do Rio Verde & 0,2819 & Cluster C & Novo Cluster B \\
\hline Ipiranga do Norte & 0,2832 & Cluster C & Novo Cluster B \\
\hline Alto Taquari & 0,2783 & Cluster C & Novo Cluster B \\
\hline Primavera do Leste & 0,2877 & Cluster C & Novo Cluster B \\
\hline Ribeirãozinho & 0,2881 & Cluster C & Novo Cluster B \\
\hline Nova Mutum & 0,2888 & Cluster C & Novo Cluster B \\
\hline Juscimeira & 0,2906 & Cluster C & Novo Cluster B \\
\hline Torixoréu & 0,2912 & Cluster C & Novo Cluster B \\
\hline Sapezal & 0,2939 & Cluster C & Novo Cluster B \\
\hline Itiquira & 0,3016 & Cluster D & Novo Cluster B \\
\hline Sorriso & 0,3013 & Cluster D & Novo Cluster B \\
\hline Araguainha & 0,3001 & Cluster D & Novo Cluster B \\
\hline Figueirópolis D'Oeste & 0,2982 & Cluster D & Novo Cluster B \\
\hline Cuiabá & 0,3082 & Cluster D & Novo Cluster B \\
\hline Santa Carmem & 0,3083 & Cluster D & Novo Cluster B \\
\hline Terra Nova do Norte & 0,3080 & Cluster D & Novo Cluster B \\
\hline Nova Olímpia & 0,3076 & Cluster D & Novo Cluster B \\
\hline Rondonópolis & 0,3072 & Cluster D & Novo Cluster B \\
\hline Sinop & 0,3036 & Cluster D & Novo Cluster B \\
\hline Várzea Grande & 0,3033 & Cluster D & Novo Cluster B \\
\hline Alta Floresta & 0,3062 & Cluster D & Novo Cluster B \\
\hline Nortelândia & 0,3053 & Cluster D & Novo Cluster B \\
\hline Juruena & 0,3127 & Cluster D & Novo Cluster B \\
\hline Santo Afonso & 0,3126 & Cluster D & Novo Cluster B \\
\hline Guiratinga & 0,3130 & Cluster D & Novo Cluster B \\
\hline Poxoréo & 0,3123 & Cluster D & Novo Cluster B \\
\hline Marcelândia & 0,3133 & Cluster D & Novo Cluster B \\
\hline Diamantino & 0,3113 & Cluster D & Novo Cluster B \\
\hline Glória D'Oeste & & & Novo Cluster B \\
\hline Pontal do Araguaia & 0,3115 D & Novo Cluster B \\
\hline Santa Rita do Trivelato D & Novo Cluster B \\
\hline & & \\
\hline
\end{tabular}




\begin{tabular}{|c|c|c|c|}
\hline Araputanga & 0,3154 & Cluster D & Novo Cluster B \\
\hline Dom Aquino & 0,3156 & Cluster D & Novo Cluster B \\
\hline São José do Povo & 0,3157 & Cluster D & Novo Cluster B \\
\hline Novo São Joaquim & 0,3152 & Cluster D & Novo Cluster B \\
\hline Campo Verde & 0,3141 & Cluster D & Novo Cluster B \\
\hline Lambari D'Oeste & 0,3146 & Cluster D & Novo Cluster B \\
\hline Curvelândia & 0,3197 & Cluster D & Novo Cluster B \\
\hline Porto dos Gaúchos & 0,3190 & Cluster D & Novo Cluster B \\
\hline Alto Araguaia & 0,3180 & Cluster D & Novo Cluster B \\
\hline Vale de São Domingos & 0,3175 & Cluster D & Novo Cluster B \\
\hline Gaúcha do Norte & 0,3167 & Cluster D & Novo Cluster B \\
\hline Pedra Preta & 0,3168 & Cluster D & Novo Cluster B \\
\hline Vera & 0,3170 & Cluster D & Novo Cluster B \\
\hline Nova Xavantina & 0,3161 & Cluster D & Novo Cluster B \\
\hline São José dos Quatro Marcos & 0,3164 & Cluster D & Novo Cluster B \\
\hline Campinápolis & 0,4402 & Cluster E & Novo Cluster C \\
\hline Colniza & 0,4382 & Cluster E & Novo Cluster C \\
\hline Acorizal & 0,3925 & Cluster F & Novo Cluster C \\
\hline Porto Estrela & 0,3910 & Cluster F & Novo Cluster C \\
\hline Jangada & 0,3941 & Cluster F & Novo Cluster C \\
\hline Alto Boa Vista & 0,3801 & Cluster F & Novo Cluster C \\
\hline Cotriguaçu & 0,3775 & Cluster F & Novo Cluster C \\
\hline Comodoro & 0,3733 & Cluster F & Novo Cluster C \\
\hline Rosário Oeste & 0,3729 & Cluster F & Novo Cluster C \\
\hline Peixoto de Azevedo & 0,3698 & Cluster F & Novo Cluster C \\
\hline Colíder & 0,3489 & Cluster G & Novo Cluster C \\
\hline General Carneiro & 0,3494 & Cluster G & Novo Cluster C \\
\hline Jauru & 0,3477 & Cluster G & Novo Cluster C \\
\hline Novo Santo Antônio & 0,3477 & Cluster G & Novo Cluster C \\
\hline Conquista D'Oeste & 0,3480 & Cluster G & Novo Cluster C \\
\hline Alto Paraguai & 0,3484 & Cluster G & Novo Cluster C \\
\hline Planalto da Serra & 0,3472 & Cluster G & Novo Cluster C \\
\hline Serra Nova Dourada & 0,3512 & Cluster G & Novo Cluster C \\
\hline
\end{tabular}


Ensaios Sobre Hiato Salarial E Pobreza Multidimensional Regional

\begin{tabular}{l|c|l|l} 
Tesouro & 0,3513 & Cluster G & Novo Cluster C \\
\hline Aripuanã & 0,3531 & Cluster G & Novo Cluster C \\
\hline Rondolândia & 0,3538 & Cluster G & Novo Cluster C \\
\hline Apiacás & 0,3651 & Cluster G & Novo Cluster C \\
\hline Nova Nazaré & 0,3655 & Cluster G & Novo Cluster C \\
\hline Barra do Garças & 0,3641 & Cluster G & Novo Cluster C \\
\hline Santa Terezinha & 0,3647 & Cluster G & Novo Cluster C \\
\hline Confresa & 0,3631 & Cluster G & Novo Cluster C \\
\hline Nova Brasilândia & 0,3569 & Cluster G & Novo Cluster C \\
\hline Vila Rica & 0,3569 & Cluster G & Novo Cluster C \\
\hline Poconé & 0,3563 & Cluster G & Novo Cluster C \\
\hline Santa Cruz do Xingu & 0,3560 & Cluster G & Novo Cluster C \\
\hline Luciara & 0,3552 & Cluster G & Novo Cluster C \\
\hline Cáceres & 0,3611 & Cluster G & Novo Cluster C \\
\hline Ribeirão Cascalheira & 0,3607 & Cluster G & Novo Cluster C \\
\hline Santo Antônio do Leste & 0,3579 & Cluster G & Novo Cluster C \\
\hline São Félix do Araguaia & 0,3591 & Cluster G & Novo Cluster C \\
\hline
\end{tabular}

Fonte: Pesquisa. 